UNIVERSIDAD NACIONAL DE LA PLATA Facultad de Ciencias Económicas Maestría en Dirección de Empresas

\title{
Ciclo de Vida Financiero de la Empresa
}

Manifestaciones en el Mercado Argentino

Trabajo final para optar al título de Magíster

Autor: Lic. Eduardo Quiroga

Tutor: Dr. Esteban P. Villar

La Plata, Noviembre de 2010 


\section{Índice de Contenidos}

1. Formulación del Problema

2. Objetivos

3. Justificación

4. Alcances de la Investigación

5. Marco Teórico

5.1. Sistema Financiero 6

5.1.1. Concepto y Generalidades 6

5.1.2. Mercados Financieros 6

5.1.3. Instituciones Financieras 9

5.1.4. Instrumentos Financieros 11

5.2. Asimetrías Informativas 12

5.2.1. Introducción 12

5.2.2. Decisiones Financieras con Información Asimétrica 13

1.2.2.1. Aspectos Generales 13

1.2.2.2. El Racionamiento del Crédito 14

1.2.2.3. Las Garantías Subsidiarias $\quad 15$

1.2.2.4. La Financiación Interna 16

5.2.3. La Información Asimétrica en los Mercados Financieros 17

5.2.3.1. Asimetría Informativa en el Mercado Intermediado 18

5.2.3.2. Asimetría Informativa en el Mercado Bursátil 20

5.2.3.3. Asimetría Inf. en los Mercados sobre el Mostrador 21

5.3. Ciclo de Vida Financiero 26

5.3.1. Presentación del concepto Ciclo de Vida Financiero 26

5.3.2. La Financiación con Capital Propio 27

5.3.3. El Financiamiento Bancario 28

5.3.4. El Financiamiento Bursátil 29

5.3.5. La Financiación con Capital Riesgo 31

5.3.5.1. Tipos de Operaciones con Capital Riesgo 32

5.3.5.2. Instrumentos Financieros del Capital Riesgo 33

5.3.5.3. Etapas de una Operación de Capital Riesgo 34

5.3.6. Ciclo de Vida Financiero: elección de fuentes en cada etapa 39

6. Metodología Aplicada $\quad 43$

7. Resultados Obtenidos $\quad 45$

7.1. Análisis del Entorno en Argentina 45 
7.1.1. Perspectiva de Evolución Económica 45

7.1.2. Los Condicionantes del Entorno 46

7.1.3. Principales Obstáculos 48

7.1.4. Factores Facilitadores 49

7.1.4. Recomendaciones de Expertos 50

7.2. El Sistema Financiero Argentino: principales características 50

7.3. El Sistema Bancario Argentino 52

7.3.1. Depósitos 52

7.3.2. Principales indicadores monetarios $\quad 55$

7.3.3. Préstamos 56

7.3.4. Utilización del crédito bancario en Argentina 63

$\begin{array}{ll}\text { 7.3.5. Tasas de interés } & 66\end{array}$

7.4. El Mercado de Capitales en Argentina 66

7.4.1. Departamento PyMEs en la Bolsa de Comercio de Bs. As. 67

$\begin{array}{ll}\text { 7.4.2. Instrumentos financieros para PyMEs } & 67\end{array}$

7.4.2.1. Cheques de Pago Diferido 67

7.4.2.2. Obligaciones Negociables $\quad 72$

$\begin{array}{ll}\text { 7.4.2.3. Fideicomisos Financieros } & 74\end{array}$

7.4.2.4. Acciones 76

7.5. El Capital Riesgo en Argentina $\quad 77$

7.6. Las Sociedades Calificadoras de Riesgo (SCR) 81

7.7. Las Sociedades de Garantía Recíproca (SGR) 82

7.7.1. Nueva reglamentación para las SGR 83

7.7.2. El proceso de otorgamiento de avales 84

7.7.3. Beneficios de contar con el aval de una SGR 84

7.7.4. Garantías Formalizadas 85

8. Conclusiones $\quad 87$

9. Recomendaciones 97

10. Bibliografía 101

11. Anexo I: Ciclo de Vida Financiero según Berger y Udell (1998) 105 


\section{Índice de Cuadros}

Cuadro 1: ¿Por qué cotizar en Bolsa?

Cuadro 2: Plazos de desinversión del capital riesgo

Cuadro 3: Esquema de Intereses

Cuadro 4: Situación de intereses según forma de financiamiento

Cuadro 5: Depósitos del sector privado no financiero en pesos

Cuadro 6: Depósitos del sector privado no financiero en dólares 52

Cuadro 7: Depósitos a plazo fijo del sector privado no financiero 53

Cuadro 8: Depósitos del sector público en pesos 53

Cuadro 9: Ahorro personal y ahorro empresario en el mundo 53

Cuadro 10: Base monetaria y reservas del BCRA 54

Cuadro 11: Préstamos al sector privado no financiero en pesos 55

Cuadro 12: Préstamos al sector privado no financiero en dólares 56

Cuadro 13: Préstamos al sector privado no financiero en pesos y dólares 57

Cuadro 14: Estructura de financ. por tramo de deuda y grupo de bancos. Marzo 200961

Cuadro 15: Estructura de financ. por tramo de deuda y grupo de bancos. Marzo 201062

Cuadro 16: Variación nominal del financ. por tramo de deuda y grupo de bancos

Cuadro 17: Variación porcentual del financ. por tramo de deuda y grupo de bancos 63

Cuadro 18: Empresas que utilizan crédito bancario en Argentina y países selec. 64

Cuadro 19: Inversiones empresarias financiadas con crédito bancario 65

Cuadro 20: Tasas de interés activas en pesos 66

Cuadro 21: Montos negociados en cheques de pago diferido 70

Cuadro 22: Tasas ponderadas de cheques de pago diferido 71

Cuadro 23: Emisiones de obligaciones negociables PyME 73

Cuadro 24: Emisiones de fideicomisos financieros PyME - colectivos 75

Cuadro 25: Emisiones de fideicomisos financieros PyME - individuales 76

Cuadro 26: Cuadro de calificaciones a escala internacional 82

Cuadro 27: Montos avalados por las SGR 85 


\section{Índice de Gráficos}

Gráfico 1: Perspectivas de evolución de la economía mundial

Gráfico 2: Perspectivas de evolución de la economía de América Latina 45

Gráfico 3: Perspectivas de evolución de la economía Argentina 46

Gráfico 4: Los condicionantes del entorno en la economía Argentina 46

Gráfico 5: Principales obstáculos encontrados en la economía Argentina 47

Gráfico 6: Factores facilitadores 48

Gráfico 7: Recomendaciones de expertos 49

Gráfico 8: Ratio de liquidez del sistema financiero 50

Gráfico 9: Variación mensual de préstamos al sector privado no financiero 56

Gráfico 10: Cantidad de empresas por tramo de deuda 59

Gráfico 11 Montos de deuda bancaria por tramo de deuda 59

Gráfico 12: Concentración del crédito bancario en Argentina 60

Gráfico 13: Estructura de activos del sistema bancario argentino 60

Gráfico 14: Montos negociados en cheques de pago diferido 64

Gráfico 15: Tasas ponderadas de cheques de pago diferido avalado 71

Gráfico 16: Cheques de pago diferido avalado: montos negociados por plazo 72

Gráfico 17: TIR requeridas en el financiamiento con Capital Riesgo 72

Gráfico 18: Cheques de pago diferido garantizados por el mercado de las SGR 78 


\section{Índice de Figuras}

Figura 1: Transferencias directas

Figura 2: Transferencias indirectas vía banco de inversión

Figura 3: Transferencias indirectas vía intermediario financiero

Figura 4: Ciclo de Capital Riesgo

Figura 5: Sendero de los instrumentos híbridos en la relación riesgo - rendimiento

Figura 6: Ciclo de Vida Financiero 40

Figura 7: Cheques de pago diferido patrocinado 42

Figura 8: Cheques de pago diferido avalado 68 70 


\section{Formulación del Problema}

El financiamiento empresarial es un aspecto clave para el desarrollo de los negocios y para que las empresas puedan crecer y evolucionar. Las pequeñas empresas no se encuentran en igualdad de condiciones a las grandes en la búsqueda de financiación, y en muchos casos, viendo limitado su acceso a la propia capacidad de generación y retención de utilidades, debido a que en su mayoría son empresas familiares en las que el patrimonio de los accionistas ya está (en gran parte) comprometido en la empresa.

Tradicionalmente, existieron en el mercado distintas alternativas de financiamiento, tanto en el sistema bancario (adelantos en cuenta, descuentos de documentos, préstamos, etc.), en el mercado de capitales (acciones, obligaciones negociables, etc.) y otras alternativas en el ámbito privado. Todas ellas han sido relativamente eficientes para el caso de las grandes empresas de producción tradicional, que disponen de amplias garantías reales, altas rentabilidades y un largo historial que las avale. Pero en el caso de las PyME, el acceso a financiamiento viene siendo un problema reiterado, ya sea por la falta de garantías, montos de crédito insignificantes para sus planes de negocios o plazos excesivamente cortos que no permiten su repago en condiciones pretendidas.

Considerando el contexto financiero y macroeconómico argentino, se hace indispensable que toda acción de financiamiento a desarrollar, esté acorde con criterios de asistencia y sustentabilidad. Es necesario analizar las características del sistema financiero argentino y las particularidades del empresariado PyME a los fines de armar un modelo de gestión efectivo, tendiente a satisfacer las necesidades de financiamiento de las PyME.

Por ello, es necesario potenciar fórmulas financieras que permitan a las PyME el acceso a nuevas fuentes de financiamiento, de manera tal, que le permitan acceder a los fondos necesarios en condiciones similares a las de la gran empresa.

En la formulación del problema, surgen varios interrogantes, tales como:

- ¿Es posible facilitar el traumático y a veces determinante proceso de financiamiento para las PyMEs?

- ¿Es posible desarrollar esquemas de financiamiento que se adapten a las necesidades específicas de las PyMEs, en las distintas etapas de su desarrollo?

- ¿Es posible superar el problemas de falta de garantías reales de los empresarios PyMEs, para la obtención de financiamiento a mediano y largo plazo?

- ¿Es factible que las PyMEs se financien en el mercado de capitales local? ¿Cuál fue la respuesta del mercado y de las empresas, al régimen simplificado para las PyME implementado por la Bolsa de Comercio de Buenos Aires?

- ¿Los inversores del mercado local, están dispuestos a invertir en instrumentos financieros destinados a las PyMEs?

- ¿Es posible que las PyME obtengan condiciones de financiamiento similares a las de la gran empresa?

- ¿Están las PyMEs argentinas preparadas a nivel de información, formación profesional, capacidad técnica y de gestión, para llevar adelante alternativas superadoras de financiamiento que requieran mayores exigencias y cualidades? 


\section{Objetivos}

\subsection{Objetivo General}

Verificar la aplicabilidad del modelo de ciclo de vida financiero (como el de Berger y Udell 1998) al sector PyME en el mercado argentino.

\subsection{Objetivos Específicos}

1) Identificar las causas de las limitaciones en el acceso al financiamiento de las PyME.

2) Comprender los efectos que genera la información asimétrica en los distintos mercados financieros, e identificar como afecta, directa o indirectamente el financiamiento de las empresas.

3) Identificar aspectos y características particulares de los mercados financieros en Argentina.

4) Identificar causales de éxito o fracaso de los instrumentos financieros utilizados por las PyMEs en el mercado argentino

5) Analizar e identificar alternativas de financiamiento para las PyMEs argentinas, en cada etapa de su desarrollo.

6) Alcanzar conclusiones que permitan proponer recomendaciones de políticas o medidas que favorezcan el financiamiento a las PyME. 


\section{Justificación}

En casi la totalidad de las economías de mercado, las PyMEs constituyen una parte sustancial de la economía. En la Argentina, la informalidad del sector opera como una restricción para contar con datos más ciertos, pero según estimaciones de expertos, las PyMEs representan el 99,6\% de los establecimientos, ocupan el $69 \%$ de la fuerza laboral y explican el $40 \%$ del Producto Bruto Nacional.

Si se consideran éstos y otros indicadores económicos no cabe duda de la importancia que tiene el sector PyME en nuestra economía. Las PyMEs constituyen el eje fundamental de la economía nacional, además de generar empleo y demanda, cumplen funciones básicas de la economía, entre las cuales es factible mencionar:

- Aportan flexibilidad y capacidad de adaptación a los nuevas condiciones del contexto.

- Constituyen un medio de movilidad social, dando posibilidad de crecimiento económico a las personas con aptitud y espíritu emprendedor.

- Promueven la innovación y el desarrollo tecnológico, desarrollando nuevos productos y servicios, y mejorando los proceso productivos con la utilización de nuevas tecnologías.

- Permiten mejorar la distribución de la riqueza y el ingreso, limitando la concentración empresarial implícita en el sistema capitalista, promoviendo la libre competencia y la eficiencia del sistema económico.

- Contribuyen al desarrollo equilibrado entre las regiones, estableciéndose en regiones no atractivas para las grandes empresas, favoreciendo la integración geográfica y el desarrollo de las regiones menos industrializadas.

- Favorecen el desarrollo armónico del mercado laboral, absorbiendo amplia variedad de personas de procedencia y características muy heterogéneas, mejorando la comunicación gracias a la cercanía entre empleado y propietario, y en muchas oportunidades formando a trabajadores no calificados que una vez que adquieren experiencia les permiten ingresar a la gran empresa.

- Fomentan la inversión y el ahorro local, como consecuencia de sus propias limitaciones para acceder a fuentes de financiamiento externas, lo que les obliga a eficientizar sus inversiones y financiarlas principalmente con capital propio.

- Constituyen una fuente importante de generación de empleo, por su falta de capacidad financiera para adquirir nuevas tecnologías.

- Son importantes contribuyentes fiscales.

- Sirven de complemento para el desarrollo de la gran empresa, como proveedores y clientes directos para sus productos.

- Satisfacen demandas específicas de productos que requieren bajos volúmenes de producción, favoreciendo la especialización y diferenciación de los productos.

- Mantienen en funcionamiento sectores poco rentables y con bajas expectativas de crecimiento, permitiendo mantener el empleo existente. 
- Ayudan a preservar el medio ambiente, por su origen fundamentalmente local (sentido de pertenencia) y por su escala, ya que las PyMEs suelen generar menos efectos negativos que las grandes empresas.

Las razones mencionadas, respecto de las funciones de las PyMEs en la economía, ponen de manifiesto la necesidad de desarrollar políticas e investigaciones tendientes a mejorar los niveles de competitividad de las PyMEs locales.

Como se ha demostrado en investigaciones anteriores, la competitividad de las empresas depende de su capacidad para vincularse y/o adaptarse a las condiciones del contexto, de potencialidades propias y de las características particulares de las distintas regiones o ámbitos en las que actúa.

El conjunto de relaciones sociales y económicas que vinculan a los actores que participan en la vida productiva local, va más allá de las transacciones que se verifican en el mercado. Esto es actores, relaciones y recursos, y sus vinculaciones en el sistema productivo local. 


\section{Alcances de la Investigación}

A continuación, se mencionan las principales limitaciones encontradas 0 alcances establecidos durante la realización del trabajo de investigación:

- La selección de los expertos para la realización de las entrevistas, por cuestiones de logística, se limitó a profesionales con domicilios reales o laborales, ubicados geográficamente en la Ciudad Autónoma de Buenos Aires o en la Provincia de Buenos Aires. Al no considerarse la opinión de especialistas de otras jurisdicciones, no se pudo constatar si las respuestas obtenidas tendrían algún tipo de sesgo específico en función del lugar desde le cual el experto percibe la realidad.

- Respecto del accionar del Capital Riesgo, no se encontraron estadísticas a nivel nacional, en lo que refiere a cantidad de inversores o entidades con operaciones activas, tampoco respecto de monto anuales invertidos, plazos promedio de inversión ni rentabilidades obtenidas en operaciones finalizadas. Con lo que las conclusiones alcanzadas, se basan exclusivamente en la información suministradas por algunos responsables de entidades de capital riesgo y la reducida información pública encontrada.

- El análisis de las fuentes de financiamiento para las PyME, se basó exclusivamente en el mercado formal de crédito, no se incluyeron en el mismo relevamientos ni estudios del mercado informal o ilegal, donde los operadores ("cuevas") hacen de la intermediación de fondos su actividad habitual, pero sin estar autorizados para ello. Cabe aclarar que obtener información confiable respecto de los números que se manejan en este mercado "negro" es extremadamente dificultoso, y que el estudio del mismo excede el objetivo pretendido en el presente trabajo de investigación.

- No se encontraron estadísticas oficiales respecto de cantidad de calificaciones de riesgo emitidas a nivel local, por instrumento, mercado, organización calificada (empresas, bancos, SGR), etc. Lo que hubiese permitido verificar, entre otros, tendencias y efectos concretos en el mercado del cambio introducido en el año 2000 donde se retira la obligatoriedad de las calificaciones en las emisiones de deuda e introduce el carácter optativo para sus emisores. 


\section{Marco Teórico}

\subsection{Sistema Financiero}

\subsubsection{Concepto y Generalidades}

El sistema financiero, como parte del sistema económico general, tiene como principal objetivo vincular las unidades superavitarias y deficitarias de la economía.

Un sistema es un conjunto de unidades inter-relacionadas. En el sistema financiero estas unidades o componentes fundamentales son:

- Los Mercados Financieros: lugar (físico o virtual) donde oferentes y demandantes de productos financieros se encuentran y negocian (según modalidades y regulaciones establecidas).

- Las Instituciones o Intermediarios Financieros: entidades que intervienen en los mercados financieros conectando a oferentes y demandantes.

- Los Instrumentos Financieros: las distintas formas de llevar a cabo las cesiones de dinero entre oferentes y demandantes.

Todo interrogante sobre la importancia de estas variables financieras tiene para su respuesta una obligada vinculación con los aspectos reales de la economía. En efecto, la deuda se vincula a las variables macroeconómicas fundamentales (inversión, consumo e ingreso) por constituir el medio que posibilita su optimización.

Los conceptos, modelos, instrumentos o herramientas utilizadas en la administración financiera de las organizaciones, deben tener vinculación directa con las condiciones del contexto dentro del cual fueron concebidos. El grado de desarrollo económico e institucional de un país, se identifica como uno de los factores más relevantes que necesariamente debe ser tomado en cuenta para el diseño y empleo de esa tecnología.

\subsubsection{Mercados Financieros}

Los mercados pueden ser de productos o de factores, los financieros son los mercados del factor capital.

Los mercados financieros es el lugar donde se negocian los activos financieros, que son derechos sobre flujos de fondos futuros. Existen muchos mercados financieros de distinta naturaleza, en cada uno de los cuales se negocian distintos tipos de instrumentos financieros que se diferencian por su vencimiento y por los activos que lo respaldan. De esta manera, distintos mercados atienden a diferentes clases de clientes.

Se mencionan algunas clasificaciones posibles de los mercados financieros en función del aspecto a considerar, como ser:

\section{a) Según el plazo de vencimiento de los activos: de Dinero o de Capital}

En el Mercado de Dinero se negocian títulos de deuda de corto plazo, son valores con vencimiento menor a un año. Su principal función radica en proveer liquidez. 
En el Mercado de Capital se negocian títulos de deuda de largo plazo y acciones corporativas. Su función principal es canalizar fondos para financiar proyectos de inversión de largo plazo.

\section{b) Según el momento de la transacción: Primarios o Secundarios}

Los Mercados Primarios son aquellos donde se obtiene capital mediante la emisión de nuevos títulos.

Los Mercados Secundarios son aquellos en los cuales se negocian los títulos existentes, que se encuentran en circulación. Estos mercados cumplen dos funciones muy importantes: proveen liquidez a los instrumentos y determinan su precio.

Se dice que los mercados secundarios son anchos cuando participan grupos diversos, profundos cuando se negocian órdenes por encima y por debajo del precio corriente y robustos cuando se negocian volúmenes importantes cada vez que se registran cambios de precios.

\section{c) Según el plazo de entrega: de Contado o a Futuro}

En los Mercados de Contado, los contratos se negocian en efectivo y los plazos de perfeccionamiento son inmediatos o en períodos muy breves (menos de 72 hs.).

En los Mercados a Futuro, las condiciones contractuales pactadas, deberán ser cumplidas en alguna fecha futura (o durante un período futuro). Los instrumentos usuales en estos mercados son los contratos forwards (personalizados), futuros (estandarizados) y opciones (que otorgan a su tenedor el derecho a comprar o vender en una momento del futuro). La contratación de estos instrumentos constituye una modalidad eficiente de cobertura ante posibles fluctuaciones de precios o para especular con el comportamiento de los precios futuros.

\section{d) Según su organización: Bursátiles (o de subasta), sobre el Mostrador (Over de Counter) y de Intermediación}

Los Mercados Bursátiles o de subasta son aquellos donde compradores y vendedores se encuentran en un lugar físico para realizar sus transacciones. Son las Bolsas organizadas, como la Bolsa de Comercio de Buenos Aires (con el MERVAL), la Bolsa de Valores de Nueva York (NYSE - New York Stock Exchange) o la Bolsa de Valores Americana (AMEX American Stock Exchange).

Las bolsas de valores organizadas, son organizaciones formales con establecimientos físicos, órganos de gobierno y reglas que rigen su funcionamiento. Se dice que los miembros tienen "asientos" en la bolsa, los cuales pueden ser comprados o vendidos, y estos "asientos" le proporcionan a su tenedor el derecho a realizar transacciones.

Los activos que se quieran comercializar deberán ser inscriptos y autorizados, sujetándose el emisor a cumplir las reglas de la Bolsa. En Argentina, se requiere previamente haber sido autorizada la emisión por parte de la Comisión Nacional de Valores (CNV).

En los Mercados sobre el Mostrador, compradores y vendedores interconectados electrónicamente, realizan transacciones de títulos no listados en mercados de valores bursátiles. 
Estos mercados cuentan con una cantidad relativamente chica de negociantes, quienes poseen inventarios y ofrecen títulos en el mercado sobre el mostrador, manteniendo continuamente un precio de compra y un precio de venta, los que se van ajustando a las diferentes condiciones de la oferta y la demanda. La diferencia entre los precios publicados de compra y venta, conforman el margen de utilidad del negociante. También existen una innumerable cantidad de agentes o corredores que se encargan de vincular a los negociantes con los inversores.

Negociantes y corredores conforman el mercado sobre el mostrador, el cual posee un órgano de gobierno, que se encarga de regular las operaciones y conceder las licencias para operar en el mercado a los agentes.

En Estados Unidos, esta organización es la NASD (National Association of Security Dealers), una organización privada, que administra la red operativa y electrónicamente interconectada que es el NASDAQ (National Association of Security Dealers Automated Quotation) que da conocer las cotizaciones de los títulos corporativos más comercializados. En Estados Unidos la mayoría de las acciones corporativas es negociada sobre el mostrador, salvo las de las más grandes empresas que se encuentran listadas en las bolsas de valores.

En Argentina, el mercado sobre el mostrador es el MAE (Mercado Abierto Electrónico), que opera fundamentalmente con títulos del estado nacional y provicial. EI MERVAL, en cambio, tiene preponderancia por el segmento de títulos corporativos.

Los Mercados de Intermediación, están formados por instituciones financieras (los intermediarios financieros) especializadas en las transferencias de fondos entre unidades superavitarias y deficitarias de la economía. Captan fondos de los agentes superavitarios (inversores), emiten sus propios títulos a cambio de esos fondos (plazos fijos, cajas de ahorro, etc) y luego canalizan esos fondos hacia las unidades deficitarias (vía préstamos, compras de ON, acciones, etc). En este mercado, el intermediario trabaja con stock, presta por cuenta propia y asume el riesgo del negocio; el spread de tasas deberá cubrir sus costos operativos y la ganancia por la actividad de intermediación.

Son entidades monetarias, que a través de su actividad, dan lugar a una creación (secundaria) de dinero, que da origen al conocido efecto multiplicador, prestando el dinero que reciben (neto del encaje definido por la autoridad monetaria, el Banco Central), luego este dinero prestado, vuelve a circular, reingresa como nuevos depósitos, dando lugar a nuevos créditos y así sucesivamente.

\section{e) Según el tipo de derecho: de Deuda o de Acciones}

En el Mercado de Deuda se negocian los instrumentos los instrumentos de deuda emitidos por empresas, entidades bancarias y gobiernos de distintas jurisdicciones. En Argentina, la CNV es quien regula las emisiones de títulos de deuda, debiendo el emisor solicitar autorización para su cotización, luego de cumplimentar las obligaciones establecidas, incluida las de calificaciones por entidades independientes previamente autorizadas.

En el Mercado de Acciones corporativas, se negocian los derechos de propiedad sobre activos reales y sobre el flujo de fondos de las sociedades constituidas por acciones. Se diferencian de los títulos de deuda por ser de rendimiento variable, por asumir el riesgo del negocio y por no tener fecha de vencimiento. 
Se sabe también de la existencia de mercados mundiales, nacionales o locales, a los cuales acuden diferentes tipos de entidades para captar fondos, dependiendo del tamaño de las organizaciones y el alcance de sus operaciones. Se podría continuar con otras clasificaciones, pero las mismas excederían el objeto del presente trabajo. Los tipos de mercados mencionados permitirán comprender que para que una economía funcione eficientemente, requerirá que las transferencias entre las unidades superavitarias y deficitarias que la componen se realicen también con eficiencia.

\subsubsection{Instituciones Financieras}

En el sistema financiero las transferencias de fondos entre unidades superavitarias y deficitarias se pueden realizar de diferentes formas, tal como se podrá observar a continuación:

\section{a) Transferencias Directas}

Figura 1

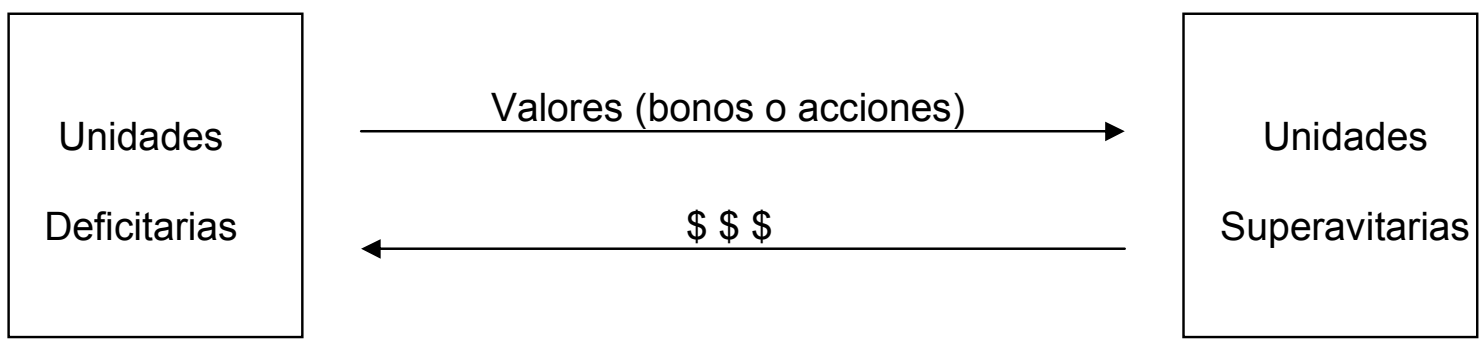

Las transferencias directas se producen cuando las unidades deficitarias (empresas) venden sus bonos o acciones a las unidades superavitarias (inversores) en forma directa, sin la intervención de instituciones financieras.

\section{b) Transferencias Indirectas vía Banco de Inversión}

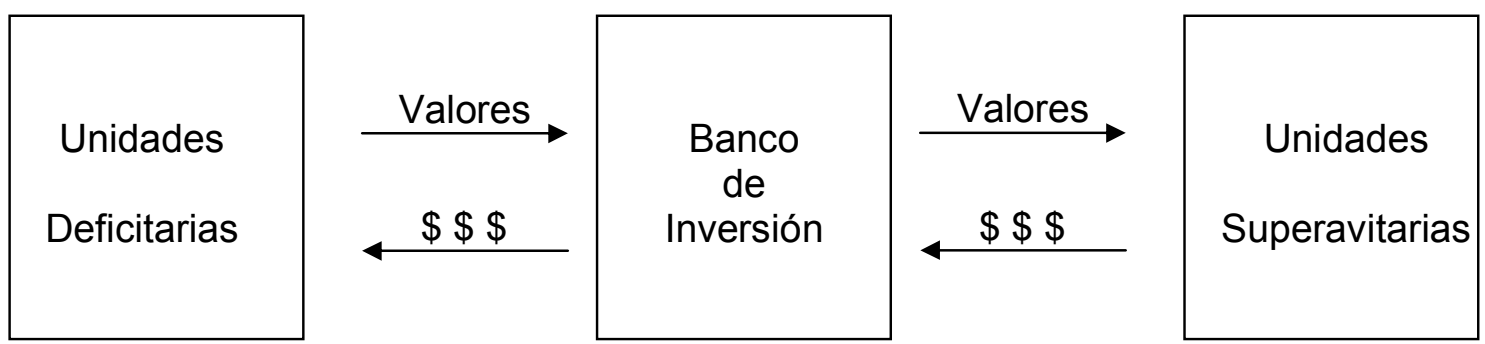

Las transferencias indirectas vía banco de inversión, se generan cuando una empresa (unidad deficitaria) vende sus bonos o acciones a un banco de inversión (como Goldman Sachs, Merrill Lynch, Morgan Stanley o Salomón Brothers), quien a su vez vende estos mismos valores a los inversores (unidades superavitarias). En este proceso el banco de inversión, asesora a la empresa respecto de las particularidades de la emisión a los efectos de que la misma resulte de interés para los inversores potenciales. Posteriormente el banco de inversión compra estos valores, para luego vendérselos a los inversores, corriendo por ende un riesgo. Es una operación de mercado primario. 


\section{c) Transferencias Indirectas vía Intermediario Financiero}

Figura 3
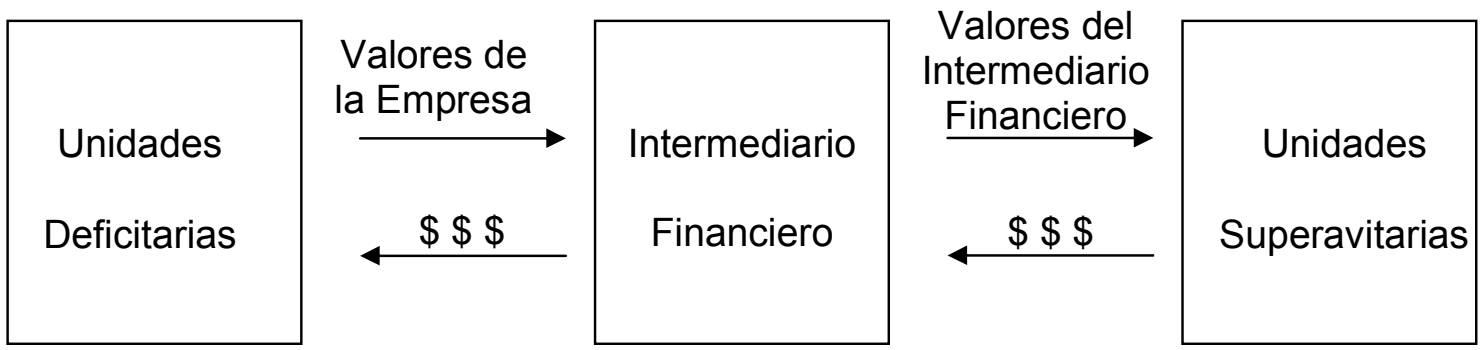

Las transferencias indirectas vía intermediario financiero, se dan cuando las unidades superavitarias (ahorristas) colocan fondos en un intermediario financiero (un banco por ejemplo) quien le entrega sus propios valores a cambio (ej. certificado de plazo fijo) y luego con los fondos obtenidos el intermediario otorga préstamos a las unidades deficitarias (empresas o individuos), creando nuevos productos financieros.

Los intermediarios financieros contribuyen significativamente en la eficiencia de los mercados de dinero y capital. A continuación se mencionan diferentes tipos de intermediarios financieros:

- Bancos Comerciales: el sistema bancario constituye el componente más importante del sistema intermediado, domina ampliamente el mercado de dinero y participa en el de capital comprando valores de empresas y gobiernos.

Las operaciones a través de entidades bancarias, posibilitan la creación secundaria de dinero, ya que los fondos obtenidos pueden ser prestados (netos de los encajes establecidos por la autoridad monetaria) y estos fondos volverán al sistema bancario como nuevos depósitos, dando lugar a nuevos préstamos y así sucesivamente, generándose de esta manera el conocido multiplicador bancario.

El banco trabaja contra stock, asume el riesgo del negocio y opera con spread de tasas. El spread cubre los gastos de funcionamiento y la ganancia de la actividad, cuando más reducido el spread más eficiente la actividad de intermediación.

- Asociaciones de Ahorro y Préstamo: las cuales captan fondos de ahorristas individuales, para luego financiar compras de viviendas y otorgar otros tipos de préstamos. Suelen tener mucha experiencia en el análisis de créditos y cobranzas, y en la diversificación de los riesgos de la cartera de préstamos.

- Uniones de Crédito: son asociaciones cooperativas que vinculan personas que forman parte de un mismo circulo, ya sea porque trabajan en una misma empresa o en una misma actividad. Los ahorros generados se prestan entre los mismos miembros y normalmente las condiciones de estos financiamientos suelen ser muy ventajosas.

- Fondos de Pensiones: son instituciones de ahorro contractual, son los planes de retiro de los trabajadores, que se financian con los aportes de las empresas y gobiernos. Normalmente son administrados por entidades bancarias o compañías de seguros de vida.

- Compañías de Seguros de Vida: también son instituciones de ahorro contractual, donde las personas adheridas pagan sus primas anuales para que llegado el momento los 
beneficiarios reciban los importes asegurados. Estas compañías ofrecen también, distintas variedades de planes de ahorro y capitalización, que prevén la entrega de determinados beneficios a sus asegurados desde el momento de su jubilación.

- Fondos de Inversión: son instituciones que captan fondos de inversores para luego invertirlos en acciones y bonos de empresas y gobiernos. Logran economías de escala, reducción de riesgos mediante diversificación y disminución de los costos de administración de cartera.

Existen distintos tipos de fondos, para satisfacer los más variados perfiles de inversión, en lo que respecta a la relación riesgo - rendimiento y el horizonte de inversión.

\subsubsection{Instrumentos Financieros}

La variedad de activos negociados en los mercados financieros suele verse permanentemente modificada, en lo que respecta a sus denominaciones y condiciones particulares, como consecuencia de los cambios en el orden económico general. A continuación se enumerarán los más representativos:

\section{a) Instrumentos Financieros del Mercado de Dinero}

- Letras de Tesorería: emitidas por gobiernos para financiar gastos federales, normalmente con vencimientos que van de los 90 días a un año de plazo.

- Papel Comercial: títulos de deuda emitidos por empresas reconocidas y financieramente seguras, cuyos destinatarios suelen ser inversores institucionales y sus plazos menores a un año

- Aceptaciones Bancarias y No Bancarias: son obligaciones entre partes (empresa empresa o empresa - banco) y consisten en una promesa de pago emitida por una empresa, pagadera a una fecha y garantizada por un banco (en el caso de las bancarias). El banco garantiza la operación y suele ser referente común ante las partes, cobra un honorario por su intervención.

La vinculación entre empresas posibilita ganancias de tasas, que ye el spread bancario permite que ambos se beneficien, al tiempo que no requiere estar al día en materia fiscal.

- Factoring: por medio de esta operatoria las empresas ceden sus facturas de venta, cheques de terceros o contratos, para obtener capital de trabajo.

- Préstamos de Corto Plazo: acuerdos en cuenta corriente o préstamos de corto plazo otorgados por entidades bancarias, uniones de crédito u otras instituciones financieras.

- Acuerdos de Recompra: préstamos de corto plazo (menos de 15 días) garantizados con letras de tesorerías de los gobiernos.

- Call Money: préstamos de muy corto plazo entre entidades bancarias, que tiene como objetivo cubrir necesidades de fondos o fallas de relaciones técnicas.

- Descuento de Cheques en el Mercado Bursátil: en una operatoria relativamente nueva en Argentina, por medio de la cual las empresas venden cheques propios o de terceros en el mercado bursátil (generalmente avalados por una Sociedad de Garantías Recíproca). Los plazos van de los 30 a los 365 días. 


\section{b) Instrumentos Financieros del Mercado de Capital}

- Bonos del Gobierno: títulos de deuda emitidos por el gobierno, para financiar gastos e inversiones federales con plazos de vencimiento que pueden ir de 1 a 30 años.

- Obligaciones Negociables: títulos de deuda emitidos por las empresas para financiar sus operaciones y proyectos de inversión a largo plazo, pueden extenderse de 1 a 40 años de plazo.

- Hipotecas: préstamos para adquisición de inmuebles (o con otro fines, pero con garantía real de inmuebles) solicitados a bancos comerciales, asociaciones de ahorro y préstamo, en Argentina también a escribanías, con plazos que pueden llegar a 30 años.

- Prendas y otros activos garantizados: préstamos para adquisición de bienes muebles (o para otro fines, pero con garantía real de bienes muebles) solicitados a bancos comerciales, asociaciones de ahorro y préstamo u otras instituciones financieras, con plazos que normalmente no exceden los 5 años.

- Leasing Financieros: son contratos de alquiler con opción de compra, mediante los cuales las empresas, en lugar de tomar préstamos, primero alquilan y luego ejercen la opción de compra de los activos.

Con esta herramienta, además de obtener financiamiento se busca obtener beneficios impositivos. Los plazos pueden variar de 1 a 10 años.

- Préstamos de Mediano y Largo Plazo: otorgados por bancos comerciales y uniones de crédito entre otras instituciones financieras para financiar (generalmente) la compra de bienes de capital.

- Fideicomisos Financieros: consisten en aislar jurídicamente un conjunto de activos, a los efectos de garantizar una posterior emisión de valores (títulos o certificados de participación).

- Acciones: son títulos de propiedad de una parte de capital social de la empresa que las ha emitido, son de renta variable y otorgan al inversor una serie de derechos. Pueden ser ordinarias, privilegiadas o sindicadas.

\subsection{Asimetrías Informativas}

\subsubsection{Introducción}

En el análisis económico tradicional, los agentes participantes toman sus decisiones bajo el supuesto de información completa y simétrica. Por este motivo, los resultados obtenidos con la aplicación de modelos que toman como base estos supuestos, suelen evidenciar un dicotomía significativa en lo que respecta al comportamiento de la variable que se desea predecir, como consecuencia de los problemas que surgen cuando los agentes económicos no se encuentran igualmente informados.

El primer trabajo referidos al estudio de las asimetrías informativas entre los agentes económicos es el de Akerlof (1970) "The Market for Lemons: Qualitative Uncertainty and the Market Mechanism" donde se ponía en evidencia los problemas de las asimetrías informativas entre los agentes del mercado de vehículos de segunda mano. 
En la década de los ochenta, como consecuencia del creciente interés en la temática, se comienza a desarrollar la Teoría de la Información, como parte de la Teoría Económica, que luego toma mayor trascendencia cuando la Teoría de los Juegos y la Teoría de la Optimización recogen las asimetrías informativas como aspectos claves en las relaciones entre los agentes económicos ${ }^{1}$.

La información asimétrica es una característica que siempre se encontrará inmersa en una transacción económica debido a que es natural que en cualquier relación comercial haya una parte mejor informada que la otra. La acción de los agentes mejor informados que intervienen en el mercado, podría afectar el buen funcionamiento y el nivel de eficiencia del mismo.

Dicho de otro modo, la asimetría informativa genera costos de transacción, que estarían dados por aquellos que las partes deben incurrir a los efectos de alcanzar una situación que a priori se vislumbre como la mejor manera posible de satisfacer sus intereses.

Según Alfredo Bullard Gonzalez "la información puede ser conceptualizada como un bien, en cuanto tiene un valor económico determinado por las circunstancias y por la utilidad que tiene para los particulares..."2

\subsubsection{Decisiones Financieras con Información Asimétrica}

\subsubsection{Aspectos Generales}

El valor de mercado de una empresa depende de los flujos de fondos esperados y del nivel de riesgo asociado a ese flujo desde la percepción de los inversores, la cual estará nutrida de la información pública disponible. Ahora bien, un directivo de una empresa tendría información más completa y oportuna, para valorar el futuro de la empresa, que la disponible en el mercado. Esta situación podría dar lugar a los problemas de selección adversa, cuando los inversores deben valorar la calidad y veracidad de la información proporcionada por los directivos, cuando saben que sus intereses están orientados a brindar solo información favorable. Como consecuencia, la empresa no se encontrará correctamente valorada por el mercado, por carecer los accionistas de la información necesaria para tal fin.

Los directores de las empresas que se encuentren subvaloradas por el mercado, se esforzarán por comunicar información valiosa no conocida por el mercado, con el objeto de llevar la cotización de las acciones a su verdadero valor, satisfaciendo de esta manera los intereses de los accionistas y los propios (como podrían ser su remuneración si la misma estuviera vinculada a la cotización, su reputación, etc). Como en muchas ocasiones esto llevaría a la empresa a tener que poner a disposición información confidencial, que por cuestiones de competitividad no pueden ser comunicadas, los directivos suelen dar señales al mercado (teoría de la señalización financiera) de manera tal que los inversores puedan inferir a través de ellas sus expectativas respecto del futuro.

Como se ha mencionado anteriormente, la información asimétrica afecta directamente las decisiones financieras, poniendo en evidencia la existencia de restricciones financieras que limitan o de algún modo, condicionan la inversión real de la empresa. "Los problemas de riesgo moral y de selección adversa vinculados con la información referida al

\footnotetext{
${ }^{1}$ Acosta Ballesteros, J y otros. "Información Asimétrica en los Mercados Bursátiles". Investigaciones Europeas de Dirección y Economía de la Empresa. Vol. 6, № 3, 2000. Pág. 53.

2 Bullard Gonzales, Alfredo. "La Asimetría de Información en la contratación a propósito del Dolo Omisivo". Lima. Palestra Editores, 2000. Pág. 292.
} 
comportamiento financiero de las empresas, dificultan la obtención de recursos financieros en el mercado, inclinando a las compañías hacia el uso de la autofinanciación"3.

\subsubsection{El Racionamiento del Crédito}

"La información asimétrica supone una ruptura en el mecanismo de los precios como criterio de asignación de recursos, y el mercado de capitales no constituye una excepción a este hecho"4.

El racionamiento del crédito por causa de asimetrías informativas, se daría cuando dada una situación en el mercado de deuda, donde por el lado de la demanda, existan un cierto número de agentes económicos de idénticas características y por el lado de la oferta exista la posibilidad de acceder a un crédito en determinadas condiciones, que no todos los agentes dispuestos a contraer un crédito pueden obtenerlo.

Como se podrá observar en la situación mencionada, el precio (interés) del préstamo, deja de ser el criterio de asignación, debiendo el oferente de fondos utilizar otro criterio a los efectos de tomar tal decisión.

Uno de los primeros estudios referidos al racionamiento del crédito fue el de Jaffee y Russell (1976), donde se ponía en evidencia cómo la información imperfecta y la incertidumbre pueden conducir a esa situación. En este estudio se mencionan dos tipos de oferentes de fondos, que llevarían a dos situaciones diferentes de mercado:

- Una situación de equilibrio estable, donde los oferentes de fondos imponen condiciones muy estrictas y limitan la cantidad de fondos que están dispuestos a conceder a cada demandante de recursos. Vandell (1984) define este racionamiento como un equilibrio de contratos simples, entendiéndose como tales los contratos que incluyen las mismas condiciones para todos los individuos. En esta circunstancia, los demandantes de fondos más solventes estarían pagando una prima para compensar el imprevisible comportamiento de los demandantes de menor calidad.

- Una situación de inestabilidad, caracterizada por la rotación de los demandantes de fondos que acceden al mercado de deuda. En esta situación, los agentes, beneficiándose del asimétrico reparto de información en el mercado, obtendrán beneficios a corto plazo, pero su posición es insostenible durante un período de tiempo prolongado, ya que la calidad de los demandantes se revelan cuando reiteran sus pedidos a los oferentes.

Dada las situaciones anteriormente mencionadas, el racionamiento del crédito se presenta como la actitud lógica de los oferentes de fondos ante el imperfecto conocimiento de los demandantes, ya se trate de supuestos de selección adversa o de riesgo moral.

La selección adversa, causada por la falta de información de los acreedores respecto de las características de los demandantes y del nivel de riesgo de sus proyectos, encarecerá el otorgamiento de créditos que financian proyectos, en principio, más arriesgados o asignados a agentes de menor confianza. Sin embargo, a medida que aumenta el tipo de interés, se deteriora la calidad de los individuos dispuestos a acceder, debido a que ante un incremento en la tasa del préstamo solo permanecerán como clientes aquellos inversores que presentan proyectos más arriesgados y para los cuales, a pesar de que el préstamo tenga un elevado costo, su concesión resulta ventajosa. Ahora bien, desde el punto del vista del banco, esta

\footnotetext{
${ }^{3}$ Azofra Palenzuela, Valentín y López Iturriaga, Felix J. "La Asimetría Informativa en los Mercados Financieros: ¿El hallazgo de un nexo de unión?. Informe de Investigación. Pág. 10.

${ }^{4}$ Azofra Palenzuela, Valentín; Ob. Cit. Pág. 22.
} 
situación resulta perjudicial si, como suele suceder, el incremento del tipo de interés no compensa el aumento de las probabilidades de quiebra del demandante, por lo que la reacción de las entidades financieras será limitar aquellas operaciones que puedan entrañar un cierto riesgo de incumplimiento (Greenwald y Stigltz 1990).

Por otro lado, el hecho de que los oferentes de fondos eleven el tipo de interés de sus créditos para protegerse de los comportamientos oportunistas de los agentes, puede llevar a una posible causalidad de riesgo moral, que se daría, si como consecuencia de esta actitud de la entidad bancaria, los demandantes de fondos al comprobar que el elevado costo del préstamo reduce el rendimiento del proyecto de inversión, deciden desviarse de los proyectos inicialmente acordados y emprender otros, aunque tengan menor probabilidad de éxito, porque proporcionan mayor rendimiento.

Otra situación de racionamiento de crédito se da cuando, a pesar de que los solicitantes parezcan disponer de similares características, puede ser que algunos obtengan el crédito mientras que otros no lo logren. Esta limitación no responde a una escasez de recursos de los oferentes, esta restricción a diferencia de las anteriormente mencionadas, es originada por un recorte del número de préstamos que se otorgan, en lugar de la cuantía o precio de los mismos.

Así como existe la justificación del racionamiento del crédito basado en el oportunismo, también es factible encontrar otra explicación de dicha situación de mercado, igualmente fundada en la asimetría informativa, pero cuyo motivo central se desplaza desde el oportunismo hacia la reputación. Se forma así el mercado de la clientela (Rivaud 1995), el cual ante la posibilidad de renovación del crédito concedido, los comportamientos de los oferentes y demandantes dejan de estar orientados por el deseo de explotar oportunistamente la asimetría informativa para pasar a guiarse por el deseo de generarse una buena reputación que les permita el mantenimiento de la relación a lo largo del tiempo. El racionamiento aparece en el mercado de clientela porque los oferentes no se rigen por el tipo de interés, sino que ante la situación de exceso de demanda, preferirá conceder los créditos a aquellos agentes que le resulten conocidos por haber mantenido relaciones crediticias con anterioridad.

\subsubsection{Las Garantías Subsidiarias}

En un mercado caracterizado por los problemas de las asimetrías informativas, cualquier elemento que contribuya a limar esas imperfecciones será bienvenido. El hecho de que los prestamistas no dispongan de información completa para valorar la confianza que puede depositarse en un determinado prestatario, los llevará a recurrir a todas las acciones que tengan a su alcance para disipar esas dudas.

En este marco, las garantías subsidiarias pueden cumplir una doble función. Primero, constituyen un medio del que disponen los prestamistas para reducir el riesgo de selección adversa. La consecuencia natural de su desconocimiento sobre las características del demandante de fondos, llevarán al prestamista a buscar alternativas con el fin de asegurarse la posibilidad de recuperar los fondos prestados.

Por otro lado, los tomadores de fondos dispuestos a otorgar garantías subsidiarias al prestamista, dan una señal que los distingue del resto de los agentes del mercado, haciendo ver su capacidad para cumplir los acuerdos contractuales, incluso ante la situación de fracaso del proyecto previsto. 
De esta forma, la utilización de garantías subsidiarias como respaldo para la obtención de un crédito, ayuda a superar los problemas ocasionados por la información asimétrica y evita el racionamiento del crédito antes mencionado. Extremando el razonamiento, un nivel suficiente de garantías permitiría actuar con los mismos criterios que los empleados en contexto de plena información, con asignación de créditos asimilable a condiciones de mercados perfectos.

A pesar de lo mencionado, no se puede afirmar tajantemente que un incremento de las garantías subsidiarias lleve a una mayor facilidad en el otorgamiento de créditos. Uno de los precursores de esta idea, Wette (1983) y posteriormente Berger y Udell (1990), quienes expresan que la existencia de mayores niveles de garantías pueden provocar problemas de selección adversa, reduciendo los agentes dispuestos a otorgar fondos a demandantes que, a pesar de poder reunir esas garantías, cuentan con proyectos excesivamente arriesgados que no resultan rentables desde el punto de vista del prestamista. Pudiendo darse la situación en la que únicamente los demandantes menos confiables sean los que están dispuestos a comprometer tales garantías, lo que conduciría a un empeoramiento del mercado de créditos.

\subsubsection{La Financiación Interna}

Los desequilibrios que se producen en el reparto de la información plantean una nueva perspectiva de las relaciones existentes entre la estructura financiera de las empresas y las decisiones sobre el empleo de fondos que dichas empresas adoptan.

La consideración de fricciones informativas en el mercado supone un quiebre en la hipótesis de ilimitación de los mercados de capitales, así como la de libre acceso de la empresa a cualquiera de las modalidades de financiación. Los mercados financieros intervendrán en la toma de decisiones por parte de la empresa, recortando los márgenes de actuación de estas e incluyendo la distribución del riesgo como factor a tener en cuenta en la determinación de los comportamientos individuales.

En el mundo ideal de Modigliani y Miller los fondos internos y externos eran sustitutos perfectos entre sí. Incluso dentro de estos últimos, la elección entre financiación propia o ajena no tenían trascendencia de cara a la valoración de la empresa. Sin embargo, las hipótesis subyacentes en este planteamiento distan mucho de verificarse en la realidad, por lo que las posteriores aportaciones sobre esta materia han tratado de dar una explicación a la preferencia de las empresas por determinadas combinaciones de recursos financieros.

En esa línea se enmarca la teoría de las preferencias financieras (Myers, 1984), que establece un orden de prioridades consistente en recurrir inicialmente a la autofinanciación, para emplear posteriormente la deuda y finalmente, los fondos propios procedentes de nuevas emisiones. Según el razonamiento del autor, el endeudamiento no será la opción inicialmente elegida por dos motivos.

En primer lugar, las empresas prefieren evitar los costos de las dificultades financieras en las que pueden verse envueltas en caso de alcanzar ratios de leverage excesivamente elevados. Por otro lado, con el fin de garantizar la flexibilidad de su comportamiento, las empresas desean mantener una capacidad adicional de obtención de fondos y encontrarse en condiciones de reaccionar con prontitud ante ciertas modificaciones del entorno.

Aún a pesar de ello, la deuda no se sitúa en el último lugar en cuanto a preferencias de la empresa, ya que, en comparación con la emisión de fondos propios, presenta ciertas ventajas. La utilización de ambas posibilidades incurre en costos de emisión, pero, desde el 
punto de vista del suscriptor, las emisiones de obligaciones resultan menos arriesgadas que las de acciones, además, de que la empresa se beneficia del carácter deducible que los gastos financieros tienen en el impuesto de sociedades.

La preferencia de una emisión de deuda sobre una emisión de fondos propios, puede justificarse también, según la visión de Myers, en que los inversores externos a la empresa, conscientes de su inferioridad informativa, conjeturarían que existe un motivo oculto que podría perjudicarlos en favor de los actuales accionistas. En concreto, el mercado interpretaría que las acciones de la empresa emisora se encuentran sobrevaluadas y no accederían a la suscripción, salvo que se ofreciese una prima para compensar el problema de selección adversa.

Desde la visión de Ross (1977), una emisión de acciones, podría constituir una señal negativa pues el mercado la podría interpretarla como un síntoma de la precariedad de la situación financiera de una empresa, al no conseguir captar capitales ajenos.

Se concluye, pues, que los fondos generados internamente constituyen la vía óptima para la financiación de la empresa. Dado que los tipos impositivos que gravan los incrementos de capital resultan inferiores a los correspondientes a los dividendos, será preferible este tipo de fondos sobre los procedentes del exterior. Una vez que la empresa haya agotado esa modalidad, se verá obligada al recurso a fondos externos, donde el endeudamiento se impone a las ampliaciones de capital.

Se llega así a una explicación, en términos informativos, que coincide con la teoría del pecking order, donde la preferencia de las empresas por las distintas clases de recursos financieros, colocan en el primer lugar a la generación interna de fondos, seguida de la emisión de deuda y finalmente, la ampliación de capital. Esta clasificación, en la medida en que hace depender las oportunidades de la empresa de su capacidad de generación de recursos, da origen a una serie de restricciones financieras que condicionan su inversión, generando una vinculación entre la estructura financiera de la empresa y su estructura de inversiones.

"La economía de la información va perfilando una nueva visión de la estructura de capital, en la que la utilización de deuda deja de obedecer exclusivamente a un intercambio óptimo entre las ventajas fiscales de la misma y los costos de quiebra a los que puede dar origen, para incluir consideraciones relativas al riesgo correspondiente a la deuda, los incentivos al esfuerzo que proporcionan y la información que transmite" 5 .

\subsubsection{Asimetrías Informativas en los Mercados Financieros}

En los mercados financieros, como en el resto de los mercado del sistema económico, es evidente la existencia de asimetrías informativas. El estudio de la formación de los precios de los activos financieros no sólo se basa en aspectos relacionados con su oferta y su demanda, sino también en la estructura y regulación de los mercados donde se negocian estos activos. Por su parte, el funcionamiento de los mercados financieros no es homogéneo, sino que aparecen diferencias relacionadas con el modo de contratación, la normativa vigente, el tipo de activo, etc. El análisis de estas diferencias en los modos de contratación y regulación de los mercados financieros se ha denominado Teoría de la Microestructura de los Mercados, desarrollada fundamentalmente a partir de los años

\footnotetext{
${ }^{5}$ Darrough, M. N. y Stoughton, N. M. "Moral hazard and adverse selection: the question of financial structure". Journal of Finance. Vol 4, № 2. Pág. 501.
} 
ochenta, tras la aparición de una enorme diversidad de mercados con características específicas.

El desarrollo de la Teoría de la Microestructura ha permitido investigar aspectos relacionados con las diferencias de información que se producen entre los agentes que intervienen en los mercados financieros, los cuales juegan un papel crucial en la formación de los precios de transacción.

\subsubsection{Asimetrías Informativas en el Mercado Intermediado}

Tradicionalmente se ha tratado de explicar la labor de los intermediarios financieros a partir de consideraciones basadas en las imperfecciones de los mercados en que dichos agentes intervienen. Desde esta perspectiva, la tarea de intermediación consistiría, básicamente, en aprovechar las diferentes necesidades y ofertas de fondos en el mercado, con el fin de llevar a cabo esas operaciones más eficientemente. La capacidad de los intermediarios de contactarse con distintos agentes les brinda la posibilidad de beneficiarse de su posición, canalizando los recursos excedentes de algunas entidades hacia otras dispuestas a aceptarlos. A través de este comportamiento, logran economías a escala y permiten un reparto más adecuado de los recursos económicos del sistema.

La intermediación financiera experimenta una notable modificación en el proceso de asignación de recursos, cuando se le incorporan los problemas de información asimétrica, afectando directamente los niveles de eficiencia del mercado.

En este sentido, "la asignación eficiente de los recursos exige la atenuación de la asimetría en el reparto de la información, correspondiéndoles a los intermediarios financieros promover un mayor intercambio de información entre los distintos agentes económicos" ${ }^{\text {. }}$ Esta función trata de eliminar la posibilidad de comportamientos oportunistas, surgidos como consecuencia de los diferentes niveles de información disponibles.

Como dice Azofra (1994), el contacto de los intermediarios con una pluralidad de agentes con necesidades financieras, permite a los primeros diversificar sus carteras de inversiones. Esta forma de proceder les protege del riesgo de incumplimiento ex post de las cláusulas contractuales, disminuyendo los problemas de riesgo moral. Al mismo tiempo, la especialización de los intermediarios financieros, les permite efectuar un control más exhaustivo del comportamiento del individuo más informado, con el objeto de reducir el margen de oportunismo del mismo.

El estudio de las asimetrías informativas en la intermediación financiera, han dado origen a diversos trabajos dentro de la literatura, como el de Leland y Pyle (1977), quienes aportan nuevas formas de explicación tendientes a comprender las ineficiencias a las que conduce los problemas informativos en los mercados de capitales.

En opinión de estos autores, se debe velar por conseguir una adecuada transferencia de información dentro de los mercados. De lo contrario, al desconocer los agentes las verdaderas características de los intervinientes, se les asigna una consideración promedio del conjunto de integrantes del mercado. Un comportamiento de ese estilo empobrece notablemente los resultados del proceso económico y supone un despilfarro de recursos.

La asimetría informativa conduce, según Leland y Pyle, a la existencia de instituciones dedicadas a la intermediación financiera, dado que dichas instituciones permiten resolver

\footnotetext{
${ }^{6}$ Azofra Palenzuela, Valentín; Ob. Cit. Pág. 11
} 
algunos problemas sobre la información a los que el mercado no da apropiada respuesta. En el trabajo citado se explican tres tipos de problemas que dificultan la transmisión de información directamente de las empresas demandantes de fondos hacia el público.

Por un lado, se plantea el problema de la apropiación del rendimiento de tal transmisión de información. Si el público pudiera, a su vez, revender la información por él adquirida sin que le supusiera un perjuicio, la empresa emisora de la misma se hallaría en una situación en la que percibe un precio de venta inferior al de la utilidad que dicha información le puede proporcionar a su comprador.

En segundo lugar, el agente interesado en mejorar su conocimiento no tiene posibilidad de determinar cuándo la información adquirida es veraz y cuándo es errónea. Por eso, los inversores dispuestos a destinar abundantes recursos para la obtención de información fiable preferirán acudir a intermediarios financieros, especializados en al recopilación de dicha información, en quienes ellos depositan su confianza.

La tercer razón para justificar la preferencia de algunas empresas por los intermediarios financieros en lugar del mercado, se basa, en los intereses de las empresas solventes, las cuales al presentar un bajo riesgo de oportunismo, desean ser identificadas para que se las trate de forma acorde a su situación, otorgándoles condiciones más favorables. Este trato deferente no sería posible en el mercado, en el que se hace una estimación promedio de riesgos, mientras que las entidades especializadas sí realizan esa distinción entre sus clientes.

Desde una perspectiva más concreta del problema, los bancos, al recabar información sobre sus empresas clientes y tratar de cerciorarse de que los directivos de esas empresas emprenden acciones eficientes, incurren en costos de control.

Así, un primer componente de los costos de control es la retribución adicional que los bancos exigen para compensar algunas exigencias legales que ese tipo de instituciones están obligadas a absorber. Normalmente los bancos, por su actividad, se hallan obligados a mantener una parte de sus activos en inversiones muy líquidas de poco o nulo rendimiento, lo que significa que desarrollarán otras acciones en las que cargarán mayores tarifas para resarcirse de las anteriores.

Otra fuente de costo, es la diferencia de liquidez entre los préstamos bancarios y los fondos obtenidos por suscripción pública, debido a que los primeros gozan de menor carácter público y son difícilmente transmisibles a terceros.

Sharpe (1990), proporciona otro modelo explicativo de la actuación de los bancos como intermediarios financieros que, a diferencia de los anteriores, en este caso los desequilibrios informativos no se dan entre otorgantes y receptores de fondos, sino entre los propios oferentes respecto a un mismo demandante de fondos.

Sharpe, postula que las empresas, debido a las asimetrías informativas existentes en el mercado, encuentran incentivos para el mantenimiento continuado de relaciones con el mismo banco. La razón se fundamenta en las dificultades para transmitir al mercado y a los intermediarios sus verdaderas características, motivo por el cual, las buenas empresas preferirán el mantenimiento a largo plazo de relaciones con el mismo banco.

Dada la estabilidad en las relaciones banco-empresa, la competencia en el sector bancario empujará a esas instituciones a una lucha por la captación de nuevos clientes, a los que es necesario ofrecer condiciones muy ventajosas, incluso experimentando pérdidas en los 
primeros momentos. La asignación de recursos adolecerá de esas ineficiencias, pues se desvían recursos desde empresas de confianza hacia empresas de menor calidad y experiencia.

Esta ineficiencia, en opinión de dicho autor, se puede eliminar si se formalizan contratos contingentes completos o si se admite la reputación como motivo que garantice un contrato implícito entre ambas partes. Estos contratos así concebidos, respaldados por la propensión del banco a mantener los compromisos adquiridos, establecen unos precios óptimos permitiendo la asignación más eficiente de los recursos.

Desde otra perspectiva, Lucas y McDonald, exponen otro problema de la asimetría informativa, al impedir que los inversores distingan entre los distintos niveles de solvencia de los bancos. Para diferenciarse del resto, los bancos de reconocida garantía, emitirán una señal consistente en la posesión de una mayor proporción de activos libre de riesgo. Con esta actuación tratan de transmitir sus verdaderas características, soportando una menor rentabilidad en aras de garantizar a sus clientes unos niveles superiores de solvencia.

No obstante, a pesar del menor rendimiento que perciben, también es cierto que estos bancos pueden ofrecer una remuneración más baja a sus clientes, ya que la seguridad que brindan es un factor a tener en cuenta. Los bancos menos solventes no pueden emitir la misma señal, puesto que el costo que les acarrearía tal actuación sería muy superior a los beneficios obtenidos, y así se explica que algunos intermediarios financieros posean una cartera más orientada hacia la seguridad que la que sería óptima en condiciones de mercados informativamente perfectos.

En resumen, la existencia de asimetrías informativas entre los agentes que intervienen en el mercado de capitales proporciona un basamento adecuado, que asigna a los intermediarios la tarea de generación y transmisión de la información necesaria para superar las desigualdades en su reparto. De esta forma, los intermediarios se perfilarían como entidades que acumulan capital-información.

\subsubsection{Asimetrías Informativas en los Mercados Bursátiles (o de subasta)}

En los Mercados Bursátiles o de contratación de subasta, se reúnen los inversores cada cierto tiempo para realizar el intercambio de activos, determinándose su precio en función de la oferta y la demanda.

"La experiencia y la teoría económica enseñan que el rendimiento de una inversión en el mercado de capitales presenta un margen de riesgo que no es posible determinar ex ante con certeza. Sin embargo, performances precedentes y resultados esperados permiten arribar a valoraciones razonables; es decir, la imposibilidad de un juicio cierto deja intacta la posibilidad que, sobre la base de las informaciones disponibles, el rendimiento previsto de una inversión sea mejor que el de otra"7.

La valoración que los inversores hacen de la empresa se encuentra mediatizada por su estructura de capital. De ahí la importancia de que cada empresa elija un nivel de leverage acorde a su situación, para lo cual debe articularse un sistema de costos de quiebra que tienda a disuadir a las empresas de enviar al mercado señales que puedan ser malinterpretadas. Así entendido el problema, y hablando en términos aproximados, una empresa que emplee deuda en su financiación está dando a entender al mercado la solidez

\footnotetext{
${ }^{7}$ Easterbrook, Frank H.; Fischel, Daniel R. "The Economic Structure of Corporate Law. Cambridge - London, 1991. Pág. 279.
} 
de su posición financiera, presentando sus títulos como una opción segura para los posibles inversores.

La información tendría también utilidad para profundizar igualmente en el origen de dicha financiación vía deuda, ya que el valor de la información que poseen los miembros internos de la empresa se encuentran condicionado por el carácter confidencial de la misma, por lo que estos tratarán de darle la menor difusión posible. Se explica así, que en muchos casos, los directivos prefieran la suscripción de deuda de carácter privado en lugar de recurrir a emisiones públicas, con el fin de preservar las ventajas informativas de las que gozan.

La información asimétrica introduce notables distorsiones en el funcionamiento de los mercados de capitales, de modo que los recursos financieros internos y externos dejan de ser perfectamente sustituibles entre sí. La empresa, dado los problemas de selección adversa y riesgo moral que se le plantean al inversor, posee incentivos para emplear el primer tipo de fondos, lo que origina el nacimiento de restricciones financieras en el caso de que dicha fuente de recursos sea insuficiente para atender las necesidades de la empresa.

La presencia de asimetrías informativas plantea entonces un problema crucial para el desarrollo del mercado de capitales. El hecho de que en los mercado de capitales, el volumen y la concentración de los intercambios, conjuntamente con la participación de sujetos altamente calificados y en condiciones de explotar economías de escala, le permiten al mercado financiero expresar precios que tienden a reflejar completamente todas las informaciones disponibles; determina los distintos niveles o hipótesis de eficiencia de los mercados, los cuales surgirán de la capacidad de los precios para reflejar los contenidos de información. ${ }^{8}$

A lo largo de la vida de la empresa, son muchos los acontecimientos que surgen y que se ven reflejados en el valor de la misma. Dentro de estos eventos, es posible mencionar, por su importancia y periodicidad, al anuncio de beneficios. Estudios empíricos realizados sobre el proceso de formación de precios han revelado que todos los anuncios de beneficios, independientemente del trimestre considerado y del hecho de que sean o no definitivos, tienen contenido informativo, el cual se recoge en los precios cotizados, si bien de forma distinta entre las empresas grandes y en las de reducido tamaño. Así mientras en estas últimas el contenido informativo se incorpora de forma inmediatamente posterior a la publicación de la información, en las grandes lo hace de forma gradual dado que se dispone de mayor información sobre las mismas.

El componente de selección adversa con antelación a la divulgación del suceso es mayor en las empresas pequeñas que en las de mayor tamaño, debido, a la mayor incertidumbre que rodea los anuncios de empresas sobre las que hay poca información.

\subsubsection{Asimetrías Informativas en los Mercados sobre el Mostrador}

En los Mercados sobre el Mostrador, funcionan los sistemas de contratación continua, dentro de los cuales se pueden diferenciar dos tipos de mercados, mercados dirigidos por precios y mercados dirigidos por órdenes.

En los mercados dirigidos por precios, existen los llamados creadores de mercado, que ofrecen en cualquier momento a lo largo del período de contratación, un precio de compra y un precio de venta, junto con las cantidades de títulos asociados a dichos precios. Dentro de estos mercados están la Bolsa de Londres y el NASDAQ.

\footnotetext{
${ }^{8}$ Perrone, Andrea. “Información en el mercado de valores y tutela del inversor”. Pólit. Crim. № 7,2009. Pág. 3.
} 
En los mercados dirigidos por órdenes, son los propios miembros del mercado (Sociedades y Agencias de Valores) los responsables de tramitar las órdenes emitidas por los inversores, bien sean de compra o de venta, siendo éstas anotadas, de forma electrónica y luego se clasifican por competitividad, permitiendo determinar el spread implícito de precios, definido como la diferencia entre el mejor precio de compra y el mejor de venta existente en cada instante en el mercado. Dentro de este tipo de mercado se encuentran la Bolsa de París, la Bolsa de Tokio, la Bolsa de Toronto y el Mercado Continuo de Madrid.

Estas diferencias entre los sistemas de contratación de los mercados dirigidos por precios y los dirigidos por órdenes, son fundamentales a la hora de formalizar un modelo que detecte la influencia de la información en la determinación de los precios de transacción de los títulos. Así, en los mercados dirigidos por precios, los modelos desarrollados estudian la asimetría informativa como un componente del spread de precios. Sin embargo, en los mercados dirigidos por órdenes, la mayor parte de la literatura se centra en el análisis de cómo la llegada de nuevas órdenes al mercado y la propia negociación implica nueva información, la cual dará lugar a reacciones diversas por parte de los operadores, en función del grado de información de que dispongan. Las diferentes actuaciones de estos operadores es lo que se conoce como efectos de información.

\section{Mercados Dirigidos por Precios}

La mayoría de los trabajos dedicados a la microestructura de los mercados financieros se ha centrado en los mercados dirigidos por precio. En este tipo de mercados, el spread de precios se define como la diferencia entre el precio al que el creador de mercado está dispuesto a vender un activo (ask) y el precio al que lo desea comprar (bid).

El primer trabajo que introdujo los problemas informacionales en mercados financieros fue el de Bagehot (1971). Este trabajo considera que en el mercado de valores existen dos tipos de inversores, diferenciados entre sí por el motivo de su negociación. Por un lado, los que disponen de mayor información y esperan ganar en sus operaciones y, por otro lado, los que actúan por motivos de liquidez y disponen de la misma información que el dealer. Debido a esta asimetría, el dealer, al establecer la horquilla de precios, tratará de ganar, en promedio, con los operadores desinformados, pues espera perder, en promedio, con los más informados.

Por su parte, Copeland y Galai (1983), en la misma línea que Bagehot, enfatiza el papel de la información asimétrica en la determinación del bid-ask spread, analizando la formación de éste en mercados financieros organizados. El modelo propuesto fue especificado bajo escenarios, bajo un comportamiento monopolista del dealer y en un contexto competitivo.

En la especificación del modelo teórico, estos autores suponían un comportamiento optimizador del dealer. Éste elige el bid-ask spread que maximice sus beneficios, teniendo en cuenta que si fija un spread demasiado amplio, se enfrentará a la posibilidad de potenciales reducciones en los beneficios derivados de sus operaciones con inversores que sólo demandan liquidez, frente a la reducción de las potenciales pérdidas resultantes de operar con inversores informados. Por el contrario, si fija un spread muy estrecho, la probabilidad de incurrir en pérdidas en las operaciones con agentes informados se eleva, frente al aumento de los potenciales beneficios resultantes de operar con agentes demandantes de liquidez. En resumen, el bid-ask spread óptimo es fijado por el dealer teniendo en cuenta este trade-off entre los beneficios y las pérdidas esperados en la negociación con ambos tipos de agentes. 
Otro supuesto del modelo teórico especificado consistía en que la nueva información llega al mercado cuando un agente con más información conduce al dealer a limitar el tamaño de sus órdenes, con el objeto de reducir sus posibles pérdidas respecto de aquél. Tras la realización de la transacción, la información privada se convierte en pública. Esto lleva al dealer a revisar su estimación de los precios.

En el modelo teórico, las diferencias encontradas entre los resultados competitivo y monopolista, señalan lo siguiente: a) el bid-ask spread disminuye al pasar de una estructura monopolista hacia una competitiva, resultando consistente con los encontrados a nivel empírico; b) si la proporción de agentes informados se eleva, la diferencia entre el spread monopolista y el competitivo desciende; y c) si la elasticidad de la demanda de los inversores que negocian por liquidez desciende, los ingresos esperados por el dealer disminuyen y, como consecuencia, el precio ask también disminuye.

Los principales resultados que se derivan del modelo, tanto en su especificación competitiva como bajo una estructura monopolista, son: que el bid-ask spread será siempre positivo en la medida que existan inversores informados, y que el spread será mayor cuando aumente la proporción de operaciones realizadas con agentes informados.

Posteriormente, Easley y O'Hara (1987) analizaron el efecto del volumen negociado sobre el precio de los títulos. Se demostraba que dicho volumen introduce un problema de selección adversa en la negociación de títulos, porque los inversores que están informados, suponiendo que desean negociar, prefieren siempre hacerlo en cantidades grandes a un precio previamente fijado. Como los inversores que no tienen información no siguen este mismo comportamiento, cuanto mayor sea el volumen negociado, más probable es que el dealer esté operando con un agente informado. Como resultado, este efecto de información implica que la estrategia de precios óptima de los creadores de mercado depende, entre otros factores, del tamaño de la transacción, de forma que los mayores volúmenes son negociados a precios menos favorables, reflejando la alta probabilidad de que esa inversión esté basada en la información. Frente a la idea de que este tipo de operaciones puede provocar un spread que compense al dealer del riesgo asumido en dicha negociación, los autores demostraron que ello no necesariamente se traduce en un bid-ask spread.

En 1989, Stoll analizó la determinación del spread, destacando tres componentes:

- El costo de procesamiento, componente que recoge los costos operativos que soporta el creador de mercado por operar en el mercado.

- El costo de mantenimiento de los activos, un componente de costos de cartera, que soporta el creador de mercado como costo de oportunidad por mantener una determinada cartera de activos con riesgo.

- El costo de selección adversa, a los que se enfrenta el creador de mercado por realizar transacciones con agentes potencialmente mejor informados sobre el verdadero valor del activo y su evolución, que le podrían llevar a incurrir en pérdidas.

Este último componente muestra la importancia de los problemas de asimetrías informativas en los mercados financieros, hasta el punto de incidir en la composición y determinación del spread de precios y, con ello, en los precios de transacción de los activos financieros.

En este trabajo se analizó el comportamiento del spread en el tiempo, profundizando en la interdependencia entre el spread que fija el creador de mercado y el spread realizado o efectivo, obteniendo una relación entre spread y las covarianzas estimadas a partir de los 
precios de transacción y a partir de los cambios de precios fijados por el operador. Esta relación depende de dos parámetros, la probabilidad de un cambio en el precio y la cuantía de ese cambio en el precio como porcentaje del spread. A partir del cálculo de las covarianzas, Stoll obtuvo la proporción que representa cada componente en el spread.

Los datos utilizados en este trabajo hacían referencia a títulos negociados en NASDAQ durante los meses de octubre y noviembre de 1984. A partir de una regresión entre las covarianzas calculadas de los datos y el spread fijado por el dealer, estimó unos coeficientes que, a su vez, le permitieron obtener los valores de los parámetros indicados arriba. Formalmente obtuvo la descomposición del spread en sus tres componentes. En particular, el componente de selección adversa representa un 43 por ciento del spread, mientras que el componente de costo de mantenimiento de inventario supone un 10 por ciento y el costo de procesamiento un 47 por ciento.

Por último, demostró que si bien el spread fijado por dealer varía considerablemente para diferentes títulos, la proporción que cada uno de sus componentes representa, se mantiene constante.

Un trabajo posterior, de George, Kaul y Nimalendran (1991), proporcionó una nueva aproximación que permite obtener estimadores eficientes e insesgados de los componentes del spread. Estos autores mostraron que la existencia de autocorrelación en al variación temporal de las rentabilidades esperadas, y/o los ajustes parciales en el precio, han conducido a que las estimaciones realizadas previamente (Stoll, 1989), tanto del spread como de las transacciones contienen también una parte importante de rentabilidad inesperada, estos estimadores resultaban ineficientes. Así, estos autores mostraron una medida del spread basada en la covarianza serial existente en la diferencia producida entre las rentabilidades utilizando precios de transacción y las calculadas a partir de los precios bid.

Utilizaron una muestra de datos diarios y semanales de títulos negociados tanto en NYSE como en NASDAQ para la contrastación de sus hipótesis. Así, el componente de selección adversa supone una proporción del spread fijado entre un 8 y un 13 por ciento, bastante inferior a la estimada anteriormente. Asimismo, encontraron que el componente de mantenimiento de inventario es nulo, por lo que los costos de procesamiento constituyen la parte más importante del spread.

\section{Mercados Dirigidos por Órdenes}

En lo que se refiere a los mercados dirigidos por órdenes son los propios inversores quienes, mediante sus órdenes de compra y de venta, determinan el proceso de formación de los precios de transacción de los activos. En este sentido, se habla de spread implícito como la diferencia entre el precio más bajo al que se está dispuesto a vender y el precio más alto al que se está dispuesto a comprar.

El problema que surge es la interpretación del spread implícito, que no puede definirse como un margen imputable a un agente concreto o a un colectivo de agentes homogéneo, como en el caso de los mercados dirigidos por precios, sino que es, simplemente, la mejor oferta a ambos lados del mercado, independientemente del agente que la envía. Dicho de otro modo, el spread no es sino la diferencia entre las mejores órdenes limitadas a ambos lados del mercado. Este aspecto modifica sustancialmente el estudio de la información asimétrica en los mercados dirigidos por órdenes respecto a los mercados dirigidos por precios, donde aquélla se analizaba como un componente del spread (componente de selección adversa). 
En la literatura que ha estudiado los mercados dirigidos por órdenes y la formación de los precios de equilibrio, es el impacto de una transacción sobre el precio lo que refleja su contenido de información.

Quizás, el trabajo más relevante en el estudio de la fijación de los precios de los activos en mercados dirigidos por órdenes, lo constituya Glosten (1994), quién presenta un modelo de determinación del precio de equilibrio de un título a partir de los precios de compra y de venta del libro de órdenes limitadas. Este libro se considera como una pantalla visible a todo el público, que proporciona demandas y ofertas, cada una especificando un precio y una cantidad. Las transacciones tienen lugar cuando coinciden dos órdenes de distinto signo a un mismo precio. Se supone que esas órdenes, sean ofertas o demandas, son el resultado de un problema de optimización racional por parte de inversores adversos al riesgo y, posiblemente, informados. Además, los emisores de las órdenes son un gran número de agentes "pacientes" neutrales al riesgo, cuyo equilibrio está caracterizado por la condición de beneficio esperado nulo.

Una vez presentado el análisis de cómo se determinan las ofertas y demandas, se estudia como estas órdenes emitidas están relacionadas con la naturaleza discriminatoria del libro, una vez que las órdenes se van casando por su grado de competitividad. La posibilidad de llevar a cabo negociaciones basadas en la información implica que el esquema de las ofertas es tal que el costo medio se incrementa con el número de acciones negociadas. Por último, hay un bid-ask spread positivo para las negociaciones de menor volumen.

Se considera al bid-ask spread como una medida de la liquidez de un valor. Como principales características de este margen se señaló, en primer lugar, que el mayor spread corresponde a las empresas más pequeñas y, en segundo lugar, que tiene forma de " $U$ " en el curso de un día de negociación para todas las categorías de tamaño de las empresas. Estos resultados se han contrastado empíricamente en casi todas las bolsas.

Los modelos más simples de un libro electrónico de órdenes limitadas sugieren que los cambios de las cuotas pueden ser a los dos lados, es decir, cuando tienen lugar cambios tanto en el precio bid como en el ask en un minuto de una transacción. Si, en cambio, la modificación tiene lugar sólo en el ask o sólo en el bid, entonces se dice que es a un lado.

Es importante entender cómo la llegada de órdenes limitadas contribuye a generar una mayor o menor liquidez y determina la formación de los precios. Un trabajo empírico exhaustivo, que describe la Bolsa de París es el de Biais, Hillion y Spatt (1995), en el que se analizó cómo el flujo de órdenes que van llegando al mercado modifica continuamente el estado del libro de órdenes, lo que se traduce en nueva información que, a su vez, influye en la evolución del libro de órdenes y en las negociaciones.

Como principales resultados obtuvieron, que los inversores proporcionan liquidez cuando el spread es grande, colocando órdenes a un lado y dentro de la cuota, y consumen liquidez cuando el spread es estrecho, colocando órdenes que se negocian a la cuota existente.

También encontraron evidencia de los efectos de información en el proceso de llegada de órdenes, por ejemplo, después de una gran venta (una señal de información negativa), el mejor precio de compra se ajusta a la baja mecánicamente, debido a que la gran operación consumió la liquidez al bid, y, a menudo, una nueva orden de venta es colocada dentro de la cuota, lo que genera, también, un decrecimiento en el ask, reflejando que el mercado ajusta sus expectativas a la baja por la información contenida en la transacción anterior. Lo contrario ocurre después de una gran compra. 


\subsection{Ciclo de Vida Financiero}

\subsubsection{Presentación del concepto Ciclo de Vida Financiero}

El ciclo de vida financiero de una empresa equivale al sendero evolutivo transitado por ella a través de su existencia. Dicha ruta inicia desde los primeros pasos de la firma y culmina con sofisticadas formas de gestión financiera empresarial. ${ }^{9}$

La financiación empresarial es uno de los temas más tratados en la literatura financiera. En un principio, tras las aportaciones de Modigliani y Miller (1958) en las que demostraban que en mercados perfectos las decisiones de financiación carecían de importancia, la mayoría de los trabajos intentaron constatar la influencia de los impuestos (Modigliani y Miller 1963, Miller 1977) y de los costos de dificultades financieras (Warner 1977, Baxter 1977) en la estructura de capital. Con posterioridad se empieza a examinar la influencia que los problemas de agencia y la información asimétrica tienen en la financiación empresarial.

Uno de los trabajos clave que ha intentado explicar como evoluciona la estructura financiera de la empresa conforme pasan los años ha sido el de Berger y Udell (1998). Estos autores afirman que las empresas siguen un ciclo de vida financiero, y que el determinante fundamental de este ciclo es la asimetría informativa, de manera que la precariedad informativa de los primeros años va reduciéndose conforme pasa el tiempo, provocando cambios en la financiación empresarial.

"Este problema de información asimétrica se combina e interactúa con el problema de los costos de agencia. Estos costos son consecuencia del hecho de que las personas que gestionan la financiación empresarial (agentes) son distintas de las que aportan dichos fondos (principales). Este conflicto de intereses tiene implicancias en la financiación ajena, tanto si efectivamente se da ese conflicto, como por el mero hecho de que los aportantes de deuda sospechen que se pueda dar. Así, la potencial aparición de este problema hace que los acreedores puedan decidir no prestar (restricciones financieras) o incrementar el costo de los recursos ajenos, para compensar ese mayor riesgo percibido, lo que a su vez causa el problema de selección adversa". ${ }^{10}$

Las empresas jóvenes, debido a las restricciones de financiamiento que encuentran, habrán de recurrir en sus primeras fases a los mercados privados de capital (financiación ángel, fondos aportados por el principal accionista y financiación capital-riesgo).

En la financiación ajena, el crédito que proporcionan los proveedores juega un papel muy importante en las PyMes más jóvenes, dado por la imposibilidad de acceder a otras fuentes de financiamiento externa. El crédito de proveedores suele ser más caro, por lo que las empresas que se encuentran en los últimos estadíos del ciclo de vida financiero podrían recurrir menos a esta fuente de financiación.

Conforme la empresa va ganando en edad, tamaño y transparencia informativa, se le va abriendo el abanico de fuentes de financiación a las que puede acceder, pudiendo recurrir a los mercados públicos de deuda y capital.

Además de lograr reducir los costos de financiamiento y controlar los costos de agencia haciendo uso de los contratos financieros adecuados, una política de financiamiento a largo

\footnotetext{
${ }^{9}$ Leiva Bonilla, Juan Carlos. "PYMES, Ciclo de Vida y Etapas de su Desarrollo". Tec Empresarial. Vol. 1, Ed. 1, 2006. Pág. 1

${ }^{10}$ Sánchez Vidal, Javier y Martín Ugedo, Juan Francisco. "Edad y Tamaño Empresarial y Ciclo de Vida

Financiero". Instituto Valenciano de Investigaciones Económicas S.A, 2008. Pág. 4.
} 
plazo puede también buscar reducir por diferentes medios los riesgos operativos y financieros de la empresa.

Resulta importante destacar, que para poder supera con éxito cada una de las etapas del ciclo de vida, dinamizando el proceso de innovación e incrementando los niveles de competitividad; la empresa deberá ir incorporando conocimiento especializado en la gestión empresarial.

Consistente con el objeto de este trabajo, se hacen fundamentalmente necesarios los conocimientos relacionados con el campo de la administración financiera, donde una gestión profesional basada en la aplicación de conocimiento formal, se distingue notoriamente de otra, que por ejemplo se instrumente tomando en cuenta apreciaciones subjetivas y motivaciones propias de los responsables, es decir, basadas en un nivel de conocimiento más débil. ${ }^{11}$

En las gestiones donde priman los criterios racionales, el conocimiento formal, reflejado en modelos y herramientas, elección de alternativas, asignación de recursos, definición de objetivos y elaboración de información referida a planes de negocios y reportes para terceros; constituye una base fundamental para alcanzar los resultados pretendidos.

\subsubsection{La Financiación con Capital Propio}

Se conoce como estructura financiera óptima a la relación entre recursos propios y ajenos, que maximiza el valor de la empresa para sus accionistas y que minimiza el costo medio ponderado del capital. Por otro lado, se conoce al leverage o efecto palanca financiero, al uso de recursos obtenidos a costo fijo con el objeto de aumentar el rendimiento del capital propio.

El financiamiento con capital propio se constituye en una fuente insustituible cuando se trata de emprendimiento nuevos y/o sin trayectoria que involucran un elevado nivel de riesgo. Inversores externos no siempre están dispuestos a aceptar esas inseguridades. Asimismo, la porción de capital propio es uno de los pilares básicos para chequear la sustentabilidad de la empresa.

En efecto, el crecimiento sostenible desde el punto de vista del financiamiento esta dado por la tasa de crecimiento del capital propio.

Dentro de esta fuente de financiamiento se incluyen, los aportes iniciales del empresario, los fondos generados internamente (reinversión de utilidades), las emisiones de acciones y el capital riesgo.

En lo que respecta al capital riesgo, el segmento no formal está integrado por inversores privados individuales y sin relación familiar con las empresas en las que invierten, conocidos en la literatura como Business Angels. El segmento formal de capital riesgo, conformado por las sociedades de capital riesgo, sus operaciones y modos de instrumentación, por la importancia que revierten, serán analizados en detalle más adelante.

\footnotetext{
${ }^{11}$ Alonso, Aldo H. y Legato, Ana M. "Racionalidad y Modelos Financieros. Demanda de educación formal según etapas del ciclo y otros aspectos". Revista ECOS de Grado y Posgrados, 2do. Ciclo, Año 5, Vol. 1 No 9 . UNLP, 2009. Pág. 23.
} 


\subsubsection{El Financiamiento Bancario}

Existen una inmensa variedad de instrumentos de deuda, en cuanto a plazos, costos, moneda, garantías, etc. y que al incorporarle aspectos como monto, disponibilidad y accesibilidad hacen significativas las diferencias entre los distintos mercados en los que se puede originar y desarrollar la operatoria de financiamiento.

El sistema bancario y el mercado de capitales surgen como las alternativas que mejor satisfacen las diferentes necesidades de las empresas y donde se concretan la gran mayoría de las operaciones de endeudamiento que realizan las empresas.

El financiamiento bancario es en casi la totalidad de los países, la principal fuente de financiamiento para las pymes, y generalmente éstas enfrentan más dificultad para financiarse que las empresas más grandes. Esta problemática es multidimensional y deriva no sólo de un acceso restringido al mercado de capitales (Hauser, 2000).

Si bien existen algunas contradicciones estadísticas respecto al grado de competitividad de las pymes y las grandes empresas, en general las pymes registran mejores tasas de ganancia operativa, pero las firmas grandes registran mayores resultados derivados de actividades financieras y no operativas. Esta situación atenta contra la evaluación de riesgo que realizan los financistas (Hauser, 2000).

Distintos análisis respecto de las diferentes formas de financiamiento bancario, han demostrado que las pymes registran una marcada tendencia a acceder a préstamos de corto plazo. Especialmente la negociación de valores y los adelantos en cuenta corriente constituyen las líneas de mayor utilización por parte de la pymes. En buena medida, esta característica se ve influenciada por la vigencia de asimetrías de información (Wossidlo, 1990).

Debido a la creciente proporción de deuda en el financiamiento de activos, la baja o inexistente intensidad de activos financieros y las menos favorables expectativas de ganancia que muestran las pymes, contrastan con las condiciones imperantes en grandes compañías, en la visión de los grandes bancos y del mercado de capitales (Ruda, 1997).

En casi todo el mundo, las pymes identifican la falta de acceso al crédito como uno de los obstáculos más importantes que deben enfrentar para el desarrollo de sus negocios. Esta situación combinada con la importancia del sector en la economía, justifica la existencia de programas gubernamentales de apoyo al desarrollo de las pymes.

En las pymes, la decisión de obtener financiamiento externo es en general definida por eventos excepcionales (por ejemplo, inversiones en equipamiento, oportunidades de mercado, etc.). Esta preferencia por la deuda como fuente de financiamiento suele ser justificada por los empresarios como necesaria para alcanzar independencia en la toma de decisiones en su negocio ${ }^{12}$. A su vez, el acceso a financiamiento externo, determina la apertura de información considerada estratégica por los empresarios pyme, a la vez que se la considera una limitación a la libertad empresarial.

Por lo tanto, el esquema financiero preferido por los empresarios pyme, en Argentina como en la gran mayoría de los países, se ubica en el campo de la deuda, en el cual los interlocutores válidos son bancos, proveedores y prestamistas no formales.

\footnotetext{
${ }^{12}$ CEPAL, Serie Estudios y Perspectivas. "Financiamiento para pequeñas y medianas empresas (pyme). El caso de Alemania. Enseñanzas para Argentina”. Por Rubén Ascúa, CEPAL, 2005. Pág. 22.
} 
Las limitaciones financieras para las pymes dependen fundamentalmente de las condiciones del mercado, de la valuación del crédito y de la posibilidad de potenciales inversores. A su vez, el ciclo económico tiende a agravar las condiciones de acceso al financiamiento de las pymes ya que se provoca una espiral divergente entre demanda de garantías que crecen, activos con valor decreciente y percepción de riesgo en ascenso para los nuevos préstamos (Wossidlo, 1990; Ruda, 1997).

El tema de las garantías aparece generalmente adherido a las dificultades que deben enfrentar las pymes para el acceso al crédito, en especial el financiamiento bancario de largo plazo.

La necesidad de dotar de mayor seguridad al proceso de otorgamiento de préstamos, intensifica la actividad de las entidades de afianzamiento de préstamos pymes. Las empresas otorgantes de avales y/o garantías constituyen una herramienta indirecta de la política pública, actuando como elemento de apoyo a la actividad de las pymes. ${ }^{13}$

Los instrumentos de deuda más utilizados en la financiación bancaria son los adelantos en cuenta corriente, descuentos de documentos, factoring, préstamos sin garantías reales, préstamos con garantías reales (hipotecas, prendas), leasing financieros, pre-financiación de exportaciones.

Las eventuales restricciones que observan en el acceso al mercado de deuda y los requerimientos crecientes de capital propio deberían impulsar a las pymes a la utilización de otros instrumentos financieros.

\subsubsection{El Financiamiento Bursátil}

Contrariamente a las firmas grandes, las PyME enfrentan reducidas posibilidades de concretar sus iniciativas por falta de alternativas de financiamiento. La existencia de planeamiento y sistemas de información está positivamente correlacionada con el tamaño de la firma. En muchos casos, la importancia de la necesidad de capital y de planes financieros es subestimada por la PyME, sólo en épocas de restricciones financieras el management de la empresa comienza a planificar financieramente ${ }^{14}$.

Como estrategia financiera en las PyME se presenta como necesario planear a mediano y largo plazo. Uno de los principales objetivos de la estrategia financiera de la firma es construir una elevada imagen financiera en el sentido de una activa política de relaciones con inversores y bancos. La creación de una imagen financiera positiva aún a pesar del tamaño relativamente pequeño de las PyME puede proveer condiciones ventajosas en la negociación con bancos (Ruda, 2003).

La decisión de la PyME de abrirse a la bolsa constituye en muchos casos una acción estratégica de fuerte impacto promocional en beneficio de la imagen financiera de la empresa.

La apertura a la bolsa generaría una mejora en el acceso al capital propio a la vez que otorgaría un espacio para la financiación con deuda en mejores condiciones. El manejo eficiente de los instrumentos de deuda, acotaría el nivel de riesgo, elevaría la liquidez y mejoraría la transparencia de la empresa, factores que contribuirían fuertemente para la futura cotización de las acciones.

\footnotetext{
${ }^{13}$ CEPAL, Serie Estudios y Perspectivas. Ob. Cit. Pág. 23.

${ }^{14}$ CEPAL, Serie Estudios y Perspectivas. Ob. Cit. Pág. 26.
} 


\section{¿Por qué cotizar en Bolsa?}

1. Porque facilita el ACCESO de las empresas al capital, contribuyendo a su desarrollo y expansión.

La Bolsa es el marco propicio para que las empresas desarrollen o consoliden sus proyectos. Para ello cuenta con una variada gama de productos adecuados a cada tipo de necesidades: acciones, obligaciones negociables, obligaciones negociables de corto plazo, valores fiduciarios y cheques de pago diferido, entre otros.

2. Porque constituye una fuente de FINANCIAMIENTO PERMANENTE A MENOR COSTO.

La empresa puede decidir el momento más oportuno para tomar capital y hacerlo a los menores costos del mercado. La Bolsa prevé para ello requisitos y mecanismos de aprobación sencillos, ágiles y de bajo costo.

3. Porque la Bolsa ACERCA LOS INVERSORES a las empresas, sin que éstas tengan que salir a buscarlos.

Las empresas no deben invertir tiempo y dinero en la captación de inversores, a quienes podrá encontrar directamente cotizando en Bolsa. Cientos de miles de cuentas operativas en la Caja de Valores son la muestra más concreta de una comunidad de inversores ávida de productos financieros y con confianza en el mercado de capitales.

4. Porque sirve al desarrollo y consolidación de la IMAGEN EMPRESARIAL.

Las empresas que cotizan en Bolsa son percibidas como más organizadas y más competitivas, cualidades que les permiten ganar prestigio frente a sus clientes, proveedores e inversores. La publicidad que ofrece el mercado a las empresas por el solo hecho de estar cotizando, es permanente $y$ gratuita, extendiéndose más allá de las fronteras de Argentina.

5. Porque garantiza la LIQUIDEZ de las inversiones.

La posibilidad de la venta de los valores en cualquier momento y a un precio determinado es uno de los atractivos principales de la inversión en la Bolsa. En casos de empresas familiares, liquidez y precio cierto, contribuyen a evitar conflictos entre socios, cuando se desea realizar cambios en tenencia accionarias, sin obstaculizar la continuidad en la gestión empresaria.

6. Porque permite la VALORACIÓN objetiva de las empresas.

En Bolsa, el precio es el resultante del libre juego de la oferta y demanda; siendo un referente incuestionable para todos los participantes del mercado, constituyéndose hoy en una de las expresiones más concretas que permiten la apreciación del resultado de la gestión empresarial moderna.

7. Porque las empresas que cotizan buscan la EXCELENCIA, racionalizando sus decisiones y respondiendo por ellas.

La cotización es un estímulo para la mayor profesionalización de la gestión corporativa. La continua información que ofrece el mercado bursátil a los inversores hace que las empresas sean necesariamente cada vez más transparentes en su accionar.

8. Porque las EMPRESAS LÍDERES están en la Bolsa.

Las principales empresas líderes del mercado han crecido y se han desarrollado en el ámbito de la Bolsa, a través de colocaciones de variados instrumentos de financiamiento. Esto ha sido así aun en tiempos de crisis severas, como la acontecida en Argentina, cuando a través de instrumentos cotizantes en Bolsa, diversas empresas han podido refinanciar abultadas deudas.

9. Porque se facilita a las empresas extranjeras su INSERCIÓN en el mercado local.

Al preverse requisitos de cotización adecuados a los estándares internacionales, la Bolsa permite a las sociedades extranjeras que ingresan a su régimen, una más rápida y efectiva integración en el mercado local.

Fuente: Bolsa de Comercio de Buenos Aires. 
Las empresas de capital riesgo, valoran mucho la opción de una salida a través de una oferta pública de acciones, ya que este medio permitiría potenciar el valor del retorno de la inversión realizada.

Los instrumentos más utilizados en la financiación bursátil son acciones, obligaciones negociables y fideicomisos financieros, a los que se debe sumar en Argentina el descuento de cheques (propios o de terceros).

\subsubsection{La Financiación con Capital Riesgo}

"El capital riesgo es una inversión a largo plazo en fondos propios de las empresas. Capital de riesgo o inversión en capital es una fórmula financiera que aporta recursos a las empresas en forma de fondos permanentes a largo plazo o con el mismo riesgo que los fondos aportados por el empresario, ya que normalmente no tienen ni garantía ni beneficio especial."15

El papel fundamental del capital riesgo consiste en apoyar financieramente a PyMes en momento críticos de su desarrollo (nacimiento, primer desarrollo, crecimiento, sucesión, etc.), en los que no podría captar recursos a largo plazo.

En la toma de participación se utilizan diferentes instrumentos financieros (capital, cuasi capital, deuda), buscando un adecuado equilibrio entre el porcentaje de capital y el control de la empresa.

El inversor en capital riesgo, aporta experiencia, conocimiento y contactos, para la solución de problemas y el armado de una estrategia de largo plazo. Una vez superada la fase crítica, el riesgo de la empresa habrá decrecido y otros inversores podrán ocupar el lugar del inversor de capital riesgo, quien se retirará realizando las plusvalías que se hubiesen generado.

El hecho de que las participaciones no puedan exceder de unos determinados porcentajes y en ningún caso lleguen a ser mayoritarios, garantiza a los empresarios participados que no se les quiere suplantar en la gestión y evita la resistencia que, en otro caso, tendrían a admitir a socios extraños.

La actividad de capital riesgo, debe ser desarrollada por entidades especializadas con profesionales cualificados en la identificación, valoración y seguimiento (asesoramiento) de empresas. Básicamente existen dos tipos de entidades:

- Sociedades de Capital Riesgo: es una sociedad que se dedica fundamentalmente a invertir sus propios recursos en la financiación temporal y minoritaria de PyMes innovadoras.

- Sociedad Gestora de Fondos de Capital Riesgo: grupo de especialistas, de reconocida experiencia y prestigio en inversiones de capital riesgo, dedicados a promover la constitución y desarrollar la gestión de fondos de capital riesgo de duración temporal, a cambio de una cantidad fija más una participación en las plusvalías realizadas en la desinversión.

\footnotetext{
${ }^{15}$ Pellón, José Martí. “La financiación de Pymes mediante capial riesgo”. Impiva, 1994. Pág. 11.
} 


\subsubsection{Tipos de Operaciones de Capital Riesgo}

Para que se desarrolle la actividad de capital riesgo es necesario apoyar y potenciar las actividades emprendedoras, ya que el capital riesgo selecciona empresas que posean reconocida capacidad empresarial y de gestión. La disponibilidad de recursos financieros, por sí misma, no determina la aparición de proyectos empresariales innovadores ${ }^{16}$.

Los distintos tipos de operaciones de capital riesgo se relacionan con las distintas fases del desarrollo de una empresa, a título enunciativo, se mencionan las más comunes:

- Capital semilla (Seed): la empresa no existe aún o está recién constituida, se trata de una inversión que pretende financiar el desarrollo de un producto, generalmente con una visión no del todo precisa y a largo plazo. El riesgo en muy alto, el período de maduración de la inversión (hasta que el inversor de capital riesgo pueda retirarse) es muy largo y la rentabilidad esperada está en línea con ello.

- Arranque (Start - up): en este caso la empresa ya existe y está lista para comenzar sus operaciones. El producto está desarrollado, el mercado está identificado y existe un análisis del mismo que justifica el lanzamiento. El riesgo relacionado a la operación es alto, pero no tanto como en el caso anterior.

- Primera fase (Early Stage): normalmente esta fase está referida a las empresas de reciente creación que hasta el momento no han comenzado a obtener beneficios. El riesgo se reduce significativamente debido a que se conoce la operación y cómo el mercado acepta el producto.

- Capital expansión: la empresa ya ha superado la fase de arranque y requiere capital para financiar procesos de expansión, tales como: lanzamiento de nuevos productos, introducción a nuevos mercados, crecimiento de ventas o nuevas instalaciones. El riesgo es menor por existir historia suficiente como para realizar un análisis detallado antes de realizar la inversión.

- Capital adquisición: igual a la anterior, donde los fondos se destinan a adquirir otra empresa que la complemente.

- Sustitución de deuda: en momentos de crisis, la caída de ventas y fuertes niveles de endeudamiento provocan la desaparición de muchas empresas, la sustitución de deuda por recursos propios trata de evitar este problema, dotando de mayor estabilidad financiera a la empresa.

- Compra de la empresa por sus directivos (Management buy-out, MBO): se puede presentar en casos de desinversiones de divisiones por parte de multinacionales o por problemas de sucesión en empreas familiares. Dado que el equipo directivo no poseerá recursos para realizar la compra, ésta suele tener lugar utilizando un fuerte volumen de deudas, que deberá ser soportada por el cash flow de la sociedad. Para evitar un riesgo financiero muy elevado, los inversores de capital riesgo podrían entrar en el capital y en algún tramo de endeudamiento.

- Compra de la empresa por un equipo directivo ajeno a la misma (Management buy-in, $\mathrm{MBI})$ : se trata de la adquisición de la empresa por un equipo directivo externo, igualmente

\footnotetext{
${ }^{16}$ Pellón, José Martí. Ob. Cit. Pág. 20.
} 
respaldado por terceros que financian vía deuda y capital, y generalmente apalancando mucho a la propia empresa.

- Capital de reemplazamiento (Replacement capital): se trata, simplemente de la sustitución de un accionista antiguo por el nuevo inversor sin que entre "nuevo capital" en la empresa. Esta modalidad por sí sola no encaja propiamente dentro de la filosofía del capital riesgo que busca, como ya se ha dicho, aportar fondos a la empresa para financiar proyectos concretos. Pero son muy frecuentes operaciones mixtas o combinadas en las que una parte de la inversión de la entidad de capital riesgo va a la propia empresa y otra, a comprar acciones viejas, facilitando que el accionista mayoritario pueda desinvertir parcialmente.

Figura 4

Ciclo de Capital Riesgo

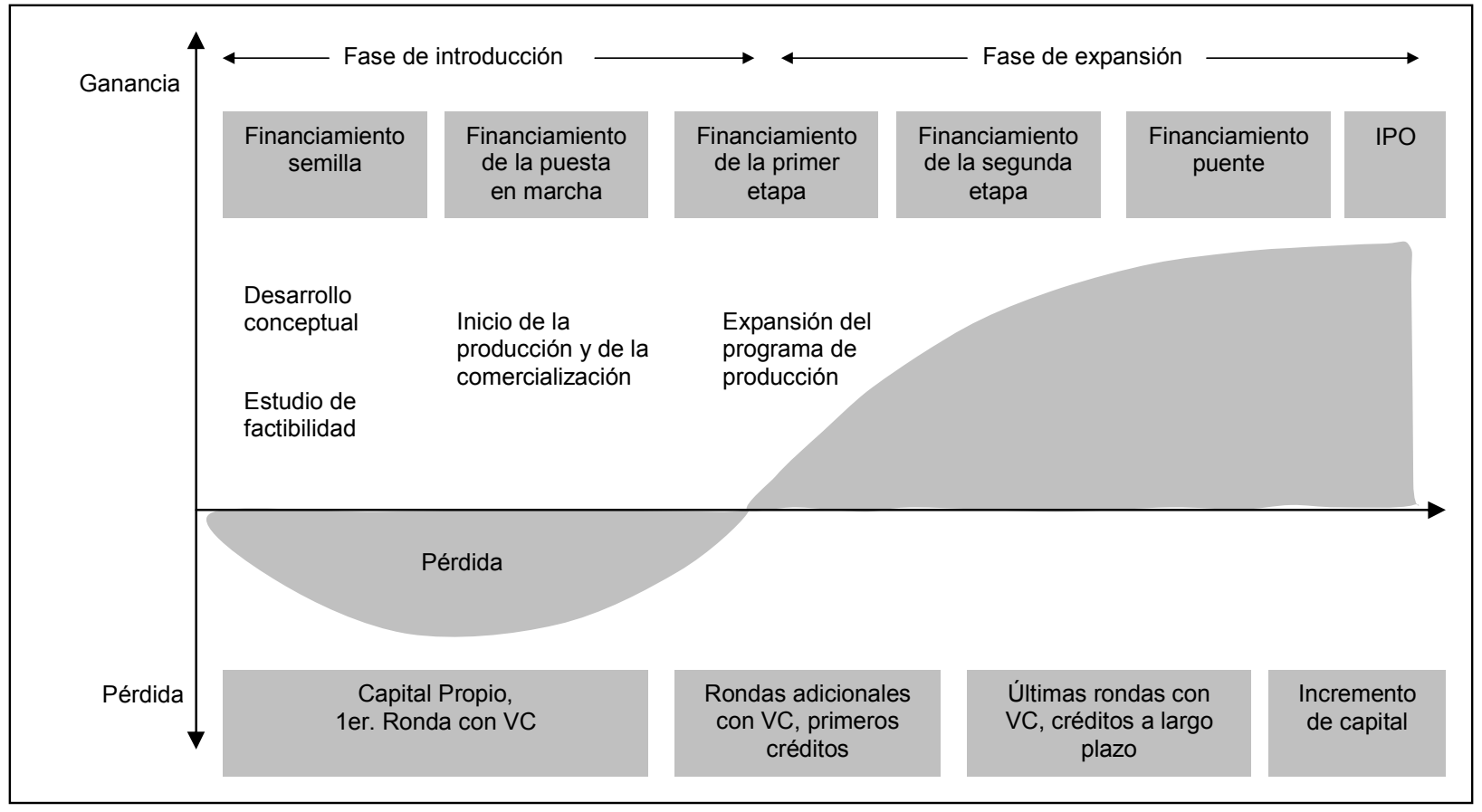

Fuente: Ruda, 2004.

\subsubsection{Instrumentos Financieros para el Capital Riesgo}

Frecuentemente, el vehículo a través del cual las entidades de capital riesgo entran en las empresas es una ampliación de capital en la que las acciones nuevas son iguales en todos los aspectos a las antiguas. Sin embargo, en muchos casos esta operación no es tan simple, utilizándose una mezcla con otros instrumentos financieros más sofisticados.

El problema más general es el que surge cuando las expectativas de futuro del empresario difieren sensiblemente de las proyecciones realizadas por los analistas de la entidad de capital riesgo, y en consecuencia, la valoración que de la empresa hacen ambas partes dista excesivamente.

Por este motivo, generalmente se buscan fórmulas, ya sea a través de préstamos convertibles, ya sea mediante la fijación de un precio variable en función de resultados futuros que permitan pagar un precio menor o disponer de un mayor porcentaje de la 
sociedad si los resultados son inferiores a los que plasmó el empresario en su Plan de Negocios, y a la inversa.

Los instrumentos que se suelen utilizar son:

- Instrumentos de capital

- Acciones ordinarias: con los mismos derechos políticos y económicos que las existentes en circulación.

- Acciones preferentes: el inversor financiero se reserva el derecho a un dividendo mínimo o a recibir compensaciones económicas de algún tipo.

- Acciones sin voto: si como consecuencia de la cantidad de dinero solicitada y del valor asignado a la empresa, el porcentaje que toma el inversor financiero supera, por sí mismo, o junto con otros minoritarios, el $50 \%$, puede plantearse la utilización de un tramo de acciones sin voto para mantener el control político de la sociedad en manos del empresario.

- Instrumentos de deuda

- Préstamos a largo plazo: la esencia del capital riesgo es tomar el riesgo implícito del capital sin garantizarse una rentabilidad determinada. Por ello, este instrumento no se usa nunca de forma aislada, sino como complementario de otros. Por ejemplo, en un $\mathrm{MBO}$, una parte menor de la inversión puede ser un préstamo.

- Préstamos puente: concedido a la espera de que se reciba una subvención ya concedida o un préstamo de una entidad financiera que ya ha sido aprobado.

- Deuda subordinada: caracterizada por su alto riesgo, al no tener prelación frente al resto de los acreedores de la empresa, la rentabilidad es mayor que en los préstamos ordinarios. En ocasiones, la rentabilidad se fija en función de los resultados, por lo que es un instrumento próximo a recursos propios.

- Instrumentos mixtos

- Préstamos convertibles: los convertible se suelen emplear para ajustar la participación definitiva de la entidad de capital riesgo con base en la evolución de los resultados.

- Obligaciones convertibles.

- Obligaciones con warrants: otorgan a sus poseedores la posibilidad de ejercer una opción de compra de un determinado número de acciones a un precio fijado.

\subsubsection{Etapas de una Operación de Capital Riesgo}

La entidad de capital riesgo es un inversor a largo plazo, pero no pretende, en principio, la permanencia a perpetuidad en una empresa. Por ello, en la financiación mediante capital riesgo pueden distinguirse tres etapas: 
- Decisión de inversión

- Seguimiento de las inversiones

- Desinversión o salida

\section{Decisión de inversión}

La etapa de análisis y negociación hasta la toma de la decisión de inversión, puede diferir mucho de una operación a otra, pero a los efectos de su exposición, a continuación se mencionarán los pasos de una operación tipo:

- Primer contacto: supone las primeras reuniones, en las que se aportará un breve resumen de la propuesta que incluya el tipo de inversión, sector, volumen de financiación requerido, el equipo de dirección y la evolución del negocio.

- Valoración inicial: que incluirá la revisión del plan de negocios, reuniones con el equipo directivo y solicitud de informes a terceros.

- Acuerdo de exclusividad: es relativamente frecuente la firma de un acuerdo con el empresario, en el cual éste se compromete por un período determinado, a no hacer la operación con otro inversor.

- Análisis y verificación de aspectos claves (Due dilligence): se inicia una vez que el inversor, ha tomado interés en la propuesta. Implica: análisis del mercado, análisis del proceso de fabricación, verificación de márgenes y rentabilidad del negocio, valoración de activos, análisis de la estructura de financiamiento, análisis de aspectos fiscales, entrevistas con clientes y proveedores, realización de auditorias específicas, revisión del equipo directivo y análisis y evaluación de los socios.

- Negociación: normalmente la etapa de negociación se inicia paralelamente con el due dilligence, en general se suelen acordar las líneas generales, las cuales luego se irán ajustando con los resultados del proceso de due dilligence.

- Oferta formal: una vez terminado el proceso de due dilligence y que el inversor ha tomado la decisión de invertir, se entrega o comunica la oferta formal al empresario, en la cual se incluyen en detalle los términos de la operación, que luego servirán de base para la preparación de los contratos.

- Requisitos legales: normalmente se realiza un contrato entre accionistas, una junta general, modificaciones estatutarias y establecimiento de garantías.

- Firma del contrato de inversión: paso formal a partir del cual el inversor y el empresario, se ponen del mismo lado y comienzan a llevar a cabo las actividades del plan de negocios acordado.

\section{Seguimiento de las inversiones}

Una vez realizada la inversión, el inversor de capital riesgo pretenderá mantenerse adecuadamente informado respecto de la marcha del negocio y asesorar y colaborar en lo que considere conveniente, a los efectos de poder realizar su inversión rentablemente.

Suele haber inversores que tienden a involucrarse activamente en la gestión de la empresa, si bien lo habitual es no hacerlo. La mayoría participan en el Consejo de Administración y 
realizan el seguimiento de las operaciones mediante reuniones, contactos telefónicos e informes mensuales.

\section{Desinversión o salida}

La finalización del ciclo de financiamiento del capital riesgo se produce cuando el inversor de capital riesgo vende su participación en la empresa. Este momento, no es uno más, sino el de mayor relevancia y complejidad, en la actividad desarrollada por la entidad de capital riesgo.

Como ya se ha mencionado, el inversor de capital riesgo no pretende permanecer indefinidamente como accionista en la sociedad participada. Su función es aportar capital propio a largo plazo en momento de la vida de la empresa en los que, por el elevado riesgo, ningún otro inversor, salvo familiares y amigos, estarían dispuestos a aportar el dinero necesario.

Una vez transcurrida esta etapa, si la empresa tiene éxito, el objetivo de la entidad de capital riesgo, en la mayoría de los casos, será la venta de su participación en la empresa, a los efectos de devolver lo invertido, más las plusvalías, a los participantes del fondo de capital riesgo; o volver a invertir en nuevos proyectos empresariales de similares características.

Su lugar podrá ser ocupado por otros inversores menos especializados y con menor predisposición a asumir riesgos.

Es muy difícil hablar de plazos en que tenga lugar la desinversión al momento de la inversión, ya que la misma se verá afectada por cuestiones como:

- El éxito o fracaso de la inversión: en los casos extremos, situaciones muy favorables o muy desfavorables, la desinversión podrá realizarse con cierta rapidez. En el segundo caso, se realizará con la pérdida total o parcial de la inversión, a través de la liquidación de la sociedad.

Ahora, si la empresa, sin ser un fracaso total, puede que no tenga pérdidas o incluso genere algunos beneficios, no ha crecido según lo previsto en el plan de negocios, ni tampoco se espera que lo haga en el futuro; la desinversión se suele demorar por la dificultad para encontrar un comprador para una participación minoritaria en una empresa pequeña de tales características.

- La tasa de crecimiento del sector del sector al que pertenece la empresa.

- La situación económica general: por su impacto sobre el precio y sobre el número de potenciales adquirentes.

- La existencia y características particulares del mercado de valores: por su capacidad de absorber títulos con riesgo, ya que de lo contrario condicionan la venta directa a un único comprador con el consiguiente efecto sobre el precio.

Como referencia y sujeto al efecto que tengan los factores anteriormente mencionados, es posible señalar intervalos de salida tentativos, según las distintas fases de desarrollo en las que se encuentren las empresas al momento de recibir la inversión. 
Plazos de Desinversión del Capital Riesgo

\begin{tabular}{|l|c|}
\hline \multicolumn{1}{|c|}{ Operaciones de Capital Riesgo } & Desinversión \\
\hline Capital semilla & 8 a 12 años \\
\hline Arranque & 5 a 8 años \\
\hline Primera fase & 4 a 7 años \\
\hline Capital expansión & 3 a 6 años \\
\hline Últimas fases de desarrollo & 2 a 3 años \\
\hline Operaciones apalancadas $(\mathrm{MBO}, \mathrm{MBI})$ & 2 a 4 años \\
\hline
\end{tabular}

Fuente: Pellón, 1994.

Una vez transcurrido el tiempo que se estimó necesario para poder plantearse la venta de la participación, la entidad de capital riesgo deberá valorar cuál es la mejor alternativa para recuperar su inversión y las plusvalías que se hubiesen generado. Las salidas para la inversión de capital riesgo pueden ser:

- Venta de la participación al empresario (accionista originario) y/o a la dirección: a través de esta modalidad el inversor de capital riesgo es sustituido por uno o varios inversores internos (accionistas o directivos).

Esta alternativa plantea dos problemas: la falta de recursos financieros, por parte de los accionistas y/o directivos, para concretar la compra; y la determinación del valor de las acciones que van a ser recompradas.

El primero surge porque los accionistas ya tendrán comprometido un porcentaje sustancial de su patrimonio en la empresa, y porque los directivos suelen tener altas rentas, pero no necesariamente elevados patrimonios.

Una solución suele ser que el pago de una parte del precio se fraccione y aplace, otra posibilidad es utilizar la capacidad de endeudamiento de la empresa a través de una operación apalancada.

En lo que se refiere a la valoración de las acciones en el momento de la recompra, la elección del método concreto y los criterios sobre los que se basará el cálculo del precio, pueden pactarse con antelación, determinando incluso un posible árbitro que controle su aplicación. En la mayor parte de los casos, los compradores mostrarán preferencia hacia criterios derivados del valor contable, que no tienen en cuenta $n$ valoran el futuro; mientras que los vendedores (la entidad de capita riesgo) preferirá métodos basados en cash flow descontados o en multiplicadores de beneficios.

Desde la perspectiva del inversor de capital riesgo, la utilización de esta vía de salida, debería ser marginal, limitándose a casos en los que no sea posible, por circunstancias del mercado, el entorno o el mismo proyecto, recurrir a las dos restantes ${ }^{17}$. Puede ser aconsejable su utilización en el caso de inversiones que, sin ser generadoras de pérdidas, no hayan respondido a las expectativas del plan de negocios, convirtiéndose en inversiones ilíquidas que inmovilizan sin un horizonte claro recursos que podrían estar colocados en otros proyectos.

\footnotetext{
17 Pellón, José Martí. Ob. Cit. Pág. 85.
} 
- Venta a terceros (posiblemente un socio industrial): la venta de la participación o de la empresa en su conjunto a otro/s inversor/es ajeno/s a la empresa, ha sido la alternativa de salida más utilizada en toda Europa y Estados Unidos en los últimas dos décadas.

Un potencial comprador puede ser un socio industrial, motivado por una cuestión estratégica o económico-financiera. Si el adquiriente pretende acceder a un producto, proceso o mercado, a través de la entrada en el capital de la empresa participada, es posible que la valoración no tenga en cuenta sólo los aspectos económico-financieros, sino el propio valor estratégico de la misma. El resultado es que el inversor de capital riesgo podrá realizar una interesante plusvalía.

Un inversor industrial puede utilizar la adquisición, también como una vía de crecimiento rápido, por lo que el precio que estará dispuesto a aceptar se acercará al valor meramente financiero de la empresa, tomando en cuenta principalmente la capacidad de generación de fondos futura e incorporando las sinergias positivas que pueda obtener.

Es posible que el adquiriente no se conforme con la participación de la entidad de capital riesgo y pretenda la mayoría o la totalidad de las acciones. Esto sería beneficioso para los accionistas originarios y para el inversor de capital riesgo, porque el precio unitario de las acciones de una misma empresa sería mayor si con él se accede al control.

Si el potencial comprador fuese un inversor financiero actuaría con criterios de valoración parecidos a los que utilizó la entidad de capital riesgo, tomaría en consideración exclusivamente aspectos económico-financieros, y no necesariamente pretendería el control.

- Salida al mercado de valores: es la alternativa que mejor podría facilitar la realización del incremento de valor que la empresa hubiese conseguido desarrollar, pero no suele ser la principal vía para que los inversores de capital riesgo vendan sus participaciones.

Las principales razones por las cuales se da esta situación son:

a) El costo y el tiempo de introducir una empresa en el mercado de valores suelen ser elevados, existiendo además los riesgo de lanzamiento, o sea, la incertidumbre acerca de la coyuntura del mercado previa al lanzamiento.

b) El reducido tamaño de las empresas hace dificultoso el cumplimiento de los requisitos para solicitar el acceso al mercado, y aún cumplimentados, el reducido número de acciones que se pondrían en circulación llevaría a una muy reducida frecuencia de transacciones.

Las razones mencionadas podrían conducir a la búsqueda de un único comprador como solución alternativa, aunque el precio pudiera no reflejar el verdadero potencial de la empresa, pero la entidad de capital riesgo podría concretar la operación con mayor rapidez y asumiendo menor riesgo respecto de las condiciones del mercado.

Ventajas de la salida al mercado de valores:

a) Permite la obtención de recursos propios como ajenos, permitiendo un crecimiento sostenido.

b) Posibilita la salida total o parcial a los accionistas.

c) Aumentaría el valor de la empresa para sus propietarios, ya que a su capacidad de generación de fondos se sumaría la liquidez. 
Inconvenientes de la salida al mercado de valores:

a) La salida al mercado de valores, conlleva a una mayor transparencia informativa que muchas empresas no están dispuestas a asumir.

b) Resistencia de los empresarios pyme a ceder parte de su capital, por miedo a perder el control o alterar su forma de actuación.

c) Mayor exposición fiscal, ya que la entrada en el mercado de valores pondría de manifiesto importantes plusvalías. Si el tratamiento fiscal de las mencionadas plusvalías no es adecuado, la salida al mercado podría penalizar a los accionistas que ofreciesen títulos.

El tamaño de las empresas no suele ser lo suficientemente grande como para cumplir los requisitos de las bolsas oficiales. Por ello, los segundos mercados bursátiles suelen surgir al amparo de los mercados oficiales, caracterizándose por una menor exigencia en las condiciones de acceso, como antigüedad de la empresa, capital social, historial de beneficios, información periódica, etc., y un más reducido costo de entrada y permanencia.

\subsubsection{Ciclo de Vida Financiero: la elección de fuentes e instrumentos en cada etapa}

Como se mencionara anteriormente, el ciclo de vida financiero de una empresa equivale al sendero evolutivo transitado por ella a través de su existencia. Las empresas siguen un ciclo de vida financiero y el determinante fundamental de este ciclo es la asimetría informativa, de manera que la precariedad informativa de los primeros años va reduciéndose conforme pasa el tiempo, provocando cambios en la financiación empresarial.

"Las empresas jóvenes, debido a las restricciones de financiamiento que encuentran, habrán de recurrir en sus primeras fases a los mercados privados de capital (financiación ángel, fondos aportados por el principal accionista y financiación capital-riesgo)"18.

En la financiación ajena, el crédito que proporcionan los proveedores juega un papel muy importante en las PyMes más jóvenes, dado por la imposibilidad de acceder a otras fuentes de financiamiento externa. El crédito de proveedores suele ser más caro, por lo que las empresas que se encuentran en los últimos estadíos del ciclo de vida financiero podrían recurrir menos a esta fuente de financiación.

Conforme la empresa va ganando en edad, tamaño y transparencia informativa, se le va abriendo el abanico de fuentes de financiación a las que puede acceder, pudiendo recurrir a los mercados públicos de deuda y capital.

Entre ambos extremos (deuda y capital propio) existe una gran diferencia en plazo, garantía, seguridad, etc. Los instrumentos híbridos (como algunos de los propuestos por las entidades de capital riesgo) vienen a cubrir un espacio financiero especialmente importante para empresas no cotizantes en la bolsa de comercio ya que representan medios financieros flexibles y dinámicos. Estos instrumentos se construyen individualmente "a medida" de los demandantes y se constituyen en puentes de relación con potenciales inversores.

Los instrumentos híbridos operan como enlace entre el capital bancario y el capital propio en la relación riesgo-rendimiento. Los inversores interesados en la empresa, pueden alcanzar

\footnotetext{
${ }^{18}$ Berger, A. N. y Udell, G. F. "The econimics of small business finance: the roles of private equity and debt markets in the financial growth cycle" Journal of Banking \& Finance, 22, 1998. Pág. 613.
} 
un mejor ratio rendimiento-riesgo ingresando al negocio desde el proceso de creación de la pyme, reemplazando el tradicional esquema de préstamos por la utilización de la vía de instrumentos híbridos de financiamiento.

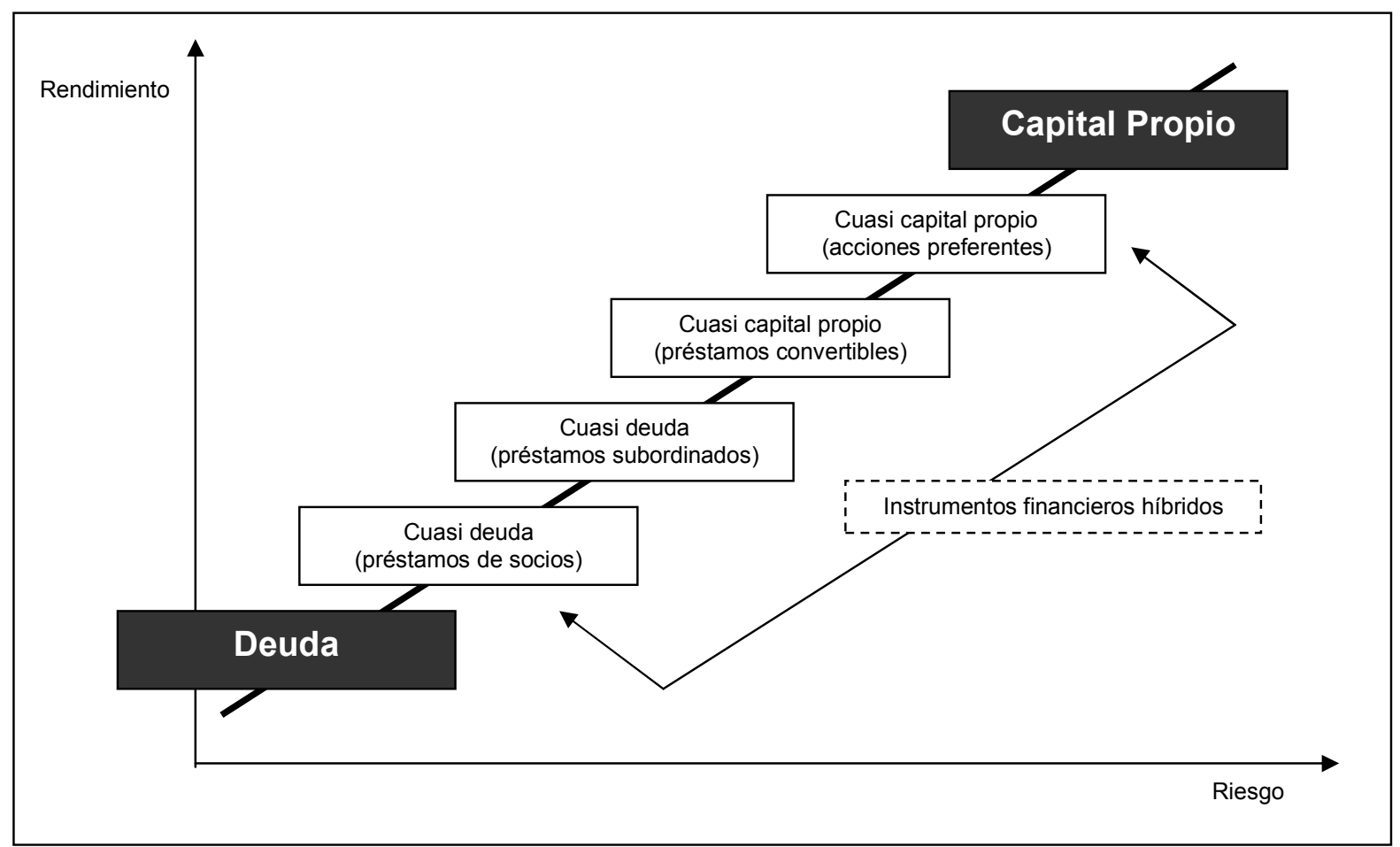

Fuente: Nathusius, 2000.

Cuadro 3

Esquema de Intereses

\begin{tabular}{|c|ll|}
\hline Financista & - Riesgo adecuado al rendimiento. \\
\hline $\begin{array}{c}\text { Tomador de } \\
\text { Financiamiento } \\
\text { (empresa) }\end{array}$ & - Financiamiento estable y de largo plazo. \\
\hline - & - Condiciones convenientes. \\
\hline Management & - Financiamiento estable y de largo plazo. \\
& - Condiciones convenientes. \\
& - Atención a los principios de financiamiento. \\
& - Apalancipación en el éxito de la empresa. \\
\hline Socio & - Crecimiento del valor de su participación. \\
& - Evitar que se diluya su actual participación en la sociedad. \\
& - Canal de salida funcionando. \\
\hline
\end{tabular}

Fuente: Nathusius, 2000. 
La estructuración financiera es un proceso complejo cuando se trabaja con varios instrumentos financieros. Para este proceso es de interés de los intervinientes conocer de antemano las distintas alternativas antes de decidir.

Cuadro 4

Situación de Intereses según forma de Financiamiento

\begin{tabular}{|c|c|c|c|c|}
\hline \multirow{2}{*}{ Interesado } & \multirow[b]{2}{*}{ Situación de Intereses } & \multicolumn{3}{|c|}{ Instrumento Financiero } \\
\hline & & Deuda & Híbridos & $\begin{array}{l}\text { Capital } \\
\text { Propio }\end{array}$ \\
\hline Financista & - $\quad$ Riesgo adecuado al rendimiento. & - & + & + \\
\hline \multirow{3}{*}{$\begin{array}{c}\text { Tomador de } \\
\text { financiamiento } \\
\text { (empresa) }\end{array}$} & - Financiamiento estable y de largo plazo. & 0 & + & + \\
\hline & $\begin{array}{l}\text { - No servicio de capital en las primeras fases } \\
\text { de desarrollo de la empresa. }\end{array}$ & - & 0 & + \\
\hline & - Condiciones convenientes. & 0 & - & + \\
\hline \multirow{4}{*}{ Management } & - Financiamiento estable y de largo plazo. & 0 & + & + \\
\hline & - Condiciones convenientes. & 0 & - & + \\
\hline & - Atención a los principios de financiamiento. & 0 & 0 & + \\
\hline & - Participación en el éxito de la empresa. & - & 0 & + \\
\hline \multirow{4}{*}{ Socio } & $\begin{array}{l}\text { - Apalancamiento del capital propio mediante } \\
\text { deuda. }\end{array}$ & + & 0 & - \\
\hline & - Crecimiento del valor de su participación. & 0 & 0 & + \\
\hline & $\begin{array}{l}\text { - Evitar que se diluya su actual participación } \\
\text { en la sociedad. }\end{array}$ & + & 0 & - \\
\hline & - Canal de salida funcionando. & 0 & 0 & + \\
\hline
\end{tabular}

Fuente: Nathusius, 2000.

Además de lograr reducir los costos de financiamiento y controlar los costos de agencia haciendo uso de los contratos financieros adecuados, una política de financiamiento a largo plazo puede también buscar reducir por diferentes medios los riesgos operativos y financieros de la empresa.

En el gráfico de Ciclo de Vida Financiero se podrá observar, a modo ilustrativo, las fuentes de financiamiento más apropiadas según las etapas de crecimiento de la empresa, el desarrollo de los sistemas de información y las relaciones riesgo-rendimiento, haciendo principal hincapié en los costos, disponibilidad y accesibilidad de cada fuente para una empresa tipo. 
Figura 6

Ciclo de Vida Financiero

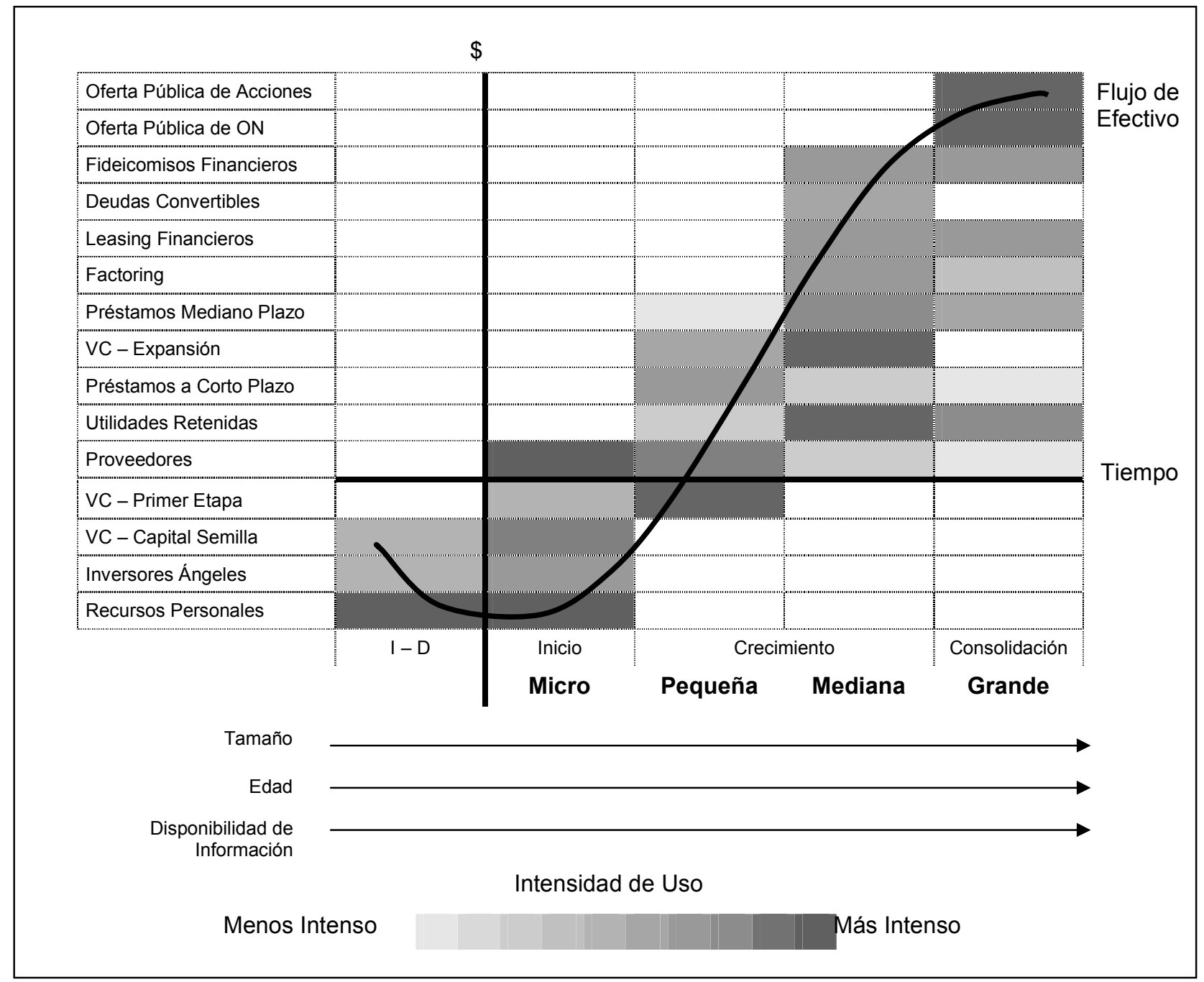

Fuente: Berger y Udell, 1998 y elaboración propia. 


\section{Metodología Aplicada}

\section{Población y Muestra}

Se seleccionaron 96 participantes para las entrevistas, que posteriormente se analizaron con la metodología Delphi, se consideró necesario incluir varios grupos de expertos, con puntos de vista complementarios sobre el fenómeno del sector PyME. Sus perfiles, se agruparon en las siguientes categorías:

- Profesionales en relación de dependencia en empresas PyMEs, que brindaron información respecto de como conseguir los medios y herramientas para poder ejercer funciones y responsabilidades claves. También identificaron los obstáculos y limitaciones encontrados.

- Docentes Universitarios (de grado y posgrado) de cursos cuya orientación principal era el desarrollo del sector PyMEs, cuya misión fue contribuir en la obtención de modelos, metodologías, herramientas y sistemas de gestión, a aplicar en pos de un desarrollo mas sustentable del sector.

- Investigadores o Expertos en conocimiento, que son especialistas con una visión global más amplia de las particularidades y potencialidades del sector PyME.

- $\quad$ Clase Política, que propone y lleva a cabo los diferentes programas; son los que tienen más capacidad para determinar las metas y asignar los medios para conseguirlo.

\section{Tipo de Investigación}

Para el análisis del contexto y las particularidades del sector PyME, se utilizó una metodología de investigación de tipo exploratoria y naturaleza cualitativa, para tomar en cuenta experiencias empresarias y de instituciones de desarrollo.

En lo que respecta al análisis de la situación actual del sistema bancario y del mercado de capitales, se utilizó una metodología de tipo descriptiva, tendiente a identificar y poner de manifiesto, tanto, aspectos positivos como falencias, de los distintos instrumentos y mercados.

\section{Técnicas de Recolección de Datos}

Se llevaron a cabo relevamientos y sistematización de la información disponible y la bibliografía existente tanto a nivel nacional como internacional.

Se realizaron entrevistas con responsables de entidades empresarias, instituciones y de gobiernos locales.

Se consiguieron entrevistas y relevamientos realizados en investigaciones anteriores, tales como: las entrevistas a especialistas del mercado financiero (UBA, 2010) y entrevistas a responsables de fondos de capital riesgo (El Cronista PyME, 2006).

\section{Técnicas de Análisis}

Para el análisis del entorno en la Argentina y su evolución en un futuro próximo, se ha utilizado la metodología Delpfhi. Esta técnica, desarrollada por la Rand Corporation en los años 60, permite generar pronósticos y escenarios de mediano plazo sobre la base de la visión de los expertos. El método se centra en la realización de una serie de entrevistas, a 
partir de las cuales se elabora un informe que permite identificar las principales perspectivas de los expertos con respecto al futuro. Estos resultados son luego compartidos con los entrevistados, que tienen la posibilidad, en función de las opiniones de sus pares, de ratificar o modificar sus respuestas. De este modo, es posible generar información colectiva, clarificar posiciones y delinear diferencias entre los distintos actores involucrados, manteniendo la confidencialidad de las opiniones.

El resultado fue una síntesis de cómo esperan los expertos que se produzca el desarrollo del sector PyME en la Argentina en los próximos 3 años.

A fin de establecer el camino hacia el futuro, se ha realizado un análisis exhaustivo de todas las respuestas recibidas y se ha enfatizado en una visión que resalta los aspectos más relevantes y que muestra tendencias definidas. Así se obtiene una visión más clara, se facilita la tarea de identificar las probables líneas de evolución y se proporciona una base sólida para un debate sobre el futuro del sector PyME en la Argentina.

También se realizó análisis de información secundaria, proveniente del Banco Central de la República Argentina, Bolsa de Comercio de Buenos Aires, entrevistas UBA 2010 y Cronista PyME 2006, entre otros. 


\section{Resultados Obtenidos}

\subsection{Análisis del Entorno en Argentina}

La volatilidad del entorno macroeconómico ha sido una característica inherente del funcionamiento de la economía argentina, que ha tenido efectos muy negativos sobre su tasa de crecimiento de largo plazo. La excesiva dependencia de flujos externos muy volátiles se tradujo en una configuración macro caracterizada por un endeudamiento no sostenible y una marcada vulnerabilidad ante shocks exógenos.

Los elevados ratios de endeudamiento indujeron una carga intolerable de servicios de la deuda, generando fragilidad sistémica e incertidumbre permanente. Así la economía se colocó en trayectorias insostenibles que conducían a trampas financieras de bajo crecimiento y alta vulnerabilidad que desembocaban típicamente en crisis recurrentes.

En los últimos treinta años, el país tuvo en promedio un año de caída por cada año de crecimiento. Hoy las condiciones están dadas para quebrar esa tendencia, aspirando a lograr un crecimiento en línea con las potencialidades productivas del país, en el marco de las nuevas condiciones que presenta la economía mundial.

\subsubsection{Perspectivas de Evolución Económica}

La situación económica de un país es determinante para la evolución y disponibilidad de infraestructuras que constituyen la columna vertebral indispensable para el desarrollo de la sociedad a largo plazo. Las grandes inversiones que se requieren, solo pueden realizarse en un ambiente económico de confianza, que permita calcular la rentabilidad esperada.

Además, las empresas solo se dotarán del equipamiento necesario si disponen de capital suficiente. A pesar de que la introducción de nuevas tecnologías, equipos y procesos productivos supongan un incremento en la rentabilidad, en un momento inicial son necesarias fuertes inversiones en bienes de capital y en formación del plantel. Para que esto suceda, el ambiente económico ha de ser optimista o al menos previsible.

Grafico 1

Perspectivas de Evolución de la Economía Mundial

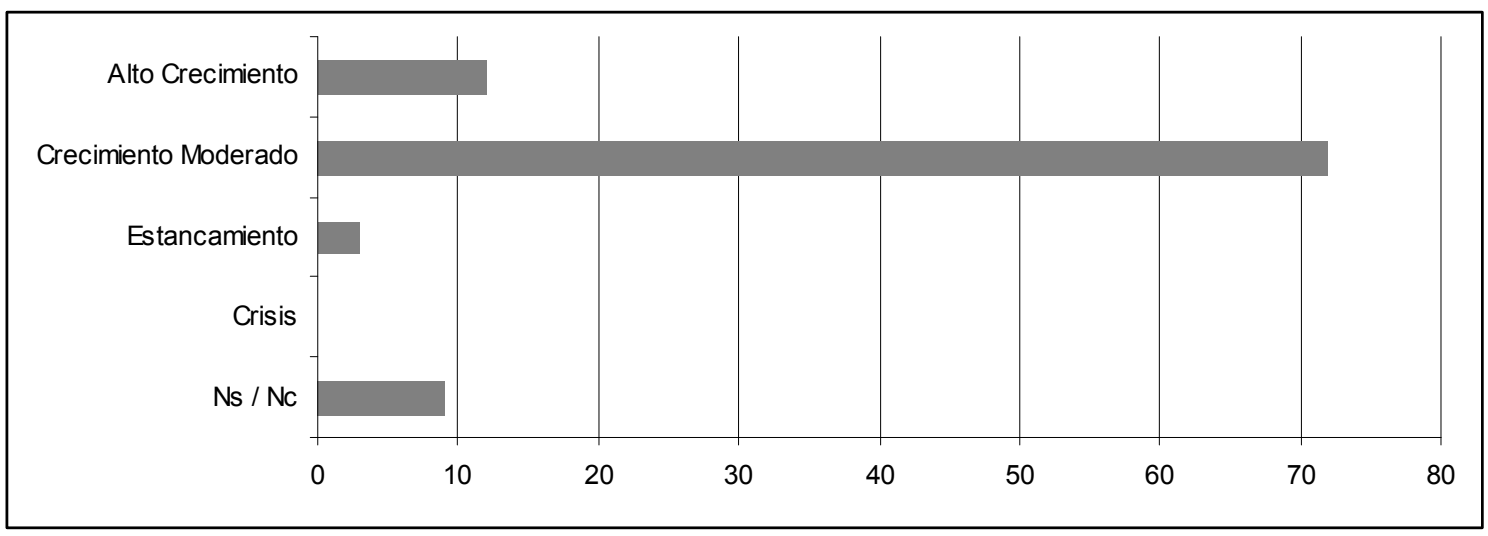

Los expertos son optimistas sobre la evolución de la economía de América Latina y más conservadores sobre la economía mundial. 
Perspectivas de Evolución de la Economía de América Latina

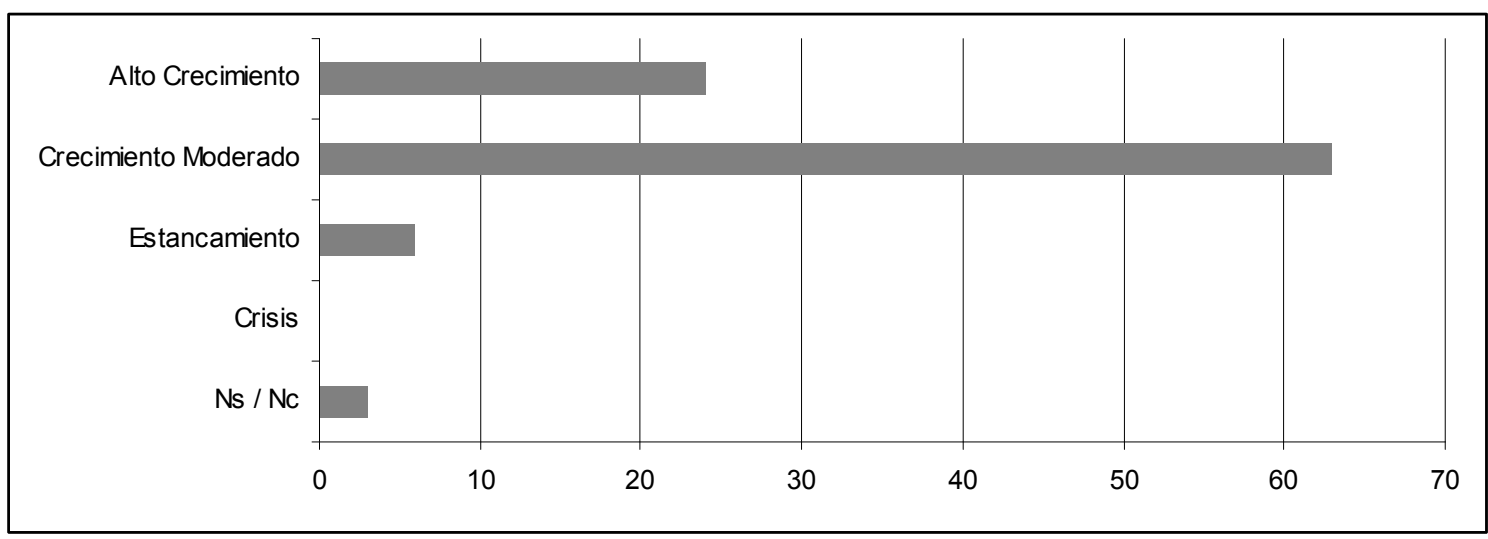

Grafico 3

Perspectivas de Evolución de la Economía Argentina

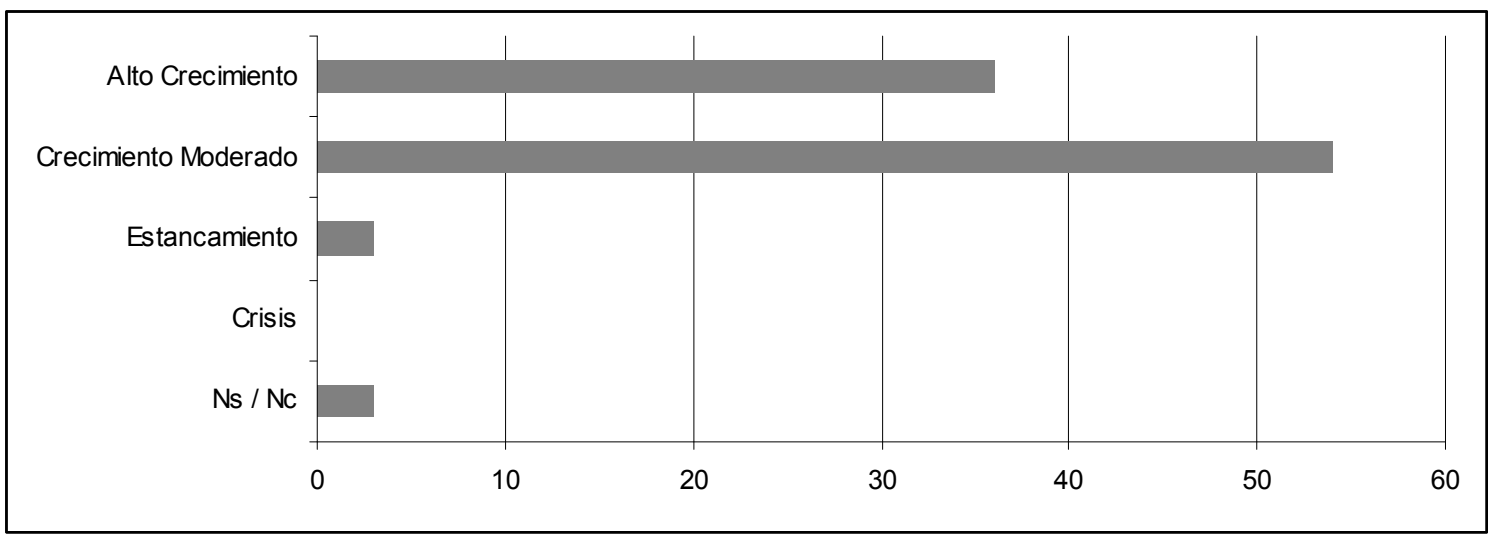

Las respuestas muestran la previsión de una economía argentina en un muy buen nivel de crecimiento y de una economía mundial menos dinámica. Dada la profundidad de la crisis argentina luego de la salida del plan de convertibilidad, es lógico pensar que el crecimiento en términos porcentuales será mayor que en países con economías más consolidadas. Quizás también sea lógico esperar esta respuesta en un país sometido a ciclos económicos de crecimiento / crisis mucho más cortos que los de otros países.

\subsubsection{Los condicionantes del entorno}

Ante la pregunta ¿Cómo valoraría las siguientes condiciones del entorno en Argentina?, se pretende determinar los elementos tanto económicos como sociales o regulatorios que favorecen o entorpecen el desarrollo del sector PyME.

Como ya se ha mencionado, la competitividad de las empresas depende de su capacidad para vincularse y/o adaptarse a las condiciones del contexto, de potencialidades propias y de las características particulares de las distintas regiones o ámbitos en las que actúa. 
Grafico 4

Los Condicionantes del Entorno en la Economía Argentina

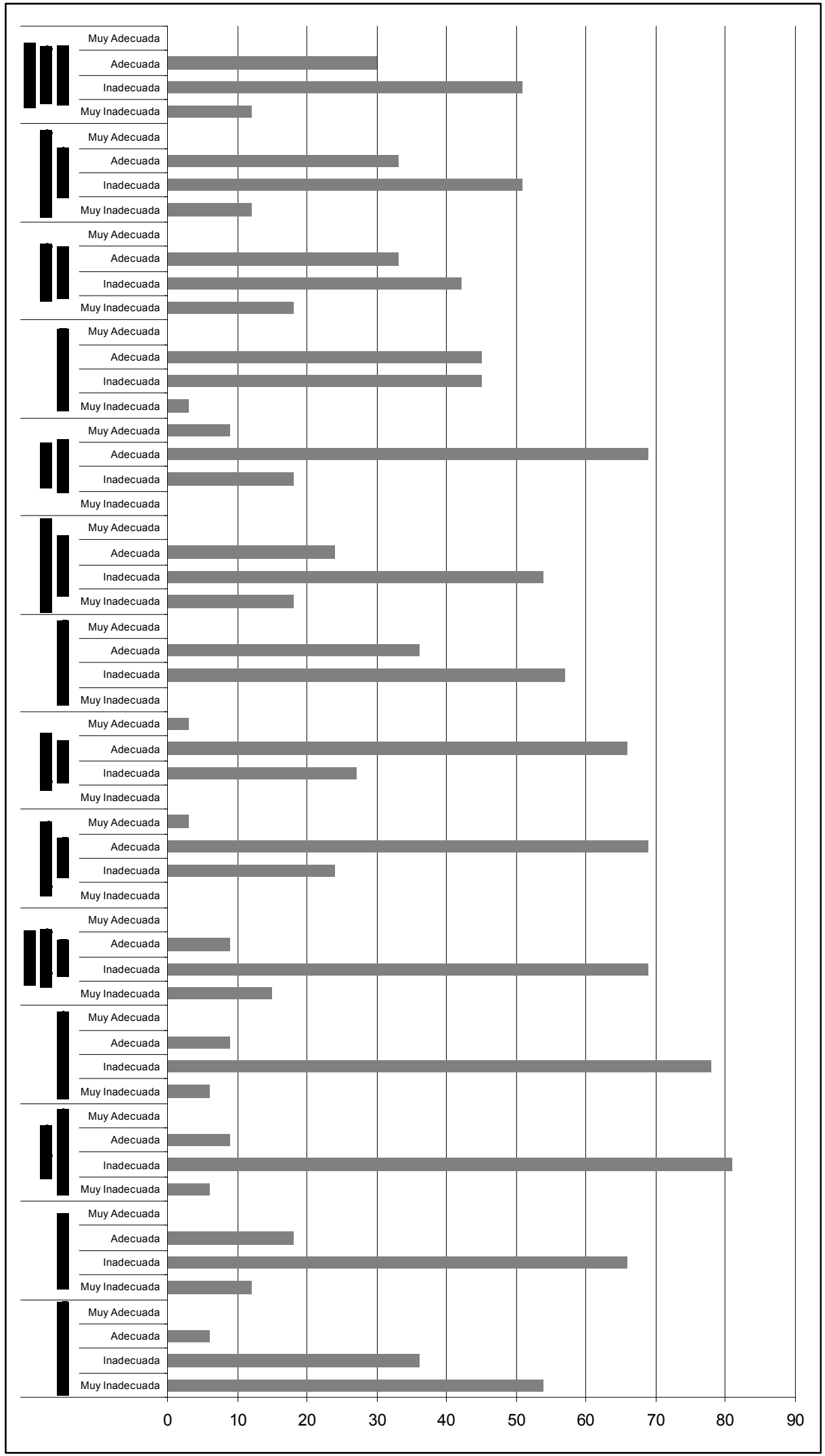


El entorno en el que actúan las empresas condiciona su comportamiento y sus posibilidades de crecimiento y desarrollo. A excepción de las Oportunidades de Negocios, la Apertura del Mercado y el Contexto Económico que han sido considerados adecuados por la mayoría de las opiniones, el resto de las condiciones del entorno puestas en consideración (seguridad jurídica, infraestructura, programas gubernamentales, políticas públicas, regímenes impositivos y laborales, apoyo financiero, contexto político - institucional, mercado laboral, nivel de educación y formación, normas sociales y culturales e investigación científica y tecnológica) son inadecuados para la opinión de los expertos, lo que evidencia una situación opuesta a la requerida para un desarrollo industrial.

\subsubsection{Principales Obstáculos}

Ante la pregunta, ¿cuál cree que son los principales obstáculos para la creación de empresas y el mejoramiento de la competitividad de las PyMEs en Argentina?, se han recibido las menciones que se grafican a continuación.

Principales Obstáculos encontrados en la Economía Argentina

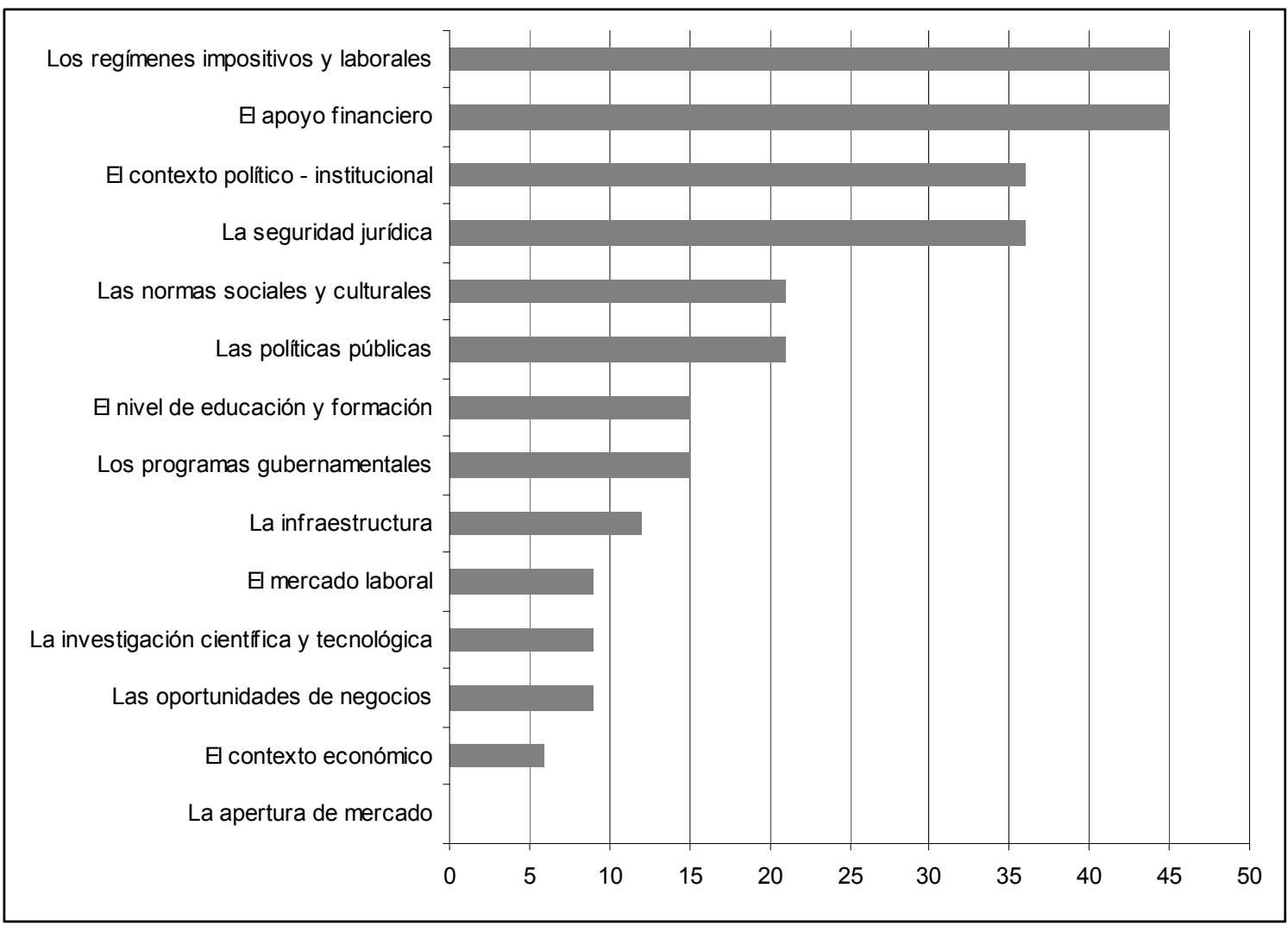

El apoyo financiero lidera el ranking de opiniones junto con los regímenes impositivos y laborales, lo que expone las importantes limitaciones que tienen las PyMEs para obtener fondos de canales institucionales, limitando su crecimiento a la reinversión de utilidades y a la propia capacidad financiera del empresario.

Se puede observar también como la debilidad institucional y reglamentaria, muchas veces mencionada y debatida, se convierten en evidentes obstáculos para el desarrollo del sector PyME en Argentina. A este respecto cabe mencionar que entre los principales obstáculos 
encontrados por los expertos se encuentran, los regímenes impositivos y laborales, el contexto político - institucional y la seguridad jurídica.

\subsubsection{Factores Facilitadores}

Cuando se consultó respecto de los principales factores facilitadores de la creación de empresas y el mejoramiento de la competitividad de las PyMEs en Argentina, los aspectos más reiteradamente mencionados fueron los relacionados con las cuestiones de mercado, a saber: el contexto económico y las oportunidades de negocios.

En tercer lugar, se tiene el nivel de educación y formación de los habitantes, un factor clave para el desarrollo de los países, incluyendo en este concepto la educación en escuelas, como así también la formación empresarial, científica y tecnológica de la sociedad. A este respecto, la investigación científica y tecnológica fue mencionada en quinto lugar en orden de mérito, confirmando la opinión de los entrevistados en esta línea de pensamiento.

El apoyo financiero fue mencionado en cuarto lugar en orden de importancia, dejándolo como un aspecto necesario pero no suficiente para el desarrollo sustentable del sector.

Grafico 6

Factores Facilitadores

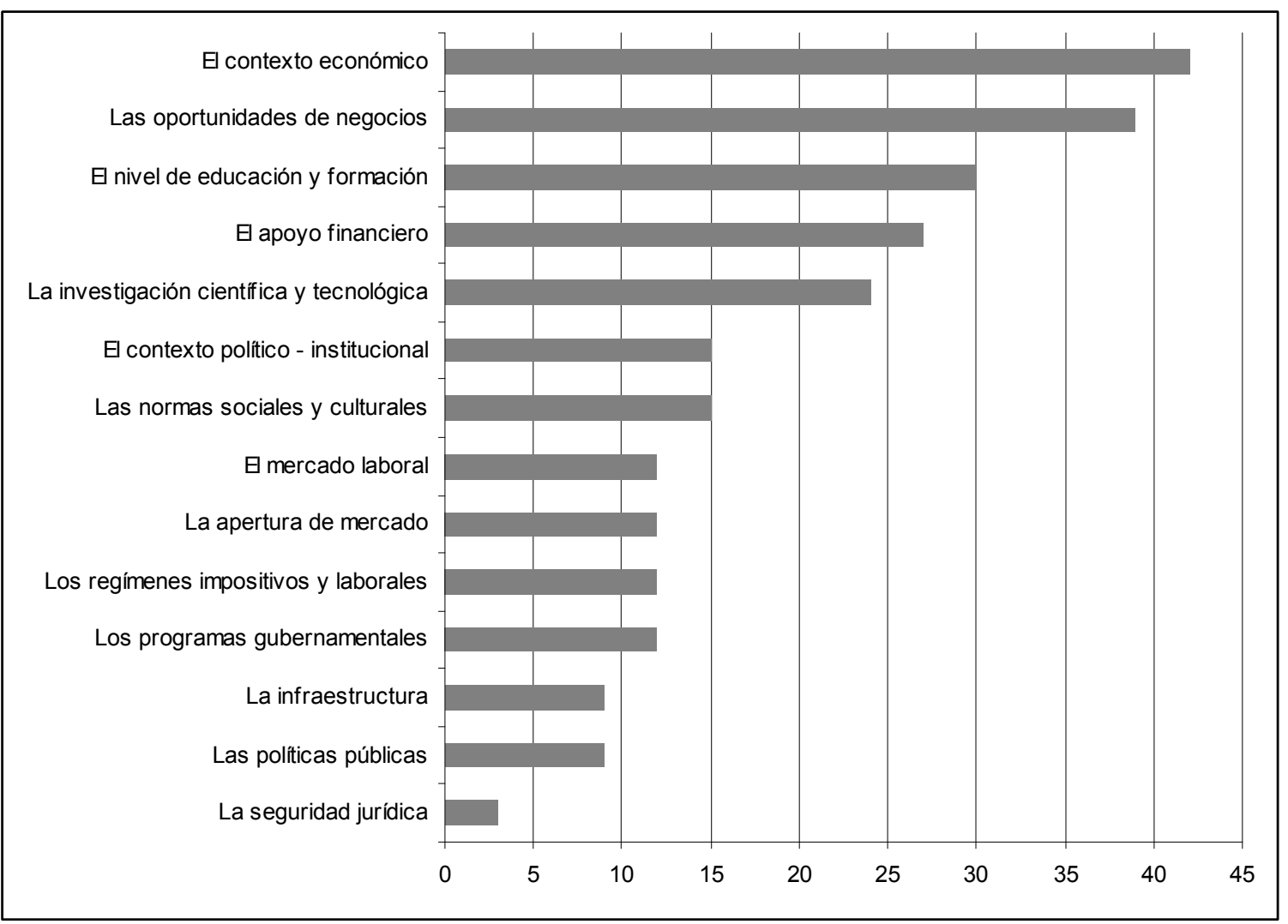




\subsubsection{Recomendaciones de Expertos}

Grafico 7

Recomendaciones de Expertos

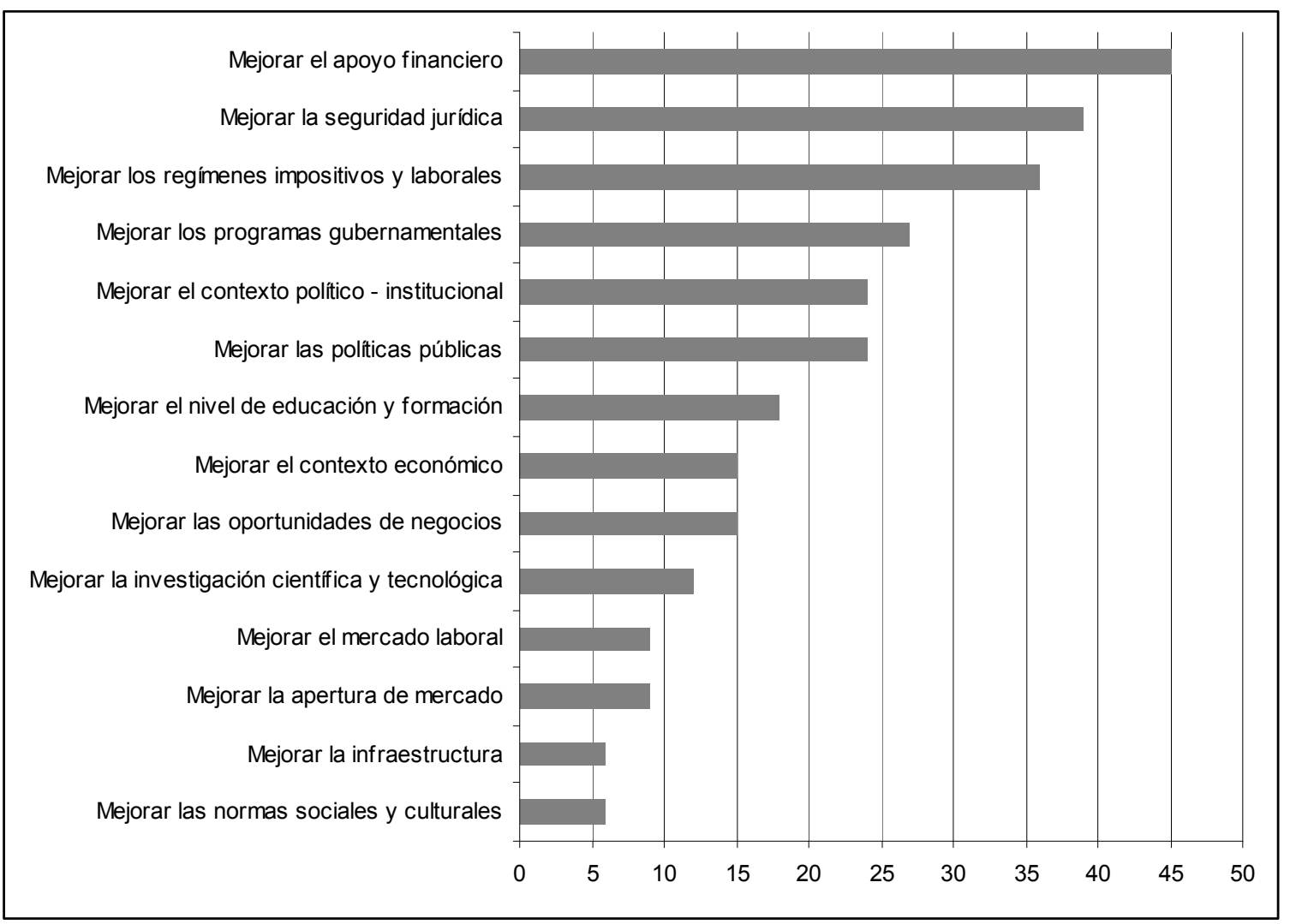

En un contexto con expectativas de crecimiento de los agentes económicos, un adecuado nivel de oportunidades de negocios y cierta estabilidad en las variables macroeconómicas para los próximos años, surgen como principales recomendaciones el mejorar el apoyo financiero y la seguridad jurídica. El apoyo financiero incentivaría al aprovechamiento de las oportunidades de negocios y permitiría el desarrollo de nuevas ventajas competitivas o usufructuar las actualmente relevantes. El fortalecimiento de la seguridad jurídica promovería mejores condiciones para la realización de inversiones y el ingreso de capitales externos, permitiría la planificación a mediano y largo plazo, el desarrollo de proyectos con períodos más largos de recupero de la inversión y reduciría el nivel de riesgo sistémico de la economía.

La necesidad de lograr instituciones fuertes y reglamentaciones claras también fue evidente al quedar entre el cuarto y el sexto lugar en orden de prioridad los regímenes impositivos y laborales, los programas gubernamentales, el contexto político - institucional y las políticas públicas.

\subsection{Sistema Financiero Argentino: principales características}

La diversidad de instituciones, mercados, canales, mecanismos e instrumentos que posibilitan la utilización y aplicación (por parte de personas físicas o jurídicas) de recursos excedentes poseídos por terceras personas; el significativo volumen total de los recursos que se canalizan a través de estos medio y los extendidos plazos, grandes montos y bajos costos que pueden obtener los demandantes de financiación, constituyen uno de los 
aspectos que más claramente distinguen las economías desarrolladas de aquellas que no lo son. ${ }^{19}$

En sentido contrario, la escasez (o carencia) de canales, mercados, instrumentos; el relativamente pequeño volumen de recursos canalizados y la escasez de financiamiento accesible a largo plazo, no sólo caracterizan al subdesarrollo sino que son su principal causa y factor ${ }^{20}$. En efecto, estos rasgos impiden el acceso fluido y la rápida acumulación de capital físico y humano por parte de las personas físicas y de las empresas, que es lo mismo que decir que retardan el crecimiento individual y del conjunto.

En la Argentina, la evidencia es incontrastable: con un volumen de ahorro doméstico agregado más que suficiente para financiar una razonable acumulación de capital, la principal causa del subdesarrollo de su economía, es la inestabilidad jurídica, fiscal y monetaria.

Entre los principales factores de esta inestabilidad, se pueden mencionar:

- La inestabilidad y volatilidad de las condiciones generales de la economía, incluyendo particularmente la inseguridad jurídica resultante de casos frecuentes de violaciones contractuales originadas en decisiones del sector público.

- La persistencia de prácticas tributarias, políticas de gasto y endeudamiento público que terminan distorsionando la tasa de interés real, los precios relativos y (en última instancia) la competitividad de las empresas.

- La ausencia de una moneda nacional que sirva para contraer derechos y obligaciones a mediano y largo plazo, con el consecuente uso de la moneda extrajera a dichos efectos.

- Las demoras y dificultades para ejecutar judicialmente obligaciones y garantías, resultado de la vigencia de leyes y prácticas jurídicas excesivamente favorables a los deudores.

- La ausencia de mercados secundarios profundos que aseguren liquidez a los instrumentos de financiación de mediano y largo plazo.

La experiencia ha mostrado claramente como estos factores de inestabilidad inhiben tanto a la punta inversora de los mercados de financiamiento, como a las partes tomadoras:

- Para los inversores, los factores de inestabilidad operan como una amenaza permanente sobre sus derechos e intereses, promoviendo la huida de ahorros locales hacia instrumentos y mercados externos, o bien, su inversión directa en activos físicos.

- Para los tomadores de fondos, aquellos factores de inestabilidad (a través de su impacto distorsivo sobre la tasa de interés real, precios relativos, tipo de cambio, etc.) ponen frecuentemente en riesgo su misma supervivencia.

Por su lado, en el Sistema Financiero Argentino se destacan las siguientes características:

- Las fuentes de financiamiento proceden principalmente del sistema bancario, y es limitado el desarrollo del mercado de capitales.

\footnotetext{
${ }^{19}$ Lagos, Martín. "Fuentes e instrumentos de financiamiento de las empresas en la Argentina". Asociación Empresaria Argentina, 2004. Pág. 3.

${ }^{20}$ Lagos, Martín. Ob. Cit. Pág. 3.
} 
- El crédito al sector privado tiende a concentrarse en las empresas de mayor tamaño y en operaciones de corto plazo.

- Hay un relativo bajo nivel general de bancarización, consecuencia de que están excluidos de ella importantes sectores de la actividad económica.

- Al existir una selección negativa respecto de los demandantes de crédito que presentan un mayor riesgo relativo, los márgenes de intermediación son elevados, y exceden notablemente a los que rigen en los sistemas financieros más desarrollados.

- Los mecanismos regulatorios presentan deficiencias, no tanto por la ausencia de normas sino por la insuficiencia de los mecanismos de supervisión, lo cual se refleja en deficiencias en el control de riesgos, en el grado de adecuación de los capitales a los niveles de riesgo e insuficiencias de las prácticas de provisionamiento por parte de los bancos.

No obstante lo mencionado anteriormente, en los últimos años las políticas de promoción y desarrollo para las pyme han experimentado cambios importantes en cuanto a los instrumentos utilizados y a la participación de los agentes públicos y privados. Los gobiernos han transformado la antigua política de préstamos y subsidios, que en muchos casos eran indiscriminados, en un abanico de medidas que buscan facilitar el acceso de las pyme a los mercados financieros privados en condiciones similares a las de la gran empresa. Para ello se han desarrollado políticas de préstamos focalizados en ciertos segmentos de las pyme y conformación de sociedades de garantías recíprocas que tienen por objeto mejorar las condiciones de acceso al crédito y alcanzar, en proyectos viables, los niveles de tasas de interés y plazos más favorables en el mercado financiero.

\subsection{El Sistema Bancario Argentino}

\subsubsection{Depósitos}

Cuadro 5

Depósitos del Sector Privado no Financiero en pesos Promedio de saldos y variaciones nominales. En millones de pesos.

\begin{tabular}{|l|c|c|c|c|}
\cline { 2 - 5 } \multicolumn{1}{c|}{} & Promedio & Promedio & \multicolumn{2}{c|}{ Variación Anual } \\
\hline \multicolumn{1}{c|}{ Depósitos } & Jul-10 & Jul-09 & Nominal & $\%$ \\
\hline Cuenta Corriente & 50.991 & 38.628 & 12.363 & $32,0 \%$ \\
\hline Caja de Ahorros & 45.264 & 36.245 & 9.019 & $24,9 \%$ \\
\hline Plazo Fijo & 70.985 & 56.630 & 14.355 & $25,3 \%$ \\
\hline Otros & 8.161 & 7.011 & 1.150 & $16,4 \%$ \\
\hline Total Depósitos \$ & $\mathbf{1 7 5 . 4 0 1}$ & $\mathbf{1 3 8 . 5 1 5}$ & $\mathbf{3 6 . 8 8 7}$ & $\mathbf{2 6 , 6 \%}$ \\
\hline
\end{tabular}

Fuente: BCRA.

Según el BCRA, durante el mes de julio de 2010, el saldo mensual de los depósitos totales en pesos y dólares expresados en pesos (sector privado no financiero y sector público) promedió los \$ 319.687 millones. En relación a julio de 2009 se observo un incremento de $31,5 \%$ (\$76.554 millones).

Los depósitos en pesos del SPNF (Sector Privado no Financiero) de julio de 2010 respecto a igual mes de 2009, mostraron una variación positiva de $\$ 36.887$ millones, $26.6 \%$. 
Cuadro 6

Depósitos del Sector Privado no Financiero en dólares Promedio de saldos y variaciones nominales. En millones de dólares.

\begin{tabular}{|l|c|c|c|c|}
\cline { 2 - 5 } \multicolumn{1}{c|}{} & Promedio & Promedio & \multicolumn{2}{c|}{ Variación Anual } \\
\hline \multicolumn{1}{c|}{ Depósitos } & Jul-10 & Jul-09 & Nominal & $\%$ \\
\hline Cuenta Corriente & 4 & 4 & 0 & $0,0 \%$ \\
\hline Caja de Ahorros & 4.469 & 3.596 & 873 & $24,3 \%$ \\
\hline Plazo Fijo & 5.826 & 5.470 & 356 & $6,5 \%$ \\
\hline Otros & 560 & 518 & 42 & $8,1 \%$ \\
\hline Total Depósitos US\$ & $\mathbf{1 0 . 8 5 9}$ & $\mathbf{9 . 5 8 8}$ & $\mathbf{1 . 2 7 1}$ & $\mathbf{1 3 , 3 \%}$ \\
\hline
\end{tabular}

Fuente: BCRA.

Los depósitos en dólares del SPNF en julio de 2010, mostraron crecimiento respecto a junio del 2009 de un 13,3\% (US\$ 1.271 millones).

Cuadro 7

Depósitos a Plazo Fijo del Sector Privado no Financiero

\begin{tabular}{|c|c|c|c|}
\hline Tramos & Jul-10 & Jul-09 & Jul-08 \\
\hline Hasta 59 días & $55,5 \%$ & $60,4 \%$ & $53,1 \%$ \\
\hline de 60 a 89 días & $16,6 \%$ & $14,7 \%$ & $14,5 \%$ \\
\hline de 90 a 179 días & $17,3 \%$ & $14,4 \%$ & $16,6 \%$ \\
\hline de 180 a 365 días & $9,6 \%$ & $9,7 \%$ & $13,7 \%$ \\
\hline de 366 y más & $0,9 \%$ & $0,8 \%$ & $2,1 \%$ \\
\hline
\end{tabular}

Fuente: BCRA.

En julio de 2010 la composición de los depósitos a plazo, mantiene su concentración relativa en el corto plazo. Respecto al mismo período del año anterior, se observa una caída de 4,9 p.p. en la participación de los depósitos entre 30 y 59 días, y un crecimiento de 2,4 p.p. en relación a igual mes de 2008. Asimismo, los depósitos a más de 180 días y hasta 365 retrocedieron pasando del $13,7 \%$ en julio de 2008 a $9,7 \%$ en el 2009 , y a $9,6 \%$ en julio del presente año. Así, en la actualidad, el $55,5 \%$ de las imposiciones se concentran en plazos menores a 60 días y el $89.5 \%$ se ubican dentro de los 180 días.

Cuadro 8

Depósitos del Sector Público en pesos

Promedio de saldos y variaciones nominales. En millones de pesos.

\begin{tabular}{|l|c|c|c|c|}
\cline { 2 - 5 } \multicolumn{1}{c|}{} & Promedio & Promedio & \multicolumn{2}{c|}{ Variación Anual } \\
\hline \multicolumn{1}{c|}{ Depósitos } & Jul-10 & Jul-09 & Nominal & $\%$ \\
\hline Cuenta Corriente & 24.560 & 24.031 & 529 & $2,2 \%$ \\
\hline Caja de Ahorros & 4.962 & 3.781 & 1.180 & $31,2 \%$ \\
\hline Plazo Fijo & 49.642 & 28.009 & 21.632 & $77,2 \%$ \\
\hline Otros & 4.331 & 3.999 & 332 & $8,3 \%$ \\
\hline Total Depósitos \$ & $\mathbf{8 3 . 4 9 5}$ & $\mathbf{5 9 . 8 2 1}$ & $\mathbf{2 3 . 6 7 4}$ & $\mathbf{3 9 , 6 \%}$ \\
\hline
\end{tabular}

Fuente: BCRA. 
Los depósitos del sector público en pesos crecieron en julio de 2010 respecto al mismo mes del 2009 un 39,6\% (\$23.674 millones). Más del 91\% de esta variación está explicada por el crecimiento de las colocaciones a Plazo Fijo.

Cuadro 9

Ahorro personal y ahorro empresario en el mundo. Los datos corresponden al promedio 1990-1995 en los países desarrollados y el promedio 1990-1996 en América Latina.

\begin{tabular}{|l|c|c|c|c|c|c|}
\cline { 2 - 6 } \multicolumn{1}{c|}{} & \multicolumn{3}{c|}{ En porcentaje del PBI } & \multicolumn{2}{c|}{ En porcentaje del Total del Ahorro Privado } \\
\cline { 2 - 7 } \multicolumn{1}{c|}{} & $\begin{array}{c}\text { Ahorro } \\
\text { Empresario }\end{array}$ & $\begin{array}{c}\text { Ahorro } \\
\text { Personal }\end{array}$ & $\begin{array}{c}\text { Total Ahorro } \\
\text { Privado }\end{array}$ & $\begin{array}{c}\text { Ahorro } \\
\text { Empresario }\end{array}$ & $\begin{array}{c}\text { Ahorro } \\
\text { Personal }\end{array}$ & Total \\
\hline Países Desarrollados & & & & & & \\
Canadá & 8.5 & 9.8 & 18.3 & 46.4 & 53.6 & 100 \\
Francia & 10.7 & 9.5 & 20.2 & 53.0 & 47.0 & 100 \\
Alemania & 13.0 & 8.2 & 21.2 & 61.3 & 38.7 & 100 \\
Italia & 5.4 & 19.2 & 24.6 & 22.0 & 78.0 & 100 \\
Japón & 12.4 & 13.2 & 25.6 & 48.4 & 51.6 & 100 \\
España & 12.4 & 7.8 & 20.2 & 61.4 & 38.6 & 100 \\
Reino Unido & 8.0 & 7.1 & 15.1 & 53.0 & 47.0 & 100 \\
Estados Unidos & 9.1 & 9.0 & 18.1 & 50.3 & 49.7 & 100 \\
Promedio & $\mathbf{9 . 9}$ & $\mathbf{1 0 . 5}$ & $\mathbf{2 0 . 4}$ & $\mathbf{4 9 . 5}$ & $\mathbf{5 0 . 5}$ & $\mathbf{1 0 0}$ \\
América Latina & & & & & & 100 \\
Argentina & 13.0 & 3.1 & 16.1 & 80.9 & 19.1 & 100 \\
Brasil & 11.5 & 4.4 & 16.0 & 72.2 & 27.8 & 100 \\
Chile & 14.6 & 5.9 & 20.6 & 71.1 & 28.9 & 100 \\
Colombia & 10.5 & 1.1 & 11.7 & 90.4 & 9.61 & 100 \\
Venezuela & 14.1 & 6.9 & 21.0 & 67.1 & 32.9 & 100 \\
Promedio & $\mathbf{1 3 . 7}$ & $\mathbf{2 . 6}$ & $\mathbf{1 6 . 3}$ & $\mathbf{8 6 . 4}$ & $\mathbf{1 3 . 6}$ & $\mathbf{1 0 0}$ \\
\hline
\end{tabular}

Fuente: Bebczuk, 1999.

El ahorro empresario representa casi el 50\% del ahorro privado en los países desarrollados y el $86 \%$ en América Latina. También surge del cuadro que el ahorro privado en los países desarrollados $(20.4 \%$ del $\mathrm{PBI})$ supera al de los países latinoamericanos $(16.3 \%)$, pero el ahorro empresario es mayor en estos últimos países (13.7\% contra 9.9\%). Estos porcentajes no se compadecen con la presunción de que las empresas invierten basándose en el ahorro personal intermediado por el sistema financiero. Más bien, es claro que las mismas empresas ahorran e invierten. 


\subsubsection{Principales indicadores monetarios}

Cuadro 10

Base Monetaria y Reservas del BCRA en millones de pesos

\begin{tabular}{|l|c|c|}
\hline \multicolumn{1}{|c|}{ Conceptos } & Jul-10 & Jul-09 \\
\hline BASE MONETARIA & 133.899 & 105.714 \\
\hline 1. Circulante en Poder del Público & 92.082 & 73.602 \\
\hline 2. Reservas Bancarias & 41.817 & 32.112 \\
\hline 2.1. Cuenta Corriente en el BCRA & 30.608 & 23.079 \\
\hline 2.2. Efectivo en pesos & 11.209 & 9.034 \\
\hline Reserva BCAR & 198.625 & 175.334 \\
\hline Tipo de Cambio & 3,93 & 3,81 \\
\hline Cuenta Corriente & 75.551 & 62.660 \\
\hline Caja de Ahorro & 50.225 & 40.026 \\
\hline Plazo Fijo & 120.627 & 84.639 \\
\hline M1/PIB & $13,77 \%$ & $11,40 \%$ \\
\hline M2/PIB & $17,90 \%$ & $14,75 \%$ \\
\hline M3/PIB & $28,83 \%$ & $22,75 \%$ \\
\hline a) Ratio de Cobertura = Base Monetaria/ Reservas & $67,4 \%$ & $60,3 \%$ \\
\hline $\begin{array}{l}\text { b) Ratio de Cobertura Amplia = (B. Monetaria +Cta Cte+C. } \\
\text { Ahorro)/Reservas }\end{array}$ & $130,7 \%$ & $118,9 \%$ \\
\hline c) Ratio de Liquidez = (Cta Cte en BCRA+Pases+ Efvo en & 18,78 & 18,17 \\
\hline Bcos)/Depósitos Totales ${ }^{*}$ & & \\
\hline
\end{tabular}

Fuente: BCRA.

Notas:

1) EI PIB (en moneda corriente) utilizado corresponde al I Trimestre de 2010 (último dato disponible) para julio de 2010 y junio de 2010 y al II Trimestre de 2009 para julio de 2009.

2) En a) y b), cuanto menor es el ratio, las reservas cubren con mayor solidez el dinero en circulación. En los tres casos el ratio corresponde al promedio de cada mes.

3) $\mathrm{M} 1=$ Billetes y monedas+ Cta. Cte. del S. Priv. y del S. Pub en pesos

$\mathrm{M} 2=\mathrm{M} 1+$ Caja de ahorro del S. Priv. y del S. Púb. en pesos

M3= Billetes y Monedas +Depósitos del S. Priv. y del S. Púb. en pesos.

$\left({ }^{*}\right)$ No se incluyen los depósitos del sector financiero.

En el mes de julio, la Base Monetaria promedió los \$ 133.899 millones, \$ 28.185 millones superior a julio de 2009 . Respecto del año anterior, la expansión de la base fue del $26,7 \%$.

El circulante en poder del público en el mes de julio promedió los $\$ 92.082$ millones, con un incremento de $\$ 18.480$ millones equivalente al $25,1 \%$ respecto de igual período del año anterior. 
Ratio de Liquidez del Sistema Financiero

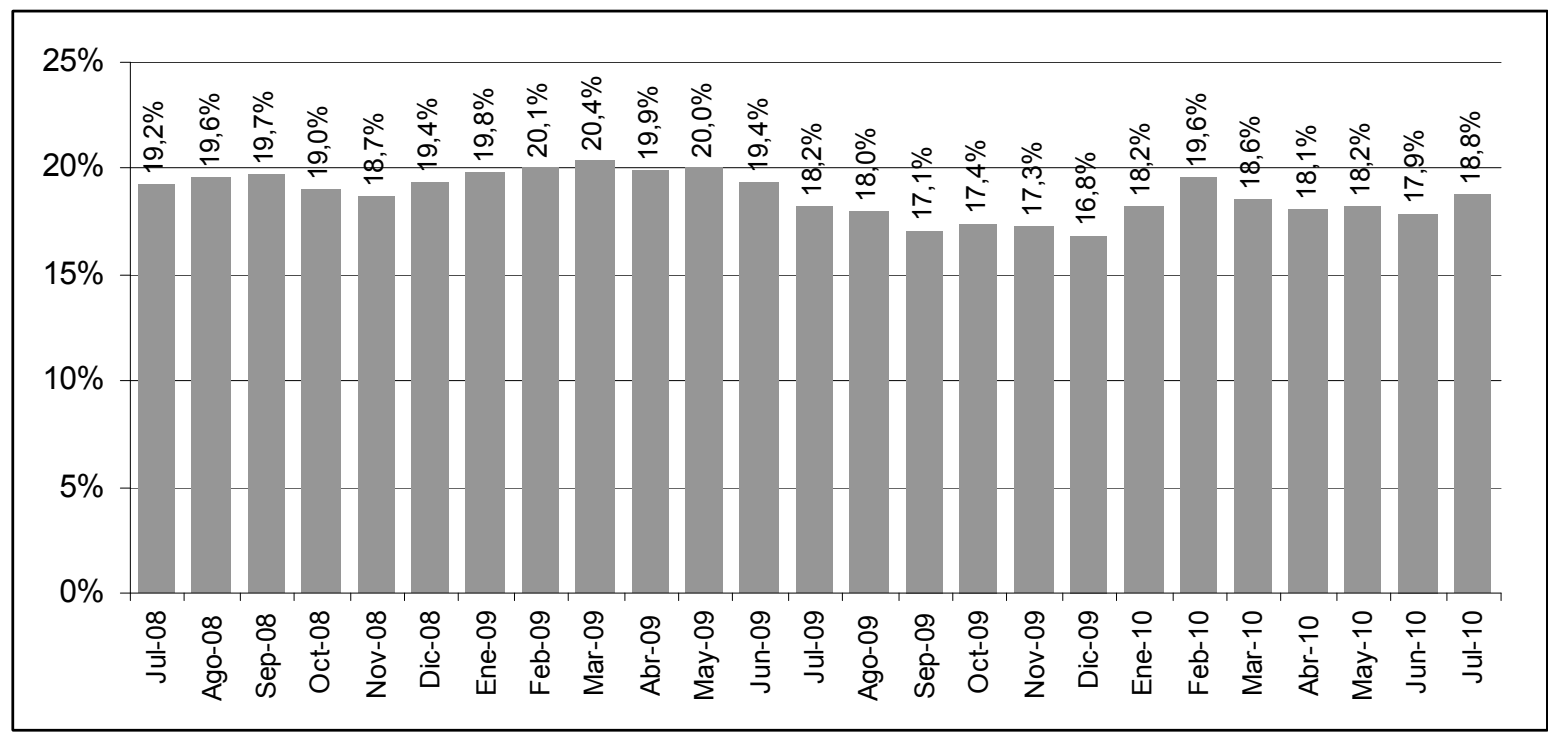

Fuente: BCRA.

Según Carlos Heller, si bien el sistema financiero emergió sano de la crisis de 2001, en 2009 el total de crédito al sector privado no financiero apenas llegó al 11,3\% del PBI, un valor que se repitió estos últimos años y que es el más bajo de América Latina. Pero, además, los bancos mantienen una liquidez excesiva que alcanza al 35\% de los depósitos, cuando gran parte de ese dinero debería haberse utilizado para dar crédito.

\subsubsection{Préstamos}

Cuadro 11

Préstamos al Sector Privado no Financiero en pesos Promedio de saldos y variaciones nominales. En millones de pesos.

\begin{tabular}{|c|c|c|c|c|c|}
\hline \multirow{2}{*}{ DESTINO } & \multicolumn{2}{|c|}{ Jul-10 } & \multirow{2}{*}{ Jul-09 } & \multicolumn{2}{|c|}{ Jul-10 vs Jul-09 } \\
\hline & Saldo & $\%$ Part. & & Var. Nom. & $\%$ Var \\
\hline Préstamos a las Empresas & 63.508 & $46,4 \%$ & 52.203 & 11.305 & $21,7 \%$ \\
\hline Adelantos & 20.251 & $14,8 \%$ & 18.448 & 1.803 & $9,8 \%$ \\
\hline Documentos & 26.779 & $19,6 \%$ & 20.188 & 6.591 & $32,6 \%$ \\
\hline Hipotecarios & 7.675 & $5,6 \%$ & 7.638 & 37 & $0,5 \%$ \\
\hline Otros & 8.804 & $6,4 \%$ & 5.928 & 2.876 & $48,5 \%$ \\
\hline Préstamos a las familias & 73.288 & $53,6 \%$ & 60.329 & 12.959 & $21,5 \%$ \\
\hline Vivienda & 10.767 & $7,9 \%$ & 10.391 & 376 & $3,6 \%$ \\
\hline Prendarios & 7.834 & $5,7 \%$ & 6.923 & 911 & $13,2 \%$ \\
\hline Personales & 33.600 & $24,6 \%$ & 27.841 & 5.759 & $20,7 \%$ \\
\hline Tarjetas & 21.087 & $15,4 \%$ & 15.174 & 5.913 & $39,0 \%$ \\
\hline Total & 136.796 & $100 \%$ & 112.264 & 24.264 & $21,6 \%$ \\
\hline
\end{tabular}

Fuente: BCRA. 
Según datos informados por el BCRA, los préstamos en pesos al Sector Privado no Financiero mostraron un crecimiento interanual de \$24.264 millones de pesos, lo que equivale a un incremento del nivel de préstamos del 21,6\%. Al 30 de julio pasado, los saldos de préstamos en pesos alcanzaban los $\$ 138.861$ millones (el promedio mensual fue de $\$ 136.796$ millones). Asimismo, se observa un mayor dinamismo en el crédito destinado a las familias, el cual representa casi el $54 \%$ del total de préstamos.

Respecto de los préstamos a las empresas, en julio 2010, los préstamos en pesos a las empresas promediaron los $\$ 63.508$ millones, lo que representa el $46,4 \%$ del total de las financiaciones en pesos al SPNF.

En relación a los niveles observados un año atrás, la financiación con destino a las empresas registró un incremento del 21,7\% (\$11.305 millones), siendo documentos a sola firma la línea crediticia que más aportó a este aumento en términos absolutos (\$6.591 millones). El conjunto de las otras líneas destinadas al financiamiento de empresas también mostró un fuerte dinamismo, con un incremento que alcanza los $\$ 2.876$ millones (48,5\% de variación interanual).

En cuanto a los préstamos a las Familias, en julio, los préstamos en pesos a las familias promediaron los $\$ 73.288$ millones (lo que representa el $53,6 \%$ del total de este tipo de financiaciones en moneda doméstica al SPNF).

En la evolución de los últimos 12 meses, se registró un incremento de \$12.959 millones, equivalente al $21,5 \%$. Las líneas que más contribuyeron a esta variación fueron los créditos personales con $\$ 5.759$ millones $(20,7 \%)$ y las financiaciones a través de tarjetas de crédito con $\$ 5.913$ millones (39\%).

Cuadro 12

Préstamos al Sector Privado no Financiero en dólares Promedio de saldos y variaciones nominales. En millones de dólares.

\begin{tabular}{|c|c|c|c|c|c|}
\hline \multirow{2}{*}{ DESTINO } & \multicolumn{2}{|c|}{ Jul-10 } & \multirow{2}{*}{ Jul-09 } & \multicolumn{2}{|c|}{ Jul-10 vs Jul-09 } \\
\hline & Saldo & $\%$ Part. & & Var. Nom. & $\%$ Var. \\
\hline Préstamos a las Empresas & 5.473 & $94,7 \%$ & 5.459 & 14 & $0,3 \%$ \\
\hline Adelantos & 438 & $7,6 \%$ & 293 & 145 & $49,5 \%$ \\
\hline Documentos & 4.473 & $77,4 \%$ & 4.436 & 37 & $0,8 \%$ \\
\hline Hipotecarios & 86 & $1,5 \%$ & 94 & -8 & $-8,7 \%$ \\
\hline Otros & 477 & $8,3 \%$ & 636 & -159 & $-25,1 \%$ \\
\hline Préstamos a las familias & 305 & $5,3 \%$ & 285 & 19 & $6,8 \%$ \\
\hline Vivienda & 129 & $2,2 \%$ & 127 & 2 & $1,3 \%$ \\
\hline Prendarios & 56 & $1,0 \%$ & 67 & -11 & $-15,8 \%$ \\
\hline Personales & 0 & $0,0 \%$ & 0 & 0 & $0,0 \%$ \\
\hline Tarjetas & 119 & $2,1 \%$ & 91 & 28 & $31,2 \%$ \\
\hline Total & 5.778 & $100 \%$ & 5.744 & 33 & $0,6 \%$ \\
\hline
\end{tabular}

Fuente: BCRA.

En relación al año anterior, se observa un incremento de los préstamos en dólares del 0,6\% (US\$ 33 millones), con dos grandes variaciones, por un lado los adelantos en cuenta 
corriente que evidenciaron un incremento del 49,5\% y por el otro, las otras líneas de financiamiento de menor importancia relativa, que mostraron una caída del $25,1 \%$.

En las líneas de financiamiento en moneda extranjera las empresas concentran el $94,7 \%$ del total, siendo los documentos la modalidad mas utilizada por las empresas con un $77,4 \%$ (\$4.473 millones) de participación.

Los préstamos a las familias en dólares son muy escasos, representan el 5,3\% (\$305 millones) de participación sobre el total y en los cuales la adquisición de viviendas es el principal destino de los mismos.

Cuadro 13

Préstamos al Sector Privado no Financiero en pesos y dólares. Promedio de saldos y variaciones nominales. En millones de pesos.

\begin{tabular}{|l|c|c|c|c|c|}
\hline \multirow{2}{*}{ DESTINO } & \multicolumn{2}{c|}{ Jul-10 } & \multirow{2}{*}{ Jul-09 } & \multicolumn{2}{c|}{ Jul-10 vs Jul-09 } \\
\cline { 2 - 3 } \cline { 5 - 6 } & Saldo & \% Part. & & \multirow{2}{*}{ Var. Nom. } & \% Var. \\
\hline Préstamos a las Empresas & $\mathbf{8 5 . 0 5 8}$ & $\mathbf{5 3 , 3 \%}$ & $\mathbf{7 3 . 0 0 0}$ & $\mathbf{1 2 . 0 5 8}$ & $\mathbf{1 6 , 5 \%}$ \\
\hline Adelantos & 21.973 & $13,8 \%$ & 19.564 & 2.410 & $12,3 \%$ \\
\hline Documentos & 44.379 & $27,8 \%$ & 37.090 & 7.289 & $19,7 \%$ \\
\hline Hipotecarios* & 8.026 & $5,0 \%$ & 7.995 & 31 & $0,4 \%$ \\
\hline Otros & 10.680 & $6,7 \%$ & 8.352 & 2.328 & $27,9 \%$ \\
\hline Préstamos a las familias & $\mathbf{7 4 . 4 7 2}$ & $\mathbf{4 6 , 7 \%}$ & $\mathbf{6 1 . 4 1 6}$ & $\mathbf{1 3 . 0 5 6}$ & $\mathbf{2 1 , 3 \%}$ \\
\hline Vivienda * & 11.260 & $7,1 \%$ & 10.876 & 384 & $3,5 \%$ \\
\hline Prendarios & 8.056 & $5,0 \%$ & 7.179 & 877 & $12,2 \%$ \\
\hline Personales & 33.600 & $21,1 \%$ & 27.841 & 5.759 & $20,7 \%$ \\
\hline Tarjetas & 21.556 & $13,5 \%$ & 15.520 & 6.036 & $38,9 \%$ \\
\hline & $\mathbf{1 5 9 . 5 3 0}$ & $\mathbf{1 0 0} \%$ & $\mathbf{1 3 4 . 4 1 6}$ & $\mathbf{2 5 . 1 1 4}$ & $\mathbf{1 8 , 7 \%}$ \\
\hline
\end{tabular}

Fuente: BCRA.

Al 30 de julio los saldos de préstamos en pesos totales alcanzaban los $\$ 162.356$ millones (el promedio mensual fue de $\$ 159.530$ millones). Las financiaciones a las empresas y a las familias representan el $53,3 \%$ y el $46,7 \%$ respectivamente.

Respecto de los préstamos totales a las Empresas, en relación a los niveles observados un año atrás, los préstamos con destino a las empresas registraron un aumento de $16,5 \%$ (\$12.058 millones), siendo los documentos a sola firma el factor más importante de este incremento con un crecimiento de $\$ 7.289$ millones. Por su parte los adelantos en cuenta corriente y las otras líneas de financiamiento tuvieron un variación interanual de 12,3\% y $27,9 \%$ respectivamente.

En cuanto a los préstamos totales a las Familias, en los últimos 12 meses, registraron un incremento de $\$ 13.056$ millones, equivalente al $21,3 \%$. Las líneas que más contribuyeron fueron la financiación con tarjetas de crédito con una variación interanual de \$6.036 millones $(38,9 \%)$, seguido por los préstamos personales, con un crecimiento de $\$ 5.759$ millones $(20,7 \%)$. 
Gráfico 9

Variación Mensual de Préstamos al Sector Privado no Financiero Préstamos en pesos y en dólares, en millones de pesos.

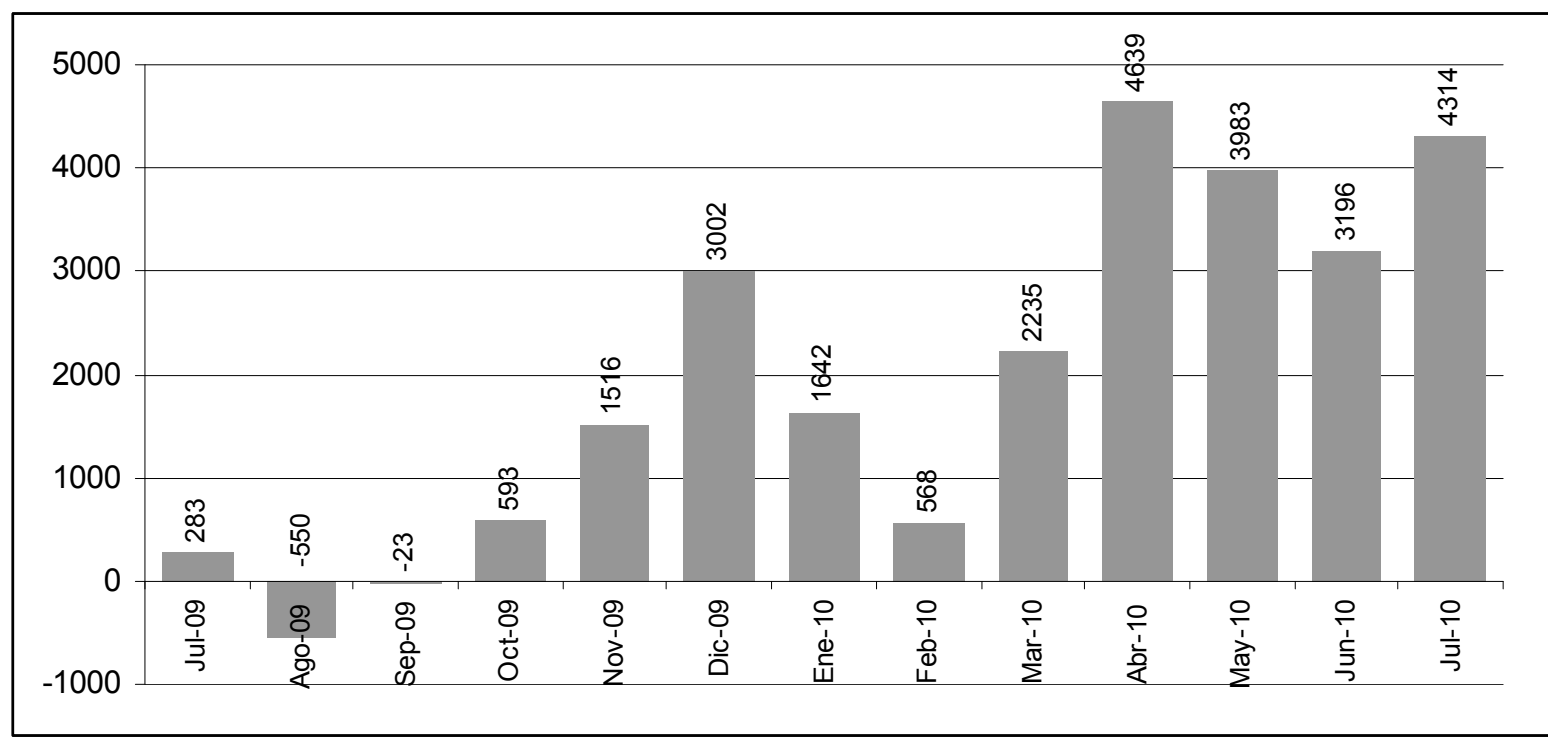

Fuente: BCRA.

Dejando de lado el crédito al consumo (que explica el $50 \%$ del crédito privado) y haciendo foco en el crédito a empresas; un aspecto importante a analizar es la distribución de los créditos por tramos de deuda, a los efectos de analizar la cantidad de empresas que hay en cada tramo y su importancia relativa en el total de la cartera del sistema bancario.

Gráfico 10

Cantidad de Empresas por Tramo de Deuda

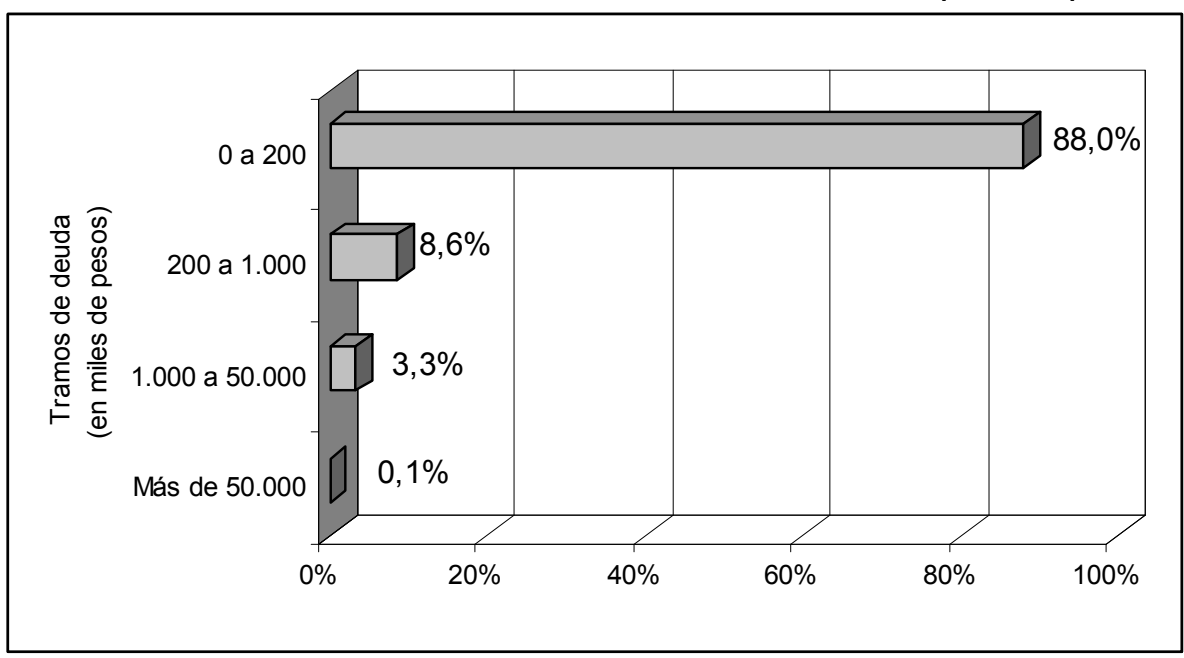

Fuente: BCRA, 2004.

Otorgar préstamos es una actividad con importantes costos fijos relacionados especialmente con su evaluación previa, pero también con su supervisión y recupero. En operaciones pequeñas los costos fijos asumen mayor importancia lo que conduce a los bancos a solicitar mayores tasas de interés o directamente a no analizar el caso. 
La percepción de existencia de demanda de financiamiento en las pyme lo da la importante cantidad de solicitudes que reciben los bancos, sin embargo, la participación en el total de préstamos de los destinados a pyme se mantienen en niveles muy bajos.

Gráfico 11

Montos de Deuda Bancaria por Tramo de Deuda

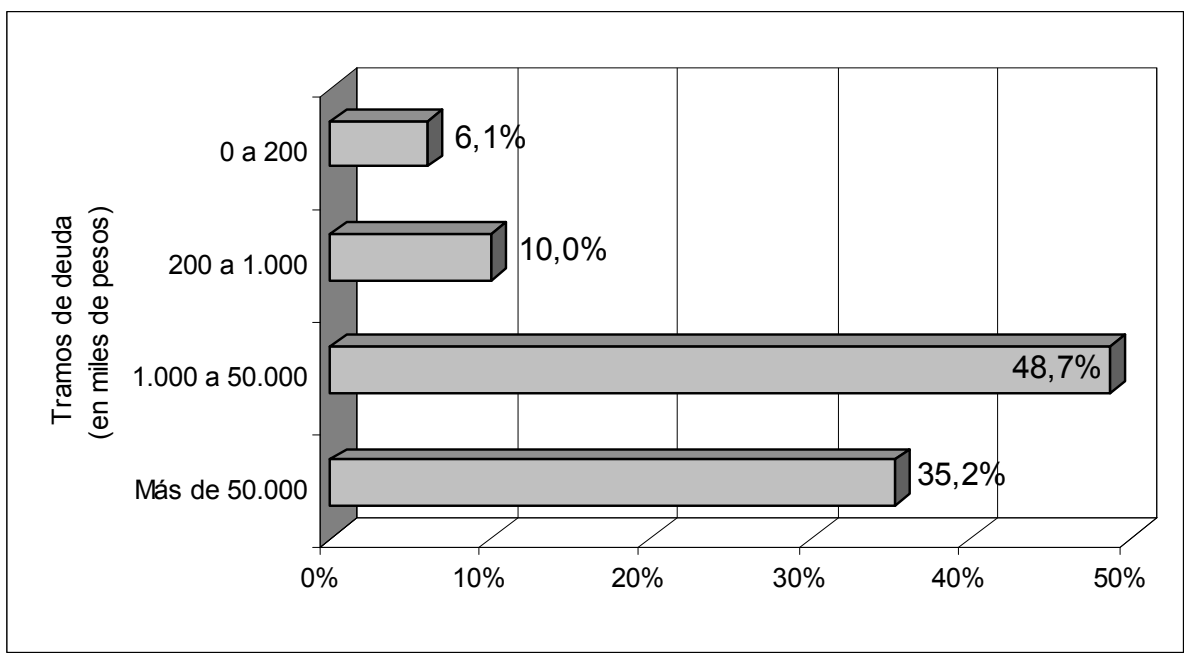

Fuente: BCRA, 2004.

En base a datos de la Central de Deudores del BCRA, Bleger (2006) encuentra que las PyMEs con crédito en el sistema bancario formal (definidas como aquellas empresas con una deuda total por debajo de 5 millones de pesos) representan el $99 \%$ del total de empresas deudoras y su deuda con el sistema llegaría al $25 \%$ del total de crédito comercial. Estas cifras revelan una importante, aunque esperable, concentración del crédito en los deudores más grandes.

Gráfico 12

Concentración del Crédito Bancario en Argentina

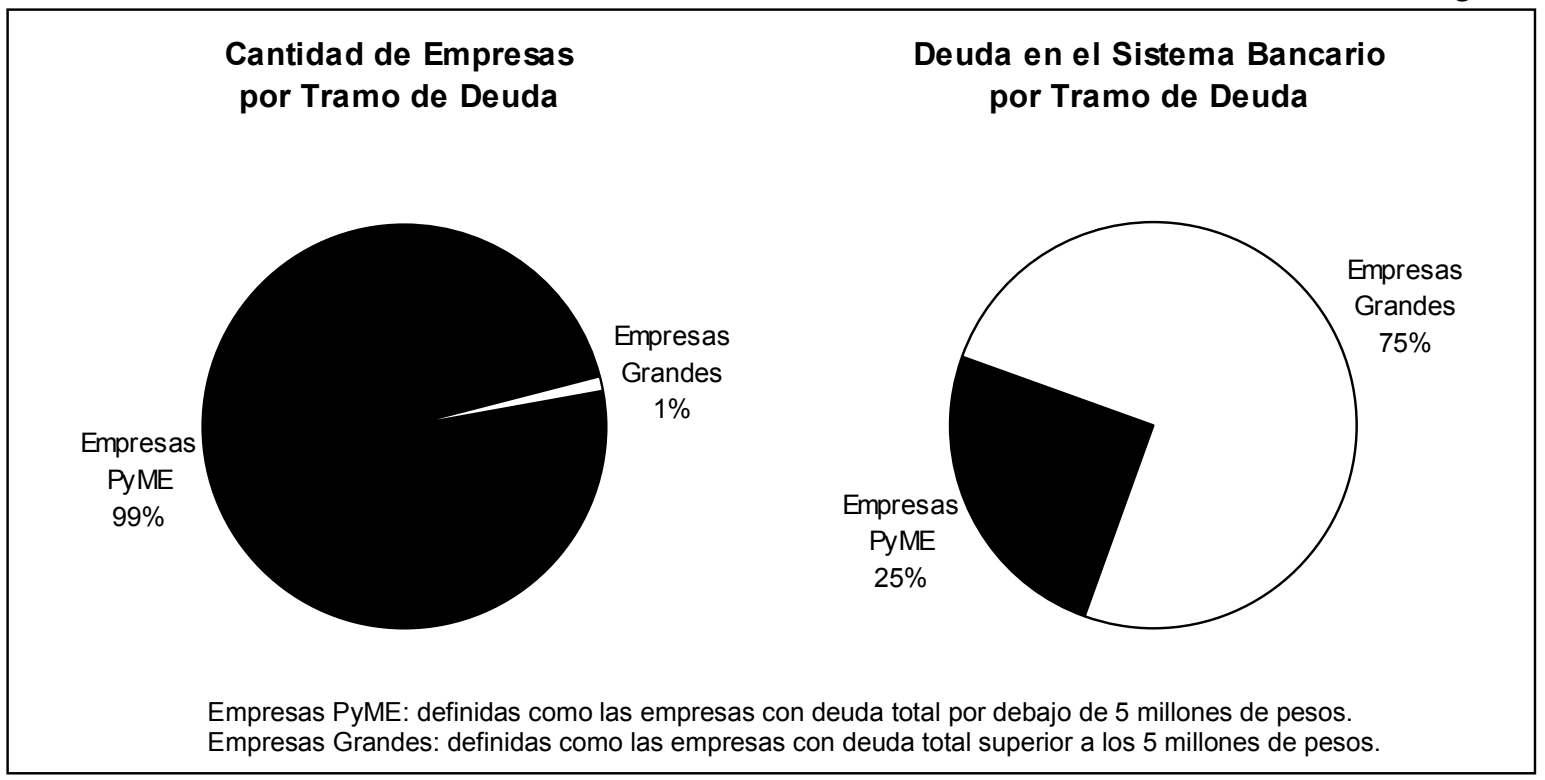

Fuente: BCRA, 2006. 
Es obvio que el gap de oferta y demanda de financiamiento para las pyme obedece en buena medida a la normativa crediticia vigente que no incentiva el acercamiento de los bancos a las pyme. En realidad se mantiene el espíritu de las normas crediticias del BCRA de los años noventa, con un manifiesto sesgo pro-corporación, toda vez que obligaban a los bancos a hacer mayores previsiones por los préstamos dados a las pyme, a partir de considerarlas como más riesgosas.

Se hace necesario actualizar la aplicación de la legislación de manera que otorgue un mayor incentivo a los bancos para atender a las pyme. En el mundo la experiencia indica la necesidad de especialización de la actividad financiera, por ejemplo en atender empresas pequeñas.

Otro aspecto importante a analizar, es la distribución del financiamiento por tramo de deuda, entre los diferentes tipos de bancos, clasificados estos en públicos y privados, los primeros según la jurisdicción, nacionales, provinciales o municipales, y los segundos en función de la conformación del capital, donde se distinguen bancos de capital nacional, cooperativos, de capital extranjero y sucursales de entidades financieras del exterior.

Cuadro 14

Estructura de Financiamiento por Tramo de Deuda y Grupo de Bancos.

Marzo 2009. En millones de pesos.

\begin{tabular}{|l|c|c|c|c|c|c|c|}
\hline & $\begin{array}{c}\text { Total } \\
\text { Deuda } \\
\text { Sist. } \\
\text { Financiero }\end{array}$ & $\begin{array}{c}\text { Total } \\
\text { Préstamos } \\
\text { al SPNF }\end{array}$ & $\begin{array}{c}\text { Cartera } \\
\text { Total PyME }\end{array}$ & $\begin{array}{c}\text { Cartera } \\
\text { Comercial } \\
\text { asimilable a } \\
\text { consumo }\end{array}$ & $\begin{array}{c}\mathbf{\$ 0 , 5}-\mathbf{\$ 1} \\
\text { Millones }\end{array}$ & $\begin{array}{c}\mathbf{\$ 1}-\mathbf{\$ 2 , 5} \\
\text { Millones }\end{array}$ & $\begin{array}{c}\mathbf{\$ 2 , 5}-\mathbf{\$ 5} \\
\text { Millones }\end{array}$ \\
\hline Total Bancos & $\mathbf{1 8 5 . 6 7 0 , 8}$ & $\mathbf{1 3 0 . 9 8 8 , 7}$ & $\mathbf{3 4 . 4 9 9 , 4}$ & $\mathbf{1 2 . 7 2 7 , 1}$ & $\mathbf{5 . 9 3 2 , 0}$ & $\mathbf{8 . 0 4 2 , 3}$ & $\mathbf{7 . 7 9 8 , 0}$ \\
\hline Bancos Públicos & $\mathbf{7 0 . 7 0 4 , 0}$ & $\mathbf{4 1 . 1 9 0 , 6}$ & $\mathbf{1 1 . 7 9 7 , 7}$ & $\mathbf{6 . 1 4 8 , 9}$ & $\mathbf{2 . 2 9 1 , 6}$ & $\mathbf{1 . 7 7 0 , 3}$ & $\mathbf{1 . 5 8 6 , 8}$ \\
\hline Nacionales & $43.026,4$ & $20.406,3$ & $6.200,5$ & $2.976,7$ & $1.521,5$ & 863,4 & 838,9 \\
\hline $\begin{array}{l}\text { Provinciales y } \\
\text { municipales }\end{array}$ & $27.677,6$ & $20.784,3$ & $5.597,2$ & $3.172,2$ & 770,2 & 906,9 & 747,9 \\
\hline Bancos Privados & $\mathbf{1 1 4 . 9 6 6 , 8}$ & $\mathbf{8 9 . 7 9 8 , 0}$ & $\mathbf{2 2 . 7 0 1 , 6}$ & $\mathbf{6 . 5 7 8 , 2}$ & $\mathbf{3 . 6 4 0 , 3}$ & $\mathbf{6 . 2 7 2 , 0}$ & $\mathbf{6 . 2 1 1 , 1}$ \\
\hline $\begin{array}{l}\text { S.A. de capital } \\
\text { nacional }\end{array}$ & $48.455,7$ & $40.521,4$ & $10.796,8$ & $3.446,9$ & $1.616,5$ & $2.854,1$ & $2.879,4$ \\
\hline Cooperativos & $5.603,2$ & $4.558,0$ & $2.660,0$ & $1.062,7$ & 465,4 & 693,7 & 438,1 \\
\hline $\begin{array}{l}\text { Locales de capital } \\
\text { extranjero }\end{array}$ & $46.275,1$ & $37.406,1$ & $7.956,3$ & $2.025,4$ & $1.314,0$ & $2.277,9$ & $2.339,0$ \\
\hline $\begin{array}{l}\text { Suc. entidades } \\
\text { fcieras del exterior }\end{array}$ & $14.632,8$ & $7.312,6$ & $1.288,6$ & 43,3 & 244,4 & 446,2 & 554,7 \\
\hline
\end{tabular}

Fuente: BCRA. 
Cuadro 15

Estructura de Financiamiento por Tramo de Deuda y Grupo de Bancos. Marzo 2010. En millones de pesos.

\begin{tabular}{|l|c|c|c|c|c|c|c|}
\hline & $\begin{array}{c}\text { Total } \\
\text { Deuda } \\
\text { Sist. } \\
\text { Financiero }\end{array}$ & $\begin{array}{c}\text { Total } \\
\text { Préstamos } \\
\text { al SPNF }\end{array}$ & $\begin{array}{c}\text { Cartera } \\
\text { Total } \\
\text { PyME }\end{array}$ & $\begin{array}{c}\text { Cartera } \\
\text { Comercial } \\
\text { asimilable } \\
\text { a consumo }\end{array}$ & $\begin{array}{c}\mathbf{\$ 0 , 5}-\mathbf{\$ 1} \\
\text { Millones }\end{array}$ & $\begin{array}{c}\mathbf{\$ 1}-\mathbf{\$ 2 , 5} \\
\text { Millones }\end{array}$ & $\begin{array}{c}\mathbf{\$ 2 , 5}-\mathbf{\$ 5} \\
\text { Millones }\end{array}$ \\
\hline Total Bancos & $\mathbf{2 1 5 . 9 3 4 , 4}$ & $\mathbf{1 4 9 . 9 2 9 , 4}$ & $\mathbf{4 0 . 4 0 9 , 4}$ & $\mathbf{1 4 . 9 3 9 , 2}$ & $\mathbf{6 . 7 3 1 , 6}$ & $\mathbf{9 . 5 2 5 , 7}$ & $\mathbf{9 . 2 1 3 , 0}$ \\
\hline Bancos Públicos & $\mathbf{8 4 . 8 4 0 , 5}$ & $\mathbf{4 4 . 9 8 1 , 3}$ & $\mathbf{1 3 . 3 2 5 , 4}$ & $\mathbf{6 . 8 7 4 , 4}$ & $\mathbf{2 . 5 8 3 , 3}$ & $\mathbf{2 . 0 5 6 , 6}$ & $\mathbf{1 . 8 1 1 , 0}$ \\
\hline Nacionales & $55.285,4$ & $22.498,4$ & $7.218,7$ & $3.487,3$ & $1.727,2$ & $1.061,6$ & 942,6 \\
\hline $\begin{array}{l}\text { Provinciales y } \\
\text { municipales }\end{array}$ & $29.555,1$ & $22.482,8$ & $6.106,8$ & $3.387,2$ & 856,1 & 995,1 & 868,4 \\
\hline Bancos Privados & $\mathbf{1 3 1 . 0 9 3 , 9}$ & $\mathbf{1 0 4 . 9 4 8 , 1}$ & $\mathbf{2 7 . 0 8 4 , 0}$ & $\mathbf{8 . 0 6 4 , 8}$ & $\mathbf{4 . 1 4 8 , 3}$ & $\mathbf{7 . 4 6 9 , 0}$ & $\mathbf{7 . 4 0 1 , 9}$ \\
\hline $\begin{array}{l}\text { S.A. de capital } \\
\text { nacional }\end{array}$ & $58.738,6$ & $49.202,9$ & $13.597,2$ & $4.271,3$ & $2.065,0$ & $3.610,4$ & $3.650,5$ \\
\hline Cooperativos & $7.085,9$ & $5.766,3$ & $3.740,3$ & $1.603,8$ & 568,3 & 864,2 & 704,0 \\
\hline $\begin{array}{l}\text { Locales de capital } \\
\text { extranjero }\end{array}$ & $50.555,1$ & $43.288,5$ & $8.475,8$ & $2.164,5$ & $1.209,4$ & $2.609,2$ & $2.411,8$ \\
\hline $\begin{array}{l}\text { Suc. entidades } \\
\text { fcieras del exterior }\end{array}$ & $14.714,3$ & $6.609,4$ & $1.270,8$ & 25,2 & 224,7 & 385,3 & 635,7 \\
\hline
\end{tabular}

Fuente: BCRA.

Cuadro 16 Variación Nominal del Financiamiento por Tramo de Deuda y Grupo de Bancos. Marzo 2010 vs. Marzo 2009. En millones de pesos.

\begin{tabular}{|l|c|c|c|c|c|c|}
\hline & $\begin{array}{c}\text { Total } \\
\text { Préstamos } \\
\text { al SPNF }\end{array}$ & $\begin{array}{c}\text { Cartera } \\
\text { Total PyME }\end{array}$ & $\begin{array}{c}\text { Cartera } \\
\text { Comercial } \\
\text { asimilable } \\
\text { a consumo }\end{array}$ & $\begin{array}{c}\mathbf{\$ 0 , 5}-\mathbf{\$ 1} \\
\text { Millones }\end{array}$ & $\begin{array}{c}\mathbf{\$ 1}- \\
\mathbf{\$ 2 , 5} \\
\text { Millones }\end{array}$ & $\begin{array}{c}\mathbf{\$ 2 , 5}-\mathbf{\$ 5} \\
\text { Millones }\end{array}$ \\
\hline Total Bancos & $\mathbf{1 8 . 9 4 0 , 7}$ & $\mathbf{5 . 9 1 9 , 1}$ & $\mathbf{2 . 2 1 2 , 1}$ & $\mathbf{7 9 9 , 6}$ & $\mathbf{1 . 4 8 3 , 4}$ & $\mathbf{1 . 4 1 5 , 0}$ \\
\hline Bancos Públicos & $\mathbf{3 . 7 9 0 , 7}$ & $\mathbf{1 . 5 2 7 , 7}$ & $\mathbf{7 2 5 , 5}$ & $\mathbf{2 9 1 , 7}$ & $\mathbf{2 8 6 , 3}$ & $\mathbf{2 2 4 , 2}$ \\
\hline Nacionales & $2.092,1$ & $1.018,2$ & 510,6 & 205,8 & 198,1 & 103,7 \\
\hline Provinciales y municipales & $1.698,5$ & 509,5 & 215,0 & 85,9 & 88,2 & 120,5 \\
\hline Bancos Privados & $\mathbf{1 5 . 1 5 0 , 1}$ & $\mathbf{4 . 3 8 2 , 4}$ & $\mathbf{1 . 4 8 6 , 6}$ & $\mathbf{5 0 7 , 9}$ & $\mathbf{1 . 1 9 7 , 1}$ & $\mathbf{1 . 1 9 0 , 8}$ \\
\hline S.A.de capital nacional & $8.681,5$ & $2.800,3$ & 824,4 & 448,5 & 756,3 & 771,1 \\
\hline Cooperativos & $1.208,3$ & $1.080,3$ & 541,1 & 102,9 & 170,4 & 265,9 \\
\hline Locales de capital extranjero & $5.882,4$ & 519,5 & 139,1 & -23.7 & 331,3 & 72,8 \\
\hline Suc. entidades fcieras del exterior & -622.2 & -17.8 & -18.1 & -19.8 & -60.9 & 81.0 \\
\hline
\end{tabular}

Fuente: BCRA. 
Variación Porcentual del Financiamiento por Tramo de Deuda y Grupo de Bancos. Marzo 2010 vs. Marzo 2009.

\begin{tabular}{|c|c|c|c|c|c|c|}
\hline & $\begin{array}{c}\text { Total } \\
\text { Préstamos } \\
\text { al SPNF }\end{array}$ & $\begin{array}{c}\text { Cartera } \\
\text { Total PyME }\end{array}$ & $\begin{array}{c}\text { Cartera } \\
\text { Comercial } \\
\text { asimilable a } \\
\text { consumo }\end{array}$ & $\begin{array}{l}\$ 0,5-\$ 1 \\
\text { Millones }\end{array}$ & $\begin{array}{c}\$ 1- \\
\$ 2,5 \\
\text { Millones }\end{array}$ & $\begin{array}{l}\$ 2,5-\$ 5 \\
\text { Millones }\end{array}$ \\
\hline Total Bancos & $14,5 \%$ & $17,1 \%$ & $17,4 \%$ & $13,5 \%$ & $18,4 \%$ & $18,1 \%$ \\
\hline Bancos Públicos & $9,2 \%$ & $12,9 \%$ & $11,8 \%$ & $12,7 \%$ & $16,2 \%$ & $14,1 \%$ \\
\hline Nacionales & $10,3 \%$ & $16,4 \%$ & $17,2 \%$ & $13,5 \%$ & $22,9 \%$ & $12,4 \%$ \\
\hline Provinciales y municipales & $8,2 \%$ & $9,1 \%$ & $6,8 \%$ & $11,2 \%$ & $9,7 \%$ & $16,1 \%$ \\
\hline Bancos Privados & $16,9 \%$ & $19,3 \%$ & $22,6 \%$ & $14,0 \%$ & $19,1 \%$ & $19,2 \%$ \\
\hline S.A.de capital nacional & $21,4 \%$ & $25,9 \%$ & $23,9 \%$ & $27,7 \%$ & $26,5 \%$ & $26,8 \%$ \\
\hline Cooperativos & $26,5 \%$ & $40,6 \%$ & $50,9 \%$ & $22,1 \%$ & $24,6 \%$ & $60,7 \%$ \\
\hline Locales de capital extranjero & $15,7 \%$ & $6,5 \%$ & $6,9 \%$ & $-1.8 \%$ & $14,5 \%$ & $3,1 \%$ \\
\hline Suc. entidades fcieras del exterior & $-8.5 \%$ & $-1.4 \%$ & $-41.8 \%$ & $-8.1 \%$ & $-13.7 \%$ & $14.6 \%$ \\
\hline
\end{tabular}

Fuente: BCRA.

De acuerdo con los datos publicados por el BCRA, entre marzo de 2010 y marzo de 2009, se mantiene el crecimiento de los préstamos a las PyMEs. Si observamos el comportamiento al interior del sistema bancario, se destaca el desempeño de la banca cooperativa, que para este período muestra un incremento en los préstamos a este sector del 40,6\% (\$1080,3 millones). En términos absolutos, la variación más importante viene dada por la banca privada nacional, que si bien parte de niveles muy bajos, logra incrementar en $\$ 2.800$ millones de pesos los créditos para este tipo de empresas. Por su parte la banca pública nacional, que parte de niveles altos como consecuencia de la aplicación de una política contracíclica de expansión del crédito durante los tres primeros trimestres del año 2009, incrementa este tipo de financiaciones en un 16,4\% (\$1.018 millones). De esta forma el desempeño de estos tres sectores permite que los préstamos a las pequeñas y medianas empresas hayan mostrado una variación positiva del $17,1 \%$ para el conjunto del sistema bancario ( $\$ 5.910$ millones).

La banca pública provincial y municipal presenta un incremento del 9,1\% (\$510 millones).

La banca extranjera, tal como viene sucediendo durante los últimos meses relevados, es la que muestra el peor desempeño en cuanto a la evolución de la asistencia crediticia a las pequeñas y medianas empresas. Los locales de capital extranjero incrementan su stock de financiamiento solo en un 6,5\% (\$520 millones) mientras que las sucursales de entidades financieras del exterior lo disminuyen en un 1,4\% (\$18 millones).

\subsubsection{Utilización del Crédito Bancario en Argentina}

Respecto de la oferta y demanda en el mercado de crédito PyME en Argentina, Ricardo Bebczuk (CEPAL, 2010) opina que "Como fruto de décadas de volatilidad macroeconómica y deficiente protección de los derechos de los ahorristas, el crédito bancario en Argentina se ha contraído hasta un valor del $13 \%$ del PBI, un valor que llega apenas al tercio del promedio para América Latina y un décimo del nivel en países de la OCDE (Organización para la Cooperación y el Desarrollo Económico). 
La baja profundidad crediticia no se explica exclusivamente por la escasez de ahorro intermediado bajo la forma de depósitos bancarios sino también por la estructura de activos a los cuales se aplica la capacidad prestable del sistema bancario. A septiembre de 2009, del total de recursos (pasivo más patrimonio neto) del sistema bancario, sólo el $35,8 \%$ se canaliza a crédito privado. Dejando de lado los activos fijos, el resto se vuelca al mantenimiento de altos niveles de disponibilidades (17\%), títulos públicos $(22,5 \%)$ y préstamos interbancarios $(11,2 \%)$. Estos usos implican que los bancos en Argentina no encuentran suficientemente atractiva la actividad de préstamo al sector privado (en general, no solamente a las PyMEs) y/o que la demanda de crédito es extremadamente baja para los cánones internacionales.

Gráfico 13

Estructura de Activos del Sistema Bancario Argentino Septiembre de 2009.

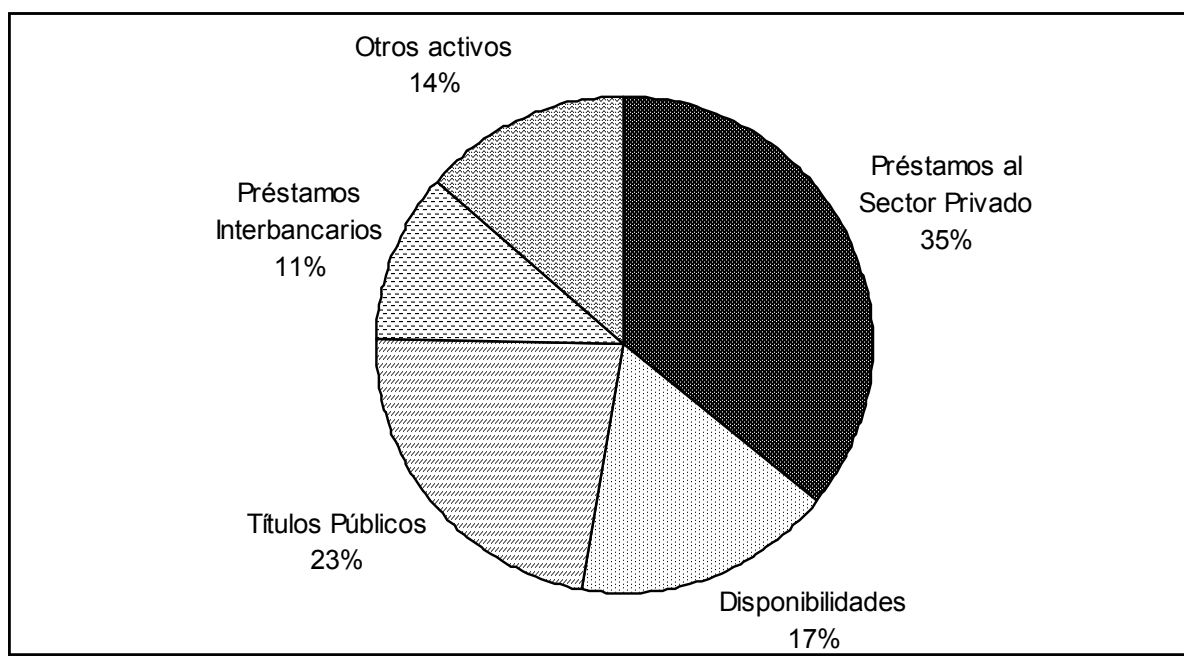

Fuente: BCRA.

Sin duda, resulta paradójico que la transformación de ahorro en crédito privado, la principal función social que justifica la existencia de los bancos, absorbe apenas la tercera parte de los recursos intermediados.

Cuadro 18

Empresas que Utilizan Crédito Bancario en Argentina y países seleccionados. Encuestas realizadas a 1500 empresas entre 2006 y 2009.

Empresa Pequeña: hasta 20 empleados, Mediana: 20 a 99, Grande: desde 100 empleados.

\begin{tabular}{|lccccc|}
\hline \multicolumn{5}{c|}{$\begin{array}{c}\text { EMPRESAS QUE UTILIZAN CRÉDITO BANCARIO } \\
\text { (En porcentaje sobre el total de empresas) }\end{array}$} \\
\hline País I & Tamaño de empresa & Total & Pequeña & Mediana & Grande \\
\hline Argentina & 6.9 & 3.3 & 8.5 & 14 \\
Brasil & 48.4 & 22.5 & 48.8 & 68.4 \\
Chile & 29.1 & 16 & 23.5 & 62.8 \\
México & 2.6 & 1.9 & 2.6 & 12.1 \\
España & 32.6 & 26.2 & 38.7 & 47.7 \\
\hline
\end{tabular}

Fuente: Banco Mundial. 
Inversiones Empresarias Financiadas con Crédito Bancario en Argentina y países seleccionados. Encuestas realizadas a 1500 empresas entre 2006 y 2009. Empresa Pequeña: hasta 20 empleados, Mediana: 20 a 99, Grande: desde 100 empleados.

\begin{tabular}{|lcccc|}
\hline \multicolumn{5}{c|}{$\begin{array}{c}\text { INVERSIONES EMPRESARIAS FINANCIADAS CON CRÉDITO BANCARIO } \\
\text { (En porcentaje sobre el total de empresas) }\end{array}$} \\
\hline País I Tamaño de empresa & Total & Pequeña & Mediana & Grande \\
\hline Argentina & 5.4 & 1.6 & 8.9 & 7.5 \\
Brasil & 33.6 & 15.1 & 32.7 & 49.7 \\
Chile & 36.1 & 33.9 & 16.9 & 59.8 \\
México & 6.8 & 5.6 & 4.2 & 23.7 \\
España & 21.9 & 20 & 24.6 & 25 \\
\hline
\end{tabular}

Fuente: Banco Mundial.

En el cuadro donde aparece el porcentaje de empresas que hacen uso de crédito bancario, se puede observar que los menores valores corresponden a México (2.6\% para el total de empresas) y Argentina (6,9\%). Estos valores también son muy bajos incluso en economías con una profundidad financiera mucho mayor, como Chile y España, donde la proporción ronda el $30 \%$ y $32 \%$ respectivamente. Se encuentra un panorama similar cuando se pasa al cuadro de inversiones financiado con crédito, en el cual se ubica Argentina con 5,4\%, luego México con $6,8 \%$, España con $21,9 \%$, Brasil con $33,6 \%$ y Chile con $36,1 \%$.

Según Ariel Llambías (Banco Galicia, entrevista UBA 2010), en Argentina las PyMEs se están financiando en gran parte con Capital Propio ya que la inestabilidad de nuestras políticas económicas repercuten en la disponibilidad de fondeo de los Bancos y a las PyME les cuesta disponer de un financiamiento sustentable en el tiempo. Hoy en día, de acuerdo con la actividad y sector en el que actúan, están trabajando con leasings, cartas de crédito, prefinanciación de importaciones y exportaciones, acuerdos en cuenta y préstamos financieros a sola firma. Los plazos en su mayoría son menores a un año, con excepción de algunas líneas de Leasing. Las tasas son en su mayoría variables en base a TEC (Tasa Encuesta Corregida) de Bancos Privados o Badlar de Bancos Privados, ambas con correcciones que aplican los bancos, rondando para plazos de un año el 19\% TNA mas gastos.

Según Jorge Ramos (Banco Ciudad, entrevista UBA 2010), el financiamiento bancario actual es casi todo a corto plazo, hay poca financiación de largo plazo para las PyMEs, solamente hay en los bancos algunas líneas de hasta 36 meses para comprar bienes de capital. El Banco Ciudad para compra de inmuebles tiene una línea hipotecaria de 10 años, pero solo esos son los plazos mas largos. El grueso de los bancos financia a corto plazo, capital de trabajo con préstamos a un año y descuento de cheques. Asimismo, en la estrategia comercial bancaria, "hoy la PyME ocupa un papel secundario, los bancos están orientados a clientes individuos, se puede ver en la calle publicidades abrumadoras de tarjetas de crédito con beneficios y descuentos en todos lados. A pesar de ello, la cartera de PyMEs del Banco creció un $100 \%$ y tenemos que seguir creciendo a este ritmo para que tenga mas peso, pero la realidad es que no representan grandes volúmenes". 


\subsubsection{Tasas de Interés}

Durante el mes de julio de 2010, la tasa de captación de fondos a nivel mayorista (BADLAR) fue de $10,5 \%$ (el 23 de julio). A nivel minorista, la tasa encuesta estuvo en el orden del $9,46 \%$. En el mercado interbancario, la tasa de Call cerro el 23 de julio a 9,12\%.

Cuadro 20

Tasas de Interés Activas en Pesos.

\begin{tabular}{|c|c|c|c|c|c|c|}
\hline Período & $\begin{array}{c}\text { Adelantos } \\
\text { en Cta. Cte. }\end{array}$ & $\begin{array}{c}\text { Doc. a sola } \\
\text { Firma (1) }\end{array}$ & $\begin{array}{c}\text { Hipotecarios } \\
\mathbf{( 2 )}\end{array}$ & $\begin{array}{c}\text { Prendarios } \\
\mathbf{( 3 )}\end{array}$ & $\begin{array}{c}\text { Personales } \\
\text { (4) }\end{array}$ & $\begin{array}{c}\text { Tarjetas de } \\
\text { Crédito }\end{array}$ \\
\hline Junio-10 & 18,24 & 14,92 & 12,65 & 17,58 & 29,81 & 30,19 \\
\hline Junio-09 & 22,77 & 18,68 & 11,83 & 22,8 & 34,08 & 29,44 \\
\hline $\begin{array}{c}\text { Variación: } \\
\text { Jun-10 vs Jun-09 }\end{array}$ & $-4,53$ & $-3,76$ & 0,82 & $-5,22$ & $-4,27$ & 0,75 \\
\hline
\end{tabular}

Notas: (1): 90 y más días de plazo; (2): más de 10 años; (3): más de un año; (4): más de 180 días.

Fuente: BCRA.

En la comparación junio de 2010 contra el mismo mes del año 2009, las tasas de interés para todas las líneas presentan una tendencia a la baja, con la excepción del segmento de hipotecarios y tarjetas de crédito.

\subsection{El Mercado de Capitales en Argentina}

Uno de los canales a través de los cuales la Bolsa participa de la economía real cada vez en mayor medida es el financiamiento de capital de trabajo, negocios y proyectos de pequeñas y medianas empresas.

Según Miguel Benedit ${ }^{21}$, las PyMEs son el motor de la economía, no sólo en Argentina sino en todos los países del mundo. Una de las principales características que tienen estas empresas es que su tamaño les permite ser "ágiles" y flexibles con lo cual se adaptan más fácilmente a cambios y pueden aprovechar mejor ciertas oportunidades. Dicho esto, y pensando en alternativas que favorezcan el desarrollo del sector PyME en Argentina, la pregunta es ¿Cuál es el rol del mercado de capitales frente a las PyMEs?

La respuesta a esta pregunta es: brindarle productos sencillos y útiles para acercarlas. Aunque creo que hay mucho por hacer y por mejorar en este sentido, lo que se hizo en los últimos años desde la bolsa no es poco. Antes de la crisis de 2001 prácticamente no había productos para financiar empresas PyMEs fuera del circuito bancario, pero con la crisis de 2001 y la apropiación de los depósitos algo en la relación banco-empresa se rompió y se abrió una puerta para que el mercado de capitales se convierta en una alternativa válida para financiar a las PyMEs.

Un aspecto a considerar, tal como menciona Marcelo Franco 22 "tampoco parece haber un gran interés genuino y real por parte de las PyMEs debido a la falta de cultura financiera del empresario PyME argentino que no identifica al mercado de capitales como una alternativa de financiamiento accesible".

\footnotetext{
${ }^{21}$ Reporte de investigación y actualidad de la Bolsa de Comercio de Buenos Aires, 31/05/2010

22 Entrevista UBA, 2010.
} 
Así como también, "todo empresario debe entender que el mercado de valores no reemplaza a la acción de los bancos sino que actúa como fuente complementaria de financiamiento". ${ }^{23}$

Según Hugo Diéguez ${ }^{24}$, "El mercado de capitales es una recurso estratégico para la PyME, con esto quiero decir que en un contexto económico variable, la mas sufrida ante la restricción de créditos es la PyME y en esos casos si no tenes acceso al crédito puede poner en riesgo la continuidad de la empresa. Entonces, poder acceder al mercado de capitales, independientemente que la tasa sea alta o no, es estratégico y las PyMEs lo deberían tener en cuenta aunque no lo usen".

\subsubsection{Departamento PyME en la Bolsa de Comercio de Buenos Aires}

A mediados de 2002 se crea el Departamento PyME en la Bolsa de Comercio de Buenos Aires con el objetivo de informar a las PyMEs sobre los instrumentos disponibles, los elementos y las características necesarias para ingresar al sistema bursátil. De esta manera, las PyMEs cuentan con un sector especializado y con un régimen simplificado para operar.

En diciembre de 2003 surge la negociación de cheques de pago diferido que, sumados a los fideicomisos financieros y las ON PyMEs, permitieron a más de 8300 PyMEs financiar sus proyectos en la bolsa, por más de 4.900 millones de pesos.

Además de las ventajas particulares que ofrece cada uno de los instrumentos de financiación disponibles para las PyMEs, y sumado a los beneficios fundamentales de financiarse a través del mercado de capitales, las PyMEs encuentran motivos específicos para recurrir a la Bolsa:

- El Departamento PyMEs de la BCBA las atiende en forma directa sin cargo alguno,

- Acceso a los agentes de bolsa interesados en la atención de PyMEs,

- En la Bolsa no existen productos "enlatados", los instrumentos se arman a la medida financiera de la PyME;

- Transparencia: la PyME conoce la tasa que percibe el inversor, los costos del agente de bolsa y de esta manera puede deducir fácilmente su tasa final o tasa activa.

\subsubsection{Instrumentos Financieros para PyMEs}

\subsubsection{Cheques de Pago Diferido}

El sistema de descuento de cheques de pago diferido en el mercado de capitales permite (por un plazo máximo de 360 días) adelantar su cobro vendiéndolos en la Bolsa.

Los cheques de pago diferido cuentan con dos sistemas de negociación:

- En el sistema patrocinado, una empresa (grande o pyme) es autorizada por la BCBA para emitir cheques de pago diferido para el pago a proveedores, que pueden ser negociados en el mercado de capitales.

- En el sistema avalado, las pymes pueden negociar cheques propios o de terceros (clientes), a través de una sociedad de garantía recíproca (SGR). La SGR autorizada por la Bolsa puede cotizar cheques que tengan como beneficiarios a sus socios pymes y garantizar el pago mediante un aval.

\footnotetext{
${ }^{23}$ Lerner, Carlos. Jefe del Departamento PyME de la Bolsa de Comercio de Buenos Aires.

${ }^{24}$ Entrevista UBA, 2010.
} 


\section{Sistema Patrocinado}

Una empresa pueden solicitar a la BCBA la autorización de cotización de cheques de pago diferido propios (llamados cheques patrocinados), una vez autorizada, los envía a la Caja de Valores S.A., donde debe presentarse el beneficiario de los documentos (proveedor) a fin de endosarlos a favor de ésta (según lo dispone el decreto 386/2003), para su posterior negociación en el mercado.

Un agente o sociedad de bolsa depositará los fondos resultantes de la negociación realizada por oferta pública, en una cuenta comitente a nombre del beneficiario para su disposición.

De esta manera, los beneficiarios de los cheques (proveedores de bienes y/o servicios) pueden hacerlos líquidos en el mercado sin que recaiga ningún tipo de calificación sobre ellos.

La operatoria concluye con el vencimiento del plazo del cheque, momento en que el emisor debe tener fondos suficientes depositados a su orden en cuenta corriente o autorización para girar en descubierto, y así cumplir con el pago del documento que tendrá como beneficiario al inversor.

La responsabilidad tanto del emisor como del beneficiario es la enunciada en la Ley de Cheques; o sea, rige la cadena de endosos, excluyendo el de la Caja de Valores S.A.

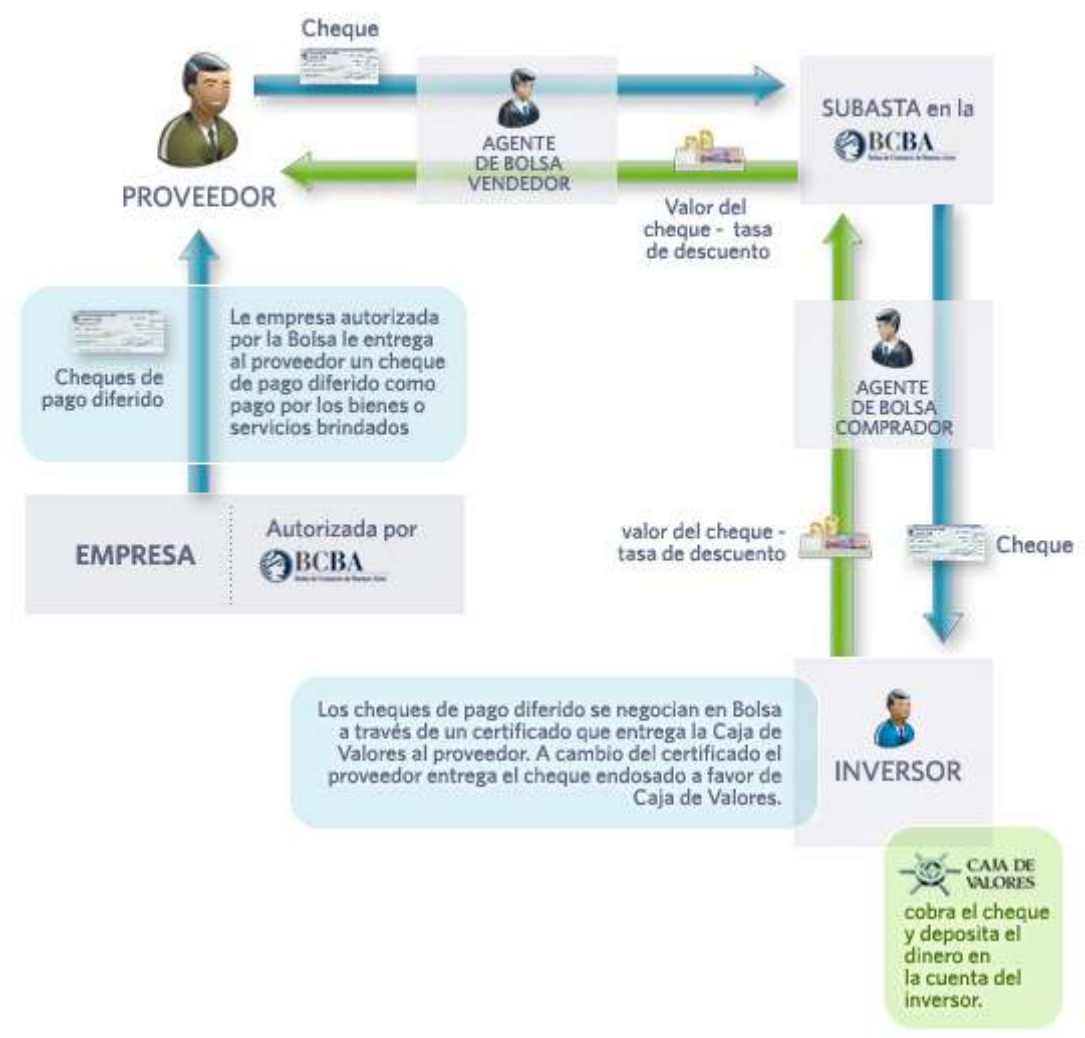

Fuente: Bolsa de Comercio de Buenos Aires. 
Los cheques de pago diferido patrocinados son una excelente herramienta de financiación de capital de trabajo y permiten:

- generar mejores condiciones y plazos de pago, liberando así otras líneas de crédito;

- ofrecer a los beneficiarios liquidar los documentos al menor costo y con la mayor agilidad;

- brindar asistencia a pymes proveedoras, ayudando así a promover la empresa y fidelizar proveedores;

- y acceder al prestigio y reconocimiento de cotizar en Bolsa.

\section{Sistema Avalado}

El sistema avalado es exclusivo para pymes. Para negociar cheques de sus clientes o propios, las pymes deben incorporarse como socio partícipe a una SGR autorizada a cotizar cheques en la BCBA, ya que la SGR puede negociar cheques que tengan como beneficiarios a sus socios pymes, y así poder garantizar el pago mediante un aval.

Las pymes entregan los cheques (propios o de terceros) a la SGR para que ésta los avale y envíe a la Bolsa para su posterior negociación. De esta manera, ante cualquier dificultad de cobro del cheque, la SGR se transforma en principal pagador abonando el monto comprometido.

Un agente o sociedad de bolsa deposita los fondos resultantes de la negociación realizada por oferta pública, en una cuenta comitente a nombre del beneficiario para su disposición.

Al vencimiento del plazo del cheque, el emisor debe tener fondos suficientes depositados a su orden en cuenta corriente o autorización para girar en descubierto y así cumplir con el pago del documento que tendrá como beneficiario al inversor.

Los cheques de pago diferido avalados constituyen una nueva alternativa de financiación que permite:

- negociar cheques propios y recibir cheques endosables,

- acceder a tasas similares a las obtenidas por grandes empresas por contar con el aval de una SGR,

- mantener al librador y a la pyme beneficiada en el anonimato, ya que la que cotiza en Bolsa es la SGR,

- equiparar tasa y comisión con todos los clientes de la pyme y

- acercar a la empresa al mercado de capitales. 
Figura 8

Cheques de Pago Diferido Avalado

\section{Cheques de pago diferido avalado}

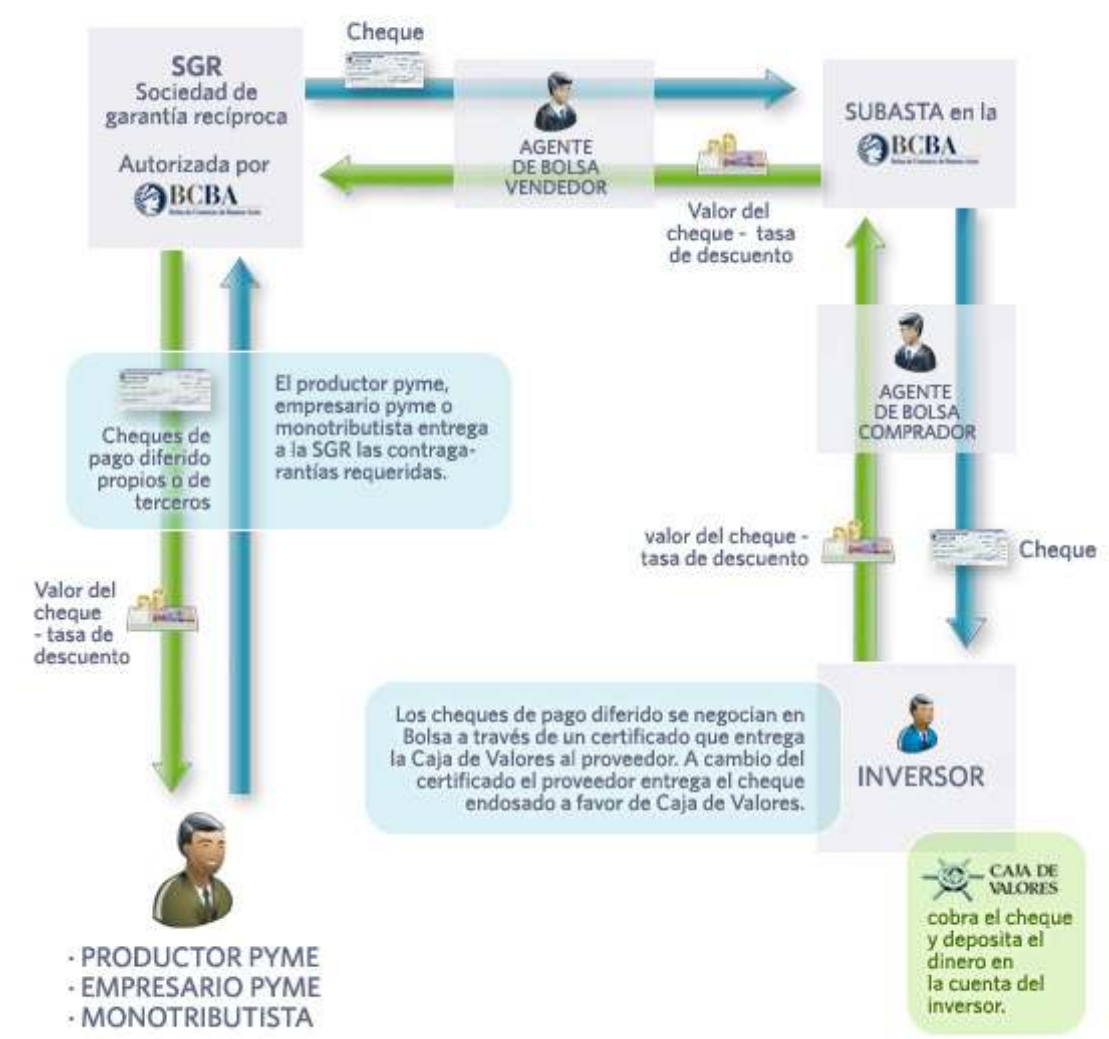

Fuente: Bolsa de Comercio de Buenos Aires.

Cuadro 21

Montos Negociados en Cheques de Pago Diferido Septiembre 2009 a Septiembre 2010.

\begin{tabular}{|c|c|c|c|c|c|c|}
\hline & \multicolumn{2}{|c|}{ Avalado } & \multicolumn{2}{|c|}{ Patrocinado } & \multicolumn{2}{|c|}{ Total } \\
\hline Período & Montos & $\begin{array}{c}\text { Cantidad } \\
\text { de Cheques }\end{array}$ & Montos & $\begin{array}{c}\text { Cantidad } \\
\text { de Cheques }\end{array}$ & Montos & $\begin{array}{c}\text { Cantidad } \\
\text { de Cheques }\end{array}$ \\
\hline Sep-09 & 83.281 .500 & 3.037 & 2.400 .818 & 51 & 85.682 .318 & 3.088 \\
\hline Oct-09 & 73.011 .814 & 2.855 & 3.835 .871 & 66 & 76.847 .685 & 2.921 \\
\hline Nov-09 & 75.375 .827 & 3.011 & 4.684 .000 & 68 & 80.059 .827 & 3.079 \\
\hline Dic-09 & 84.440 .896 & 3.043 & 3.482 .879 & 39 & 87.923 .775 & 3.082 \\
\hline Ene-10 & 77.266 .182 & 2.926 & 2.634 .674 & 63 & 79.900 .856 & 2.989 \\
\hline Feb-10 & 71.328 .530 & 2.487 & 2.622 .422 & 45 & 73.950 .952 & 2.532 \\
\hline Mar-10 & 85.982 .063 & 3.384 & 5.062 .942 & 87 & 91.045 .005 & 3.471 \\
\hline Abr-10 & 69.752 .851 & 3.005 & 2.422 .019 & 55 & 72.174 .870 & 3.060 \\
\hline May-10 & 75.956 .147 & 3.378 & 1.917 .886 & 52 & 77.874 .033 & 3.430 \\
\hline Jun-10 & 91.255 .864 & 3.955 & 2.473 .150 & 64 & 93.729 .014 & 4.019 \\
\hline Jul-10 & 102.685 .224 & 3.619 & 3.386 .555 & 39 & 106.071.779 & 3.658 \\
\hline Ago-10 & 102.068 .027 & 3.909 & 7.026 .553 & 90 & 109.094 .580 & 3.999 \\
\hline Sep-10 & 102.405 .553 & 4.277 & 9.441 .617 & 94 & 111.847 .170 & 4.371 \\
\hline
\end{tabular}

Fuente: Bolsa de Comercio de Buenos Aires. 
Gráfico 14

Montos Negociados en Cheques de Pago Diferido Septiembre 2009 a Septiembre 2010.

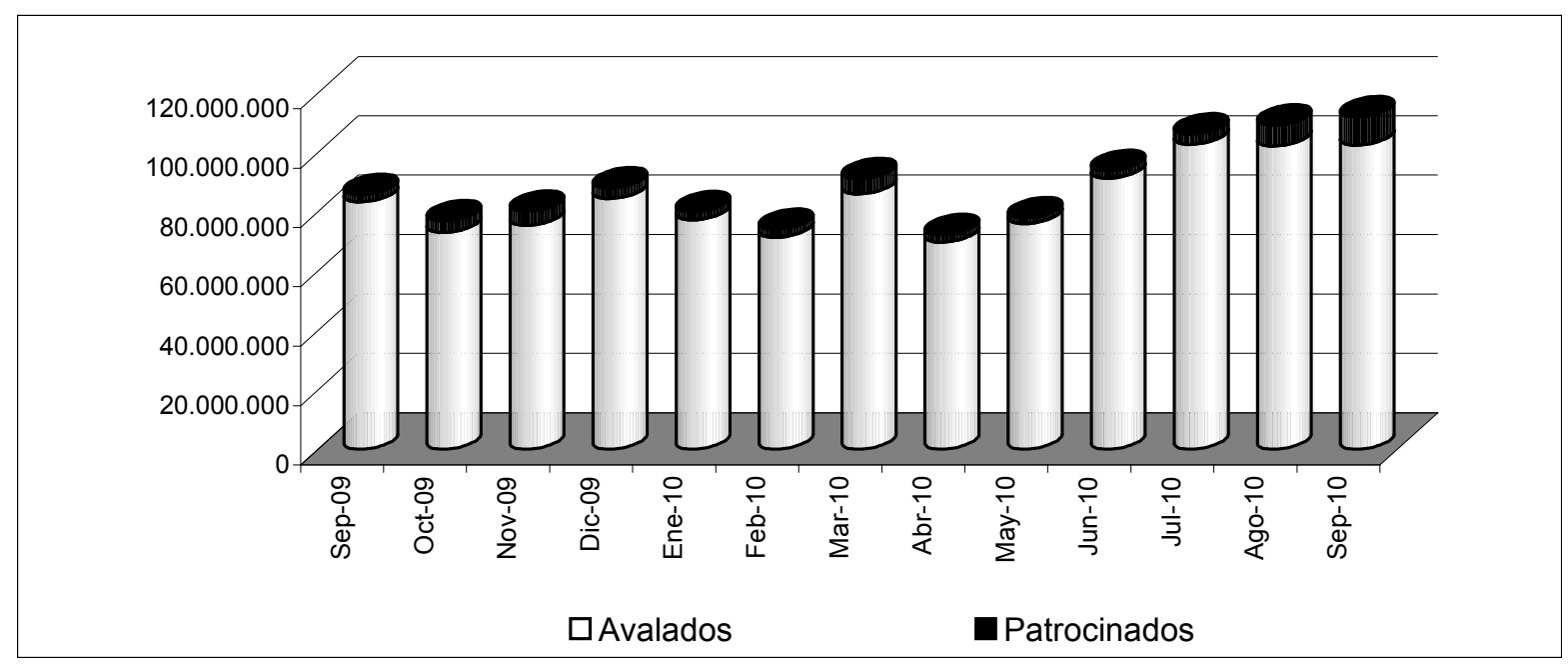

Fuente: Bolsa de Comercio de Buenos Aires.

En septiembre de 2010 se negociaron 4.371 cheques de pago diferido (casi un $42 \%$ mayor que septiembre de 2009 y un $9 \%$ más con relación al mes anterior) alcanzando un monto, en ambas modalidades, de $\$ 112$ millones (un 31\% más que el mismo mes del año anterior y un $3 \%$ mayor que el mes anterior).

Tasas Ponderadas de Cheques de Pago Diferido Septiembre 2009 a Septiembre 2010.

\begin{tabular}{|c|c|c|c|c|c|c|c|c|c|}
\hline \multicolumn{7}{|l|}{ Avalados } & \multicolumn{3}{|l|}{ Patrocinados } \\
\hline Días de plazo & 31 a 60 & 61 a 90 & 91 a 120 & 151 a 180 & 241 a 270 & 331 a 360 & Días de plazo & 31 a 60 & 91 a 120 \\
\hline Sep-09 & 12.68 & 13.38 & 14.03 & 15.82 & 17.34 & 18.52 & Sep-09 & 17.81 & 22.96 \\
\hline Oct-09 & 12.32 & 13.61 & 14.60 & 15.89 & 17.04 & 19.35 & Oct-09 & 19.65 & 28.07 \\
\hline Nov-09 & 12.28 & 13.36 & 14.64 & 15.83 & 17.02 & 20.14 & Nov-09 & 17.04 & 20.29 \\
\hline Dic-09 & 11.64 & 13.00 & 13.97 & 15.44 & 17.14 & 19.00 & Dic-09 & 14.81 & 20.07 \\
\hline Ene-10 & 11.15 & 12.07 & 12.88 & 14.12 & 15.79 & 17.65 & Ene-10 & 11.73 & 19.72 \\
\hline Feb-10 & 10.67 & 11.85 & 12.64 & 14.10 & 16.94 & 19.53 & Feb-10 & 10.50 & 19.67 \\
\hline Mar-10 & 11.17 & 12.38 & 13.37 & 15.18 & 16.83 & 18.67 & Mar-10 & 12.02 & 21.68 \\
\hline Abr-10 & 10.47 & 12.07 & 12.97 & 14.21 & 15.80 & 17.95 & Abr-10 & 11.48 & 20.24 \\
\hline May-10 & 11.15 & 12.43 & 13.04 & 13.88 & 15.29 & 17.03 & May-10 & 13.80 & 18.47 \\
\hline Jun-10 & 10.69 & 11.63 & 12.16 & 13.14 & 14.00 & 14.88 & Jun-10 & 16.05 & 18.21 \\
\hline Jul-10 & 10.16 & 11.50 & 12.15 & 12.54 & 14.52 & 14.21 & Jul-10 & 11.92 & 19.25 \\
\hline Ago-10 & 10.17 & 11.38 & 12.21 & 12.72 & 13.10 & 14.21 & Ago-10 & 11.83 & 17.74 \\
\hline Sep-10 & 10.29 & 11.57 & 12.18 & 12.67 & 12.63 & 13.33 & Sep-10 & 12.28 & 17.88 \\
\hline
\end{tabular}

Fuente: Bolsa de Comercio de Buenos Aires.

La tasa promedio para ambos sistemas fue del $11,75 \%$, mientras que las tasas promedio ponderadas del sistema avalado y del patrocinado fueron del $11,70 \%$ y $15,26 \%$ respectivamente. 
Gráfico 15

Tasas Ponderadas de Cheques de Pago Diferido Avalado Septiembre 2010.

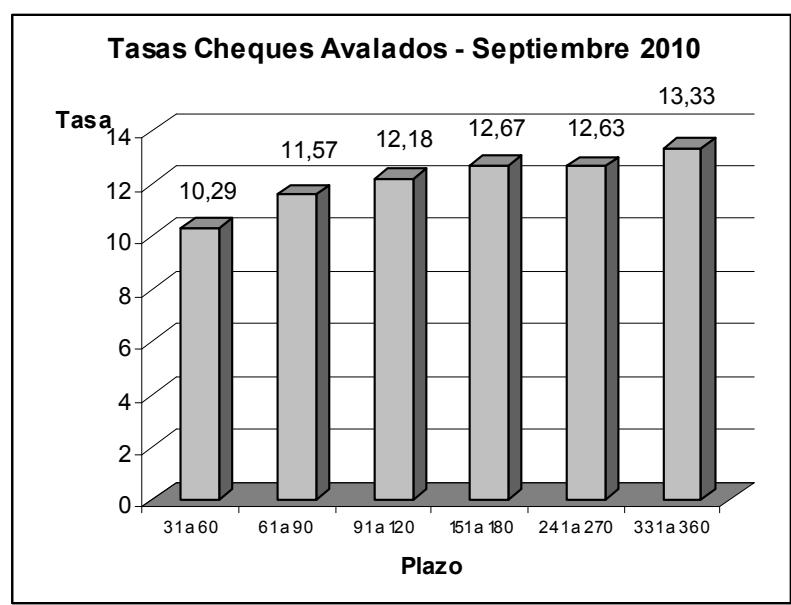

Al realizarse una comparación interanual se puede observar un descenso en las tasas ponderadas para todos los plazos en ambos sistemas.

Gráfico 16

Cheques de Pago Diferido Avalado: Montos Negociados por Plazo Semana del 25/10/2010 al 29/10/2010.

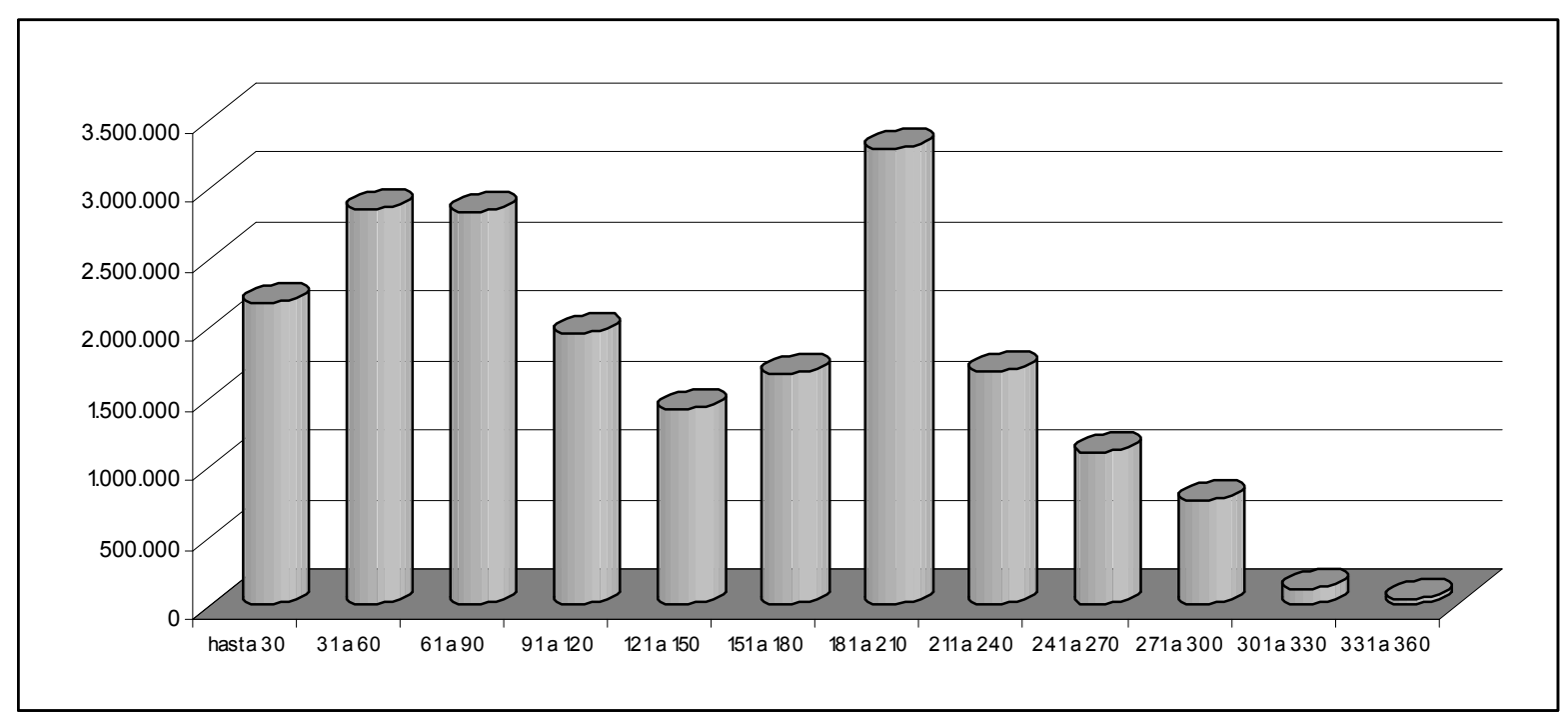

Fuente: Bolsa de Comercio de Buenos Aires.

\subsubsection{Obligaciones Negociables}

Las obligaciones negociables son bonos privados que representan valores de deuda de la sociedad anónima y/o cooperativa que las emite y pueden ser colocadas entre el público inversor calificado mediante su cotización y negociación en la Bolsa.

Las pequeñas y medianas empresas pueden emitir estos valores bajo un régimen simplificado de oferta pública y cotización, creado a efectos de que estas empresas accedan al financiamiento necesario para el desarrollo de sus actividades y proyectos, ya sea para la 
realización de inversiones o el refinanciamiento de deudas. Muchas empresas recurren a estos bonos para ampliar capital, mejorar tecnología o implementar proyectos de investigación.

El monto máximo de una emisión de ON Pyme no puede superar los quince millones de pesos (\$15.000.000.-) por empresa ni el plazo de 5 años. Las emisoras pueden solicitar la autorización de cotización para una emisión a colocar en series sucesivas dentro del plazo máximo de dos años de otorgada aquélla.

El emisor se obliga a realizar los pagos de servicios de interés y de amortización de capital y a cumplir con todas las condiciones estipuladas en el prospecto de emisión del instrumento.

Es de destacar que el Consejo de la BCBA resolvió en junio de 2007, bonificar los aranceles que correspondan por derechos de cotización de obligaciones negociables emitidas en el marco del sistema FONAPYME (Resoluciones de Consejo Nro. 3 y 4/2007).

La emisión de ON Pyme para el financiamiento de pequeñas y medianas empresas cuenta con una serie de ventajas:

- la presentación de información contable básica, una vez autorizada la cotización,

- menor costo financiero total respecto de otras alternativas disponibles,

- acceso a una gran cartera de inversores,

- la disponibilidad de un canal de financiación, incluso en momentos difíciles de la economía,

- un sistema de financiación transparente en el que se conoce claramente los componentes esenciales; por ejemplo, la tasa final de una emisión de deuda,

- la posibilidad de estructurar la emisión en función del flujo de fondos y demás necesidades de la empresa,

- el acceso a nuevos clientes, proveedores y otras fuentes de financiación, como los bancos, que trae como consecuencia la exposición que adquiere la empresa al cotizar en Bolsa.

Cuadro 23

Emisiones de Obligaciones Negociables PyME $2009-2010$.

\begin{tabular}{|c|c|c|c|c|c|c|}
\hline Denominación & Sector & $\begin{array}{l}\text { Fecha de } \\
\text { Colocación }\end{array}$ & Moneda & $\begin{array}{l}\text { Monto } \\
\text { Colocado }\end{array}$ & Vencimiento & Garantía \\
\hline Umbro - Serie II & Comercial & $27 / 01 / 2009$ & $\$$ & 1.000 .000 & $10 / 01 / 2011$ & SGR \\
\hline Ovoprot International - Serie II & Alimentos & $14 / 05 / 2009$ & US\$ & 1.800 .000 & $15 / 05 / 2012$ & \\
\hline Álvarez Hermanos S.A. - 2 P - Serie IV & Alimentos & $14 / 09 / 2009$ & US\$ & 300.000 & $11 / 09 / 2011$ & SGR \\
\hline Pop Argentina S.A. - Serie I & Alimentos & $04 / 05 / 2010$ & US\$ & 925.000 & 07/05/2012 & \\
\hline Total 2009 Emitido & $\$ 8.840 .500$ & US\$2.391.206 & & & & \\
\hline Total 2010 Emitido & $\$ 3.581 .600$ & US\$ 925.000 & & & & \\
\hline
\end{tabular}

Fuente: Bolsa de Comercio de Buenos Aires. 


\subsubsection{Fideicomisos Financieros}

Se trata de una herramienta financiera mediante la cual las pymes, en forma individual o conjunta, pueden obtener fondos, separando determinados activos (reales o financieros) de su patrimonio y cediéndolos a un administrador en propiedad fiduciaria. El administrador interviene para que los activos cedidos sean transformados en activos financieros líquidos y se puedan negociar en el mercado bursátil.

Es así como los bienes fideicomitidos quedan exentos de la acción de acreedores, el inversor no se perjudica ante eventuales inconvenientes y la pyme y su balance quedan fuera del instrumento. De esta manera, aún teniendo dificultades, una empresa con buenos negocios proyectados puede ingresar al sistema.

El hecho de que los bienes fideicomitidos queden separados del riesgo comercial de la empresa, hace que ésta pueda acceder a mejores calificaciones de riesgo y emitir títulos valores garantizando su pago con el flujo de fondos generado por esos activos específicos. La mejor calificación de riesgo y las mejores garantías implican un menor costo de financiamiento para la emisora. Además, los costos para grupos de empresas son menores a los de una emisión individual.

El fideicomiso financiero permite que los derechos de los beneficiarios se encuentren representados por dos tipos de valores fiduciarios:

- Los certificados de participación; que son emitidos por el fiduciario, y

- Los títulos representativos de deuda, que pueden ser emitidos por el fiduciante, el fiduciario o un tercero.

Es importante advertir que las condiciones de emisión de los fideicomisos financieros para pymes (tasas y plazos) los convierten en una alternativa de inversión muy atractiva para adquirir y mantener hasta su vencimiento, pero no puede asegurarse la existencia de un mercado secundario para estos instrumentos, ni su liquidez en un mercado secundario, si existiere.

La reglamentación que rige a los fideicomisos financieros se encuentra en la Ley 24.441 y normas de la CNV.

El financiamiento a través de los fideicomisos financieros permite:

- transformar activos ilíquidos en activos financieros líquidos,

- que los bienes cedidos queden exentos de la acción de los acreedores,

- que la empresa y su balance sean independientes del instrumento.

- que la evaluación crediticia se realice sobre el negocio y no sobre la empresa,

- que en la medida que tengan buenos negocios proyectados, las empresas con dificultades financieras puedan acceder igualmente al financiamiento,

- distribuir los costos fijos cuando se trata de una emisión de un grupo de empresas. 


\begin{tabular}{|c|c|c|c|c|c|c|c|c|c|}
\hline Denominación & Sector & $\begin{array}{l}\text { Fecha de } \\
\text { colocación }\end{array}$ & Moneda & $\begin{array}{l}\text { Monto } \\
\text { Colocado }\end{array}$ & Vto & Garantía & \begin{tabular}{|c|} 
Cant. de \\
empresas
\end{tabular} & $\begin{array}{l}\text { Destino de } \\
\text { los fondos }\end{array}$ & Provincias \\
\hline Agro Alianza I & Agropecuario & ene-09 & u\$s & 2.325 .000 & sep-09 & SGR & 24 & $\begin{array}{l}\text { Soja, maíz y } \\
\text { girasol. }\end{array}$ & $\begin{array}{l}\text { Buenos Aires, Córdoba, } \\
\text { Santa Fe y Entre Ríos. }\end{array}$ \\
\hline Agro Finance IV & Agropecuario & feb-09 & $\mathrm{u} \$ \mathrm{~s}$ & 5.532 .112 & ago-09 & SGR & 22 & $\begin{array}{l}\text { Insumos y } \\
\text { productos } \\
\text { agroquímicos }\end{array}$ & $\begin{array}{l}\text { Buenos Aires, Tucumán, La } \\
\text { Pampa y Santa Fe. }\end{array}$ \\
\hline La Agropecuaria I & Agropecuario & feb-09 & u\$s & 1.500 .000 & ago-09 & & 2 & $\begin{array}{l}\text { Soja, trigo, } \\
\text { cebada, } \\
\text { colza, maiz, } \\
\text { girasol, sorgo } \\
\text { y soja de } \\
\text { segunda. }\end{array}$ & Buenos Aires. \\
\hline Aval Rural X & $\begin{array}{l}\text { Agropecuario } \\
\ldots\end{array}$ & ago-09 & u\$s & 8.075 .000 & ago-10 & SGR & 38 & $\begin{array}{l}\text { Maíz, trigo, } \\
\text { girasol y } \\
\text { soja. }\end{array}$ & $\begin{array}{l}\text { Buenos Aires, Córdoba, } \\
\text { Entre Rios, Salta, y Santa } \\
\text { Fe. }\end{array}$ \\
\hline Puente PyMEs I & Sector Mixto & sep-09 & $\mathrm{u} \$ \mathrm{~s}$ & 1.851 .274 & sep-12 & SGR & 8 & Varios. & $\begin{array}{l}\text { Buenos Aires, Catamarca, } \\
\text { Mendoza, Misiones y Salta. }\end{array}$ \\
\hline Don Mario VI & Agropecuario & sep-09 & $u \$ s$ & 4.448 .941 & jun-10 & SGR & 27 & Semillas. & $\begin{array}{l}\text { Buenos Aires, Córdoba y } \\
\text { Santa Fe. }\end{array}$ \\
\hline Aval Rural XI & Agropecuario & sep-09 & u\$s & 8.337 .000 & ago-10 & SGR & 51 & $\begin{array}{l}\text { Maíz, trigo, } \\
\text { girasol y } \\
\text { soja. }\end{array}$ & $\begin{array}{l}\text { Buenos Aires, Córdoba, } \\
\text { Entre Ríos, La Pampa, } \\
\text { Salta y Santa Fe. }\end{array}$ \\
\hline Agro Aval VIII & Agropecuario & oct-09 & u\$s & 5.509 .400 & jun-10 & SGR & 66 & Soja. & $\begin{array}{l}\text { Buenos Aires, Córdoba, } \\
\text { Salta, Chaco, Santa Fe, } \\
\text { Tucumán, Jujuy y La } \\
\text { Pampa. }\end{array}$ \\
\hline MultiPyME IX & Agropecuario & oct-09 & u\$s & 2.035 .000 & ago-10 & SGR & 13 & $\begin{array}{l}\text { Soja, maíz y } \\
\text { girasol. }\end{array}$ & $\begin{array}{l}\text { Entre Ríos, Santa Fe, Salta, } \\
\text { Córdoba y Buenos Aires. }\end{array}$ \\
\hline Agro Aval IX & Agropecuario & nov-09 & u\$s & 6.326 .000 & jun-10 & SGR & 97 & Soja. & $\begin{array}{l}\text { Buenos Aires, Córdoba, } \\
\text { Salta, Chaco, Santa Fe, } \\
\text { Tucumán y La Pampa. }\end{array}$ \\
\hline Don Mario VII & Agropecuario & nov-09 & u\$s & 3.706 .781 & jul-10 & SGR & 41 & Semillas. & $\begin{array}{l}\text { Buenos Aires, Córdoba, } \\
\text { Santa Fe, Buenos Aires y } \\
\text { Chaco. }\end{array}$ \\
\hline Agro Alianza II & Agropecuario & nov-09 & u\$s & 2.460 .000 & jul-10 & SGR & 35 & Maíz y soja. & $\begin{array}{l}\text { Buenos Aires, Córdoba, } \\
\text { Santa Fe, Buenos Aires y } \\
\text { Chaco. }\end{array}$ \\
\hline Agro Aval X & Agropecuario & dic-09 & u\$s & 5.686 .500 & jul-10 & SGR & 65 & Soja. & $\begin{array}{l}\text { Buenos Aires, Córdoba, } \\
\text { Salta, Chaco, Santa Fe, } \\
\text { Tucumán y CABA. }\end{array}$ \\
\hline SecuPyME XXXIV & Agropecuario & dic-09 & $u \$ s$ & 1.225 .000 & ago-10 & SGR & 9 & Soja. & $\begin{array}{l}\text { Buenos Aires, Entre Ríos, } \\
\text { Santa Fe, Salta y Córdoba. }\end{array}$ \\
\hline $\begin{array}{l}\text { Agro Aval XI } \\
\text { Granar III }\end{array}$ & $\begin{array}{l}\text { Agropecuario } \\
\text { - - - - - - - } \\
\text { Agropecuario } \\
\end{array}$ & 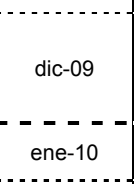 & $\begin{array}{l}\mathrm{u} \$ \mathrm{~s} \\
\mathrm{u}-\overline{\mathrm{s}}\end{array}$ & $\begin{array}{c}7.583 .100 \\
-\mathbf{-}-\mathbf{-}-\mathbf{-} \\
2.760 .000\end{array}$ & $\begin{array}{l}a b r-10 \\
\text { nov-10 } \\
---\end{array}$ & $\begin{array}{c}\text { SGR } \\
-\mathbf{-}-\mathbf{-} \\
\text { SGR }\end{array}$ & $\begin{array}{c}99 \\
-\mathbf{-}--\end{array}$ & $\begin{array}{l}\text { Maíz, trigo, } \\
\text { girasol y } \\
\text { soja. } \\
\text { Soja. - - - - }\end{array}$ & $\begin{array}{l}\text { Buenos Aires, Córdoba, } \\
\text { Salta, Santa Fe, Catamarca, } \\
\text { Corrientes La Pampa y } \\
\text { CABA. } \\
\text { Córdoba, Santa Fe, Buenos } \\
\text { Aires, La Pampa y CABA. }\end{array}$ \\
\hline MultiPyME X & Agropecuario & ene-10 & u\$s & 1.955 .000 & ago-10 & SGR & 20 & $\begin{array}{l}\text { Soja, maíz y } \\
\text { girasol. }\end{array}$ & $\begin{array}{l}\text { Entre Rios, Santa Fe, Salta, } \\
\text { Córdoba, Corrientes, } \\
\text { Formosa, Santiago del } \\
\text { Estero y Buenos Aires }\end{array}$ \\
\hline Cofina I & Agropecuario & ene-10 & $u \$ s$ & 1.125 .000 & dic-10 & SGR & 10 & Soja. & $\begin{array}{l}\text { Buenos Aires, Córdoba y } \\
\text { CABA. }\end{array}$ \\
\hline Aval Rural XII & Agropecuario & jul-10 & u\$s & 7.446 .000 & jul-11 & SGR & 31 & $\begin{array}{l}\text { Maíz, trigo, } \\
\text { girasol y } \\
\text { soja. }\end{array}$ & $\begin{array}{l}\text { Buenos Aires, Córdoba, } \\
\text { Entre Ríos, La Pampa y } \\
\text { Santa Fe. }\end{array}$ \\
\hline Aval Rural XIII & Agropecuario & ago-10 & $u \$ s$ & 4.910 .000 & Ago-11 & SGR & 19 & $\begin{array}{l}\text { Maíz, trigo, } \\
\text { girasol y } \\
\text { soja. }\end{array}$ & $\begin{array}{l}\text { Buenos Aires, Córdoba, } \\
\text { Entre Ríos y Santa Fe. }\end{array}$ \\
\hline MultiPyME XI & Agropecuario & sep-10 & $u \$ s$ & 2.200 .000 & jul-11 & SGR & 13 & $\begin{array}{l}\text { Maíz, girasol } \\
\text { y soja. }\end{array}$ & $\begin{array}{l}\text { Salta, Buenos Aires, } \\
\text { Córdoba, Entre Ríos, } \\
\text { Santiago del Estero, } \\
\text { Corrientes y Santa Fe. }\end{array}$ \\
\hline Aval Rural XIV & Agropecuario & sep-10 & u\$s & 4.480 .000 & ago-11 & SGR & 23 & $\begin{array}{l}\text { Maíz, trigo, } \\
\text { girasol y } \\
\text { soja. }\end{array}$ & $\begin{array}{l}\text { Buenos Aires, CABA, } \\
\text { Córdoba, Entre Ríos y } \\
\text { Santa Fe. }\end{array}$ \\
\hline $\begin{array}{l}\text { Cantidad de } \\
\text { emisiones }\end{array}$ & 7 & $\begin{array}{l}\text { Cantidad } \\
\text { de PyMEs }\end{array}$ & 127 & $\begin{array}{c}\text { Total } \\
\text { emitido en } \\
\$\end{array}$ & $\begin{array}{l}97.299 .1 \\
12\end{array}$ & & & $\begin{array}{l}\text { Total } \\
\text { emitido en } \\
\text { U\$S }\end{array}$ & 24.876.000 \\
\hline
\end{tabular}

Fuente: Bolsa de Comercio de Buenos Aires. 
Emisiones de Fideicomisos Financieros PyME - Individuales $2009-2010$.

\begin{tabular}{|c|c|c|c|c|c|c|}
\hline Denominación & Sector & $\begin{array}{l}\text { Fecha de } \\
\text { colocación }\end{array}$ & & $\begin{array}{c}\text { Monto } \\
\text { Colocado }\end{array}$ & Vto. & Garantía \\
\hline Rizzibono V & Comercial & ene-09 & $\$$ & 6.773 .908 & nov-10 & - \\
\hline Otero IX & Comercial & ene-09 & $\$$ & 18.664 .685 & nov-11 & - \\
\hline Meroli XIII & Comercial & feb-09 & $\$$ & 7.546 .764 & sep-11 & - \\
\hline Bonesi XXII & Comercial & feb-09 & $\$$ & 18.721 .654 & jul-11 & - \\
\hline Stoller II & $\begin{array}{l}\text { Industrial y } \\
\text { Comercial }\end{array}$ & abr-09 & US\$ & 2.112 .963 & oct-09 & - \\
\hline Rizzibono VI & Comercial & jun-09 & $\$$ & 3.898 .922 & jul-10 & - \\
\hline Meroli XIV & Comercial & ago-09 & $\$$ & 7.673 .070 & abr-12 & - \\
\hline Cerrito I & Consumo & ago-09 & $\$$ & 8.386 .482 & $a b r-12$ & - \\
\hline Rizzibono VII & Comercial & nov-09 & $\$$ & 3.706 .443 & $a b r-11$ & - \\
\hline Cerrito II & Consumo & feb-10 & $\$$ & 6.695 .675 & abr-13 & - \\
\hline Rizzibono VIII & Consumo & mar-10 & $\$$ & 5.944 .938 & ago-11 & - \\
\hline Euroamericana II & Comercial & mar-10 & $\$$ & 4.960 .468 & ago-13 & - \\
\hline Nutrientes I & Agropecuario & $a b r-10$ & US\$ & 1.965 .846 & jul-10 & SGR \\
\hline Crédito Solidario I & Consumo & may-10 & $\$$ & 9.674 .410 & may-15 & - \\
\hline Rizzibono IX & Consumo & sep-10 & $\$$ & 5.784 .801 & Jul-12 & \\
\hline
\end{tabular}

Cantidad de emisiones
Total emitido en \$

40.672.048
Total emitido en US\$

10.456.296

Fuente: Bolsa de Comercio de Buenos Aires.

\subsubsection{Acciones}

En la Bolsa, las pymes cuentan con un régimen simplificado de oferta pública y cotización, creado a efectos de que estas empresas accedan al financiamiento necesario para el desarrollo de sus actividades y proyectos.

De esta manera, pueden abrir su capital incorporando nuevos socios a través del aumento del capital social, con la emisión de nuevas acciones. Es importante aclarar que las acciones pymes sólo pueden ser adquiridas por inversores calificados, según lo regulan las normas de la CNV (ver Resolución General 506/2007).

Las acciones lanzadas a la oferta pública son negociables en el mercado de capitales una vez realizada la colocación en el mercado primario. Luego, el precio de la acción estará determinado por la interacción de oferta y demanda entre los inversores en el mercado secundario, quienes podrán desprenderse de su participación cuando así lo deseen sin afectar el capital social de la empresa.

Pueden emitir acciones pymes, aquellas pequeñas y medianas empresas que califiquen dentro de la disposición 147/2006 de la Subsecretaría de la Pequeña y Mediana Empresa y Desarrollo Regional (Sepyme) o de la resolución general 506/2007 de la Comisión Nacional 
de Valores (CNV), y que a su vez cumplan con los requisitos del régimen acciones pyme de la BCBA.

Es de destacar que el Consejo de la BCBA resolvió en mayo de 2007, bonificar los aranceles que correspondan por derechos de estudio y de cotización de acciones emitidas por pequeñas y medianas empresas (Resoluciones de Consejo Nro. 2 y 4/2007).

Además de las ventajas generales para toda sociedad que cotiza en Bolsa, la emisión de acciones Pyme como canal de financiamiento:

- es conveniente para aquellas empresas que no desean asumir deuda y prefieren incorporar socios,

- permite a la pyme encarar negocios que sin la incorporación de socios-inversores no podría y

- aporta una valoración objetiva de la empresa y facilita la resolución de situaciones familiares.

\subsection{El Capital Riesgo en Argentina}

En el financiamiento de nuevos emprendimientos en el Mercado Argentino, se pueden destacar algunos aspectos salientes:

En cuanto al financiamiento con capital propio:

- Ahorro es la fuente más popular

- Financiamiento de Ángeles es menos frecuente

- Financiamiento de Fondos de Capital Riesgo es menos frecuente aún

- Oferta Pública Inicial (IPO), es casi una utopía

En lo que respecta al financiamiento con deuda:

- Los Bancos suelen prestar dinero a quienes tienen dinero, es decir a aquellos con capacidad de repago en tiempo y forma. En las etapas iniciales generalmente le prestan a los dueños y no al emprendimiento.

- Las tasas de interés son más grandes que las de las grandes empresas, por el riesgo a lo nuevo o desconocido.

La opción de IPO es casi una utopía, porque:

- El mercado de valores es pequeño en capitalización, y con etapas involutivas.

- La importancia del mercado de valores en insignificante en la economía del país

- Pocas firmas, con mercados altamente concentrados

- El costo de un IPO es elevado

- El mercado de valores suele ser más caro para transaccionar 
TIR Requeridas en el Financiamiento con Capital Riesgo

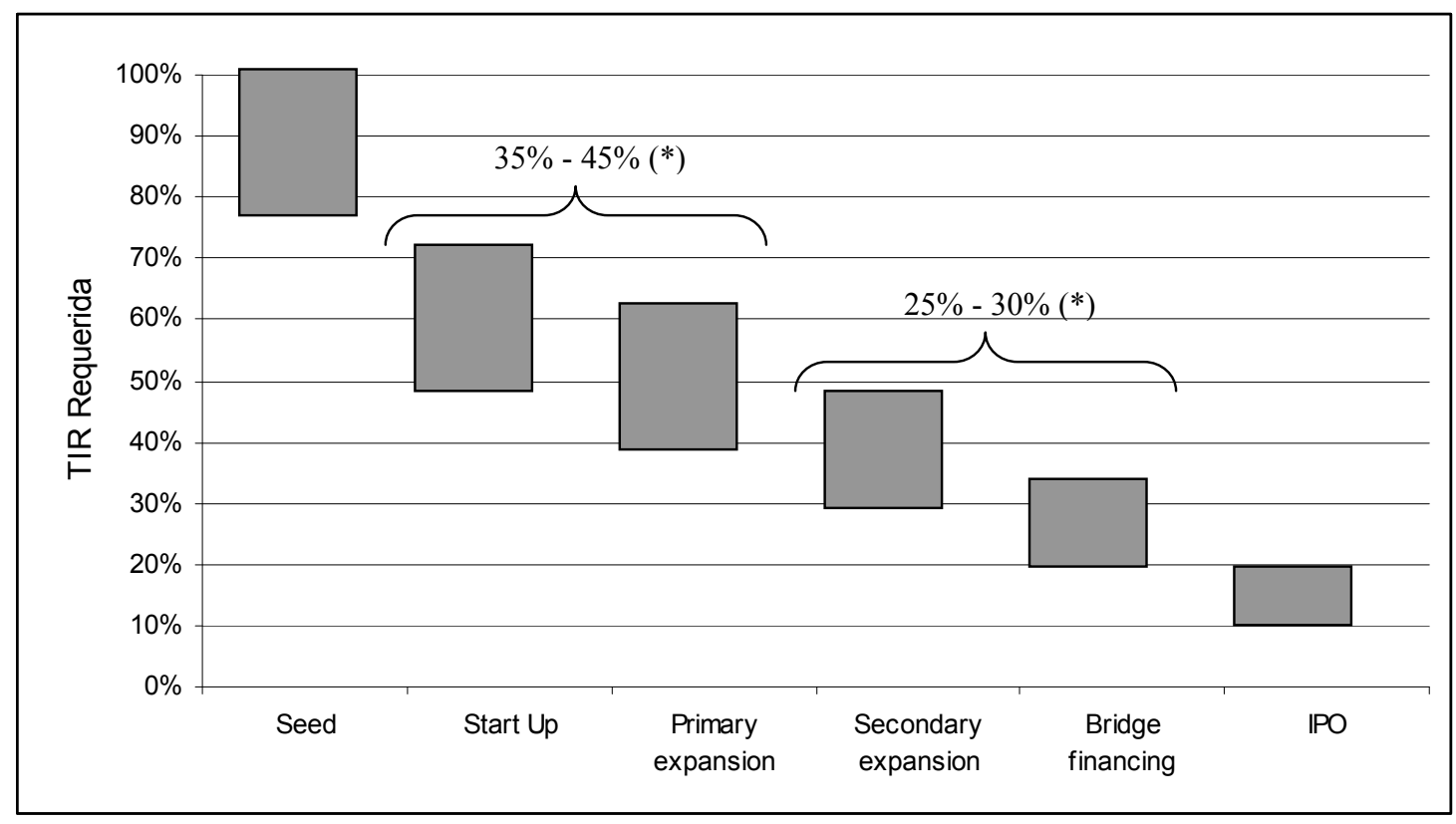

Fuente: Serrot, Daniel - Executive MBA 2010 - Universidad Torcuato Di Tella (*) Average for 200 VC firms in US, UK, France, Belgium and the Netherlands (Marigart, 2002).

De acuerdo con cada etapa, los inversores pueden clasificarse en dos categorías. Por un lado está el ángel, que además de invertir hasta US\$500.000 en el nacimiento de la firma, aporta un valor agregado a través de su red de contactos. Tras el ángel, cuando la necesidad de dinero es mayor, aparece la figura de los Fondos de Capital Riesgo, por lo general para invertir en emprendimientos ya encaminados y de alto potencial. Los Venture Capital pueden llegar a invertir entre US\$ 500.000 y US\$ 3 millones, demandando en promedio, una tasa de retorno anual que oscila entre el $25 \%$ y $35 \%$ de la inversión.

Para elegir al fondo de capital riesgo más apropiado, se le deberían realizar 8 preguntas claves, a saber:

- ¿Buscan mayoría o minoría accionaria?

- ¿Invierten en una industria en particular? ¿En cuál?

- ¿Son inversores activos o pasivos? Sin son activos: ¿estratégicos, operacionales o ambos?

- ¿Tienen contactos con potenciales, proveedores, clientes, etc...?

- ¿Cuál es el rango de sus inversiones?

- ¿Cuánto tiempo normalmente esperan quedarse en sus inversiones?

- ¿Qué tasa anual de retorno tienen como objetivo conseguir?

- ¿Qué estrategia de salida esperan (venta a inversores estratégicos, IPO, etc.)? 
A continuación se mencionan, para algunos fondos de capital riesgo que actúan en el Mercado Argentina, dónde ponen el foco los principales inversores. En entrevistas con Martín Coccaro ${ }^{25}$ los responsables de manejar y decir dónde invertir su dinero cuentan sus motivaciones y exigencias.

- Fondo Chrysalis. Jorge Villalonga, conduce, junto a Pedro Dhers, el Club de Ángeles de antiguos alumnos del IAE, y dirige el Fondo Chrysalis. Como uno de los 70 inversores que conforman actualmente este nido de nuevos proyectos, Villalonga destaca que el emprendedor debe iniciar el vínculo enviando un resumen ejecutivo de lo que será la empresa. El proceso continúa con entrevistas y prosigue con el due dilligence, y si todo va bien, se comienza a armar el acuerdo de asociación.

El Club de Ángeles apuesta a los proyectos en fase start up, que están por nacer y exige, como condición fundamental, que sean innovadores. "No nos metemos donde ya hay otros. Deben ser nuevos productos o servicios, o tener un enfoque distintivo". Además debe ser un proyecto escalable (a medida que se incorpora capital, el negocio va creciendo) y replicable (con una proyección regional o global).

Chrysalis nació en el 2004 y apunta a financiar compañías que ya superaron la fase inicial y están creciendo. "Ponemos un énfasis muy grande en las ventajas competitivas del sector, luego analizamos el entendimiento del mercado. Pero no solo inyectamos capital, también ofrecemos management. Somos conscientes de que los emprendedores siempre tienen algún perfil a reforzar, y es ahí donde aportamos el know how del negocio, con redes de contactos y transmitiendo nuestra experiencia, que a largo plazo, puede resultar más valorable que el propio capital, asegura el inversor.

- Holdinvest. Lisandro Brill inició en abril de 2005 el manejo de Holdinvest, enfocado a buscar proyectos de exportación, básicamente en tres áreas: actividades relacionadas con la tecnología, sectores vinculados con el valor agregado y el turismo.

"Buscamos que la oportunidad sea grande, que esa empresa ya esté facturando como mínimo un millón de dólares y pueda llegar a 15 o 20 millones de dólares en un plazo de 5 años" dice Brill al exponer sus requisitos.

Un negocio que pueda escalar de esta manera, inevitablemente se caracteriza por tener un fuerte perfil exportador. Por eso, cuando la compañía ya tiene un grado de madurez, posee un producto en el mercado, cuenta con sólido management consituído y su objetivo inmediato es escalar el negocio, es el punto exacto en el que aparece la posibilidad de inversión de este Fondo.

"Para calificar, el plan de negocios debe tener una tasa de retorno anual de al menos $35 \%$. Recibimos muchos proyectos vinculados al mercado interno que no tienen la capacidad de crecer de acuerdo con lo pretendido", agrega Brill.

- Mark Ventures. Federico Cánepa fundó Mark Ventures a principios del 2006, un fondo que apuesta a proyectos chicos, con inversiones que oscilan entre los US $\$ 300.000$ y el millón de dólares.

Este inversor analiza además de la posible expansión de la empresa, la ética del emprendedor, es decir, cómo trabaja con sus clientes, empleados, proveedores, su estrategia de manejo en términos de negociación.

${ }^{25}$ El Cronista PyME, "Cómo pasar el examen ante los Inversores de Riesgo". 2 de noviembre de 2006. 
"Buscamos negocios en funcionamiento, que tengan un número de clientes conquistados y una relación en crecimiento. Los que apuntan a mercados muy grandes tienen mayores probabilidades de conseguir dinero", asegura. Cada plan de negocios tiene una capacidad de repago diferente, pero el mínimo que exige como retorno anual varía de un 25 a $30 \%$ de la inversión.

- PCP Inversiones. Carlos Adamo, al frente de PCP Inversiones, subraya qué es lo primero que observa cuando se enfrenta a un emprendedor. "Evaluamos su personalidad, su forma de relacionarse, todo lo que se define como variables blandas, la formación que tiene. Por supuesto también analizamos el proyecto", destaca.

Adamo, fue uno de los pioneros del Venture Capital a fines de los 90, focaliza su trabajo en propuestas que no demanden un enorme capital y que sean exportables, en lo posible. Como la mayoría de los inversores de riesgo, apunta a desarrollos de tecnología, ya que "se puede hacer más con menos inversión. Es la contracara de los procesos industriales, donde la posibilidad de éxito es menor".

Adamo, recibe unos 30 proyectos por mes, pero muy pocos califican para evaluar, ya que una buena idea no basta para conseguir capital, se debe tener capacidad para implementarla. Por eso el management es fundamental.

Las tasas de retorno que solicita Adamo oscilan entre 15 y $35 \%$ anual, según el riesgo del proyecto.

- FS Partners. Pedro Querio comanda FS Partners, una sociedad que se especializa en el asesoramiento de fusiones. Pero en este contexto, no desaprovecha la oportunidad cuando aparece una atractiva opción de inversión, siempre que la alternativa no se encuentre en la etapa de start up. El claro ejemplo de esto es Globant, una firma que nació en 2003 con un mínimo capital y con la idea de exportar servicios de software. Con su desarrollo y la inyección (en el 2004) de 2 millones de dólares de un pool de inversores liderado por Querio, pegaron el gran salto y hoy se identifican como una de las compañías de servicios globales de IT de más rápido crecimiento en Latinoamérica.

"Somos oportunistas, cuando avizoramos un buen negocio armamos un grupo de inversores, un vehículo específico para esa oportunidad" sostiente Querio.

- Enrique Draier. Inversor Ángel y presidente del Instituto de Emprendimientos Científicos y Tecnológicos (IECyT), destaca que "en cuanto al modelo de negocio, lo primero que se mira es que sea una propuesta innovadora; si no es así, no será de fácil crecimiento. Luego, es muy importante que tenga volumen de negocio suficiente. Hay gente que tiene muy buenas ideas para un mercado poco expansivo y saturado", dice. Por eso, lo que hay que buscar es la demanda insatisfecha.

La herramienta que cualquier inversor exige para analizar el financiamiento requerido para un proyecto, como mínimo, consiste en la correcta confección del plan de negocios, instrumento de presentación donde se resume como se ejecutará el proyecto. Muchos emprendedores no se encuentran en condiciones de enfrentar este requerimiento, para ellos, muchas universidades y organizaciones suelen ofrecer capacitación y apoyo (técnico y práctico) en la confección de la documentación. La fundación Endeavor es un ejemplo de esta ayuda, Alejandro Mashad (director ejecutivo de Endeavor) dice "Proveemos el management para que el emprendedor acceda a redes de contacto y consiga el capital". 


\subsection{Las Sociedades Calificadoras de Riesgo (SCR)}

Las calificadoras de riesgo son sociedades anónimas constituídas con el objeto exclusivo de calificar valores mobiliarios y otros riesgos, de acuerdo con lo establecido por el decreto 656/92. Esta figura se introdujo en el mercado de capitales con el objeto de facilitar la toma de decisiones por parte de los inversores. En un principio, la calificación fue de carácter obligatorio para los valores negociables representativos de deuda como, por ejemplo, las obligaciones negociables. Esta exigencia fue modificada en el año 2000 por el decreto 749/00, que introdujo el carácter optativo según expresa el artículo 2: "a solicitud de las emisoras, las sociedades calificadoras podrán calificar cualquier valor mobiliario, sujeto o no al régimen de la oferta pública. Sin perjuicio de ello la Comisión Nacional de Valores podrá establecer la obligatoriedad de la calificación cuando las especiales condiciones de la emisión así lo requieran".

Si bien las calificaciones son optativas y representan un costo adicional en el proceso de emisión de los valores negociables, las empresas suelen contratar el servicio de las SCR con el objeto de mejorar, ampliar y validar la información que se brinda a los potenciales inversores.

Cada SCR tiene su propio sistema y metodología de calificación, que deben ser aprobados, en Argentina, por la Comisión Nacional de Valores. Estos criterios son similares y comparables, tanto a nivel internacional como a nivel local, y se resumen a través de categorías de calificación o notas, representadas por medio de un sistema de letras o números.

Así, un título calificado como "AAA" representa la máxima calidad crediticia y, en el otro extremo, una nota "D" representa a los títulos en situación de incumplimiento (default). Entre estos extremos, las calificaciones se dividen a su vez en dos sub-grupos: las consideradas "Grado de Inversión" o "Investment Grade" y las emisiones "Grado Especulativo" o "Non Investment Grade". Por último, se utiliza la letra E cuando la calificación no se puede emitir por falta de información o información insuficiente.

Para diferenciarlas de las calificaciones que se otorgan a nivel internacional, las notas válidas para el mercado local se completan con algún tipo de referencia al nombre del país. Así, S\&P precede la calificación con la sigla "ra." (ejemplo: "ra.AAA"), Moody's agrega la sigla ".ar" (ejemplo: "AAA.ar"), mientras que Fitch y Evaluadora Latinoamericana incorporan al final de la nota la sigla "(arg)" (ejemplo: "AAA (arg)").

En el caso de las calificaciones de acciones, las notas se expresan con números en una escala de 1 a 5 , en la que 1 equivale a una empresa con la máxima capacidad para generar ganancias y 5 a las acciones de empresas que no proporcionan información válida 0 representativa para la evaluación.

Adicionalmente, cuando se emite la calificación otorgada, se informa la perspectiva o Credit Watch, es decir, la posibilidad de que se produzca en el corto o mediano plazo una mejora o empeoramiento de la nota.

Por otra parte, las SCR también evalúan el riesgo global de un emisor. En este caso, no se trata de calificar a un determinado valor negociable, sino de pone una nota a la empresa emisora. Es decir, que hay calificaciones que reflejan el riesgo global de una empresa y otras que reflejan el riesgo específico de un valor negociable emitido por esa misma empresa. 
Cuadro de Calificaciones a Escala Internacional Calificadoras de Riesgo que actúan en Argentina.

\begin{tabular}{|c|c|c|c|c|}
\hline \multirow{2}{*}{$\begin{array}{l}\text { Características de las } \\
\text { categorías y subcategorías }\end{array}$} & \multicolumn{4}{|c|}{ Agencias } \\
\hline & $S \& P$ & Moody's & Fitch & Eval. Latinoam \\
\hline \multicolumn{5}{|c|}{ Grado de Inversión } \\
\hline \multirow[t]{2}{*}{ Máxima calidad crediticia } & AAA & Aaa & AAA & AAA \\
\hline & $A A+$ & Aa1 & $\mathrm{AA}+$ & $A A+$ \\
\hline \multirow[t]{3}{*}{ Calidad crediticia muy elevada } & $A A$ & Aa2 & $A A$ & $A A$ \\
\hline & AA- & Aa3 & AA- & AA- \\
\hline & $A+$ & $\mathrm{A} 1$ & $A+$ & $A+$ \\
\hline \multirow[t]{3}{*}{ Calidad crediticia elevada } & $A$ & $\mathrm{~A} 2$ & $A$ & $A$ \\
\hline & A- & A3 & A- & A- \\
\hline & $\mathrm{BBB}+$ & Baa1 & $\mathrm{BBB}+$ & $\mathrm{BBB}+$ \\
\hline \multirow[t]{2}{*}{ Calidad crediticia buena } & BBB & Baa2 & BBB & BBB \\
\hline & BBB- & Baa3 & BBB- & BBB- \\
\hline \multicolumn{5}{|c|}{ Grado Especulativo } \\
\hline & $\mathrm{BB}+$ & Ba1 & $\mathrm{BB}+$ & $\mathrm{BB}+$ \\
\hline \multirow[t]{3}{*}{ Especulativo } & $\mathrm{BB}$ & $\mathrm{Ba} 2$ & BB & BB \\
\hline & BB- & Ba3 & BB- & BB- \\
\hline & $\mathrm{B}+$ & B1 & $\mathrm{B}+$ & $\mathrm{B}+$ \\
\hline \multirow[t]{3}{*}{ Altamente especulativo } & B & B2 & B & B \\
\hline & B- & B3 & B- & B- \\
\hline & $\mathrm{CCC}$ & $\mathrm{CCC}$ & $\mathrm{CCC}$ & $\mathrm{CCC}$ \\
\hline \multirow[t]{2}{*}{ Riesgo crediticio vulnerable } & $\mathrm{CC}$ & $\mathrm{CC}$ & $\mathrm{CC}$ & $\mathrm{CC}$ \\
\hline & $\mathrm{C}$ & $\mathrm{C}$ & $\mathrm{C}$ & $\mathrm{C}$ \\
\hline Default & $\mathrm{D}$ & $\mathrm{D}$ & $\mathrm{D}$ & $\mathrm{D}$ \\
\hline Incumplimiento de información & $E$ & $E$ & $E$ & $E$ \\
\hline
\end{tabular}

Fuente: Instituto Argentino de Mercado de Capitales (IAMC), 2010.

Finalmente, como consecuencia del desarrollo de nuevos instrumentos financieros, las SCR han tenido que incorporar evaluaciones dirigidas a otros actores, como por ejemplo, los fiduciarios financieros son evaluados por su capacidad para administrar los activos que forman el patrimonio del fideicomiso, en beneficio de los inversores. Otro ejemplo, son las calificaciones referidas a las Sociedades de Garantía Recíproca que, a través del aval que otorgan a los valores negociables, cumplen un rol central en las emisiones de las pequeñas y medianas empresas.

\subsection{Las Sociedades de Garantía Recíproca (SGR)}

Las PyMEs puede acudir a una SGR, a fin de que garantice sus obligaciones, con el objeto de darle mayor certeza de cumplimiento y que como consecuencia del menor riesgo percibido por parte del inversor (o acreedor), se obtenga una tasa de interés mas baja. 
Para que la PyME pueda acceder a este tipo de garantía, posteriormente a su ingreso como socio participe, deberá presentar a la SGR la documentación necesaria para superar un proceso de análisis como sujeto de crédito, a través del cual calificara para la gestión de líneas de créditos en el mercado financiero.

En estos casos los acreedores evaluaran la solicitud de la PyME considerando la garantía emitida por la SGR, permitiéndole acceder a plazos mas extensos de financiamiento y a tasas mas competitivas.

Las dos SGR mas significativas en el mercado financiero por volumen de operaciones, montos y trayectoria, son Garantizar SGR (el Banco de la Nación Argentina fue su primer socio protector y fundador) y Garantía de Valores SGR (el socio protector principal es la Caja de Valores S.A., cuyos accionistas son la B.C.B.A. y el Mercado de Valores de Buenos Aires).

\subsubsection{Nueva reglamentación para las SGR}

El sistema de las SGRs está regulado por la Ley $N^{0} 24.467$ y sus modificatorias y normas complementarias. Las nuevas normas reglamentarias reunidas en la disposición 128/2010, implican una suerte de digesto que unifican una serie de disposiciones que se fueron sucediendo en el tiempo, y a la vez innovan en el funcionamiento y control de las sociedades de garantía.

Con los cambios establecidos en el marco normativo se esperan alcanzar los siguientes objetivos: lograr una mayor solidez de las Sociedades de Garantía Recíproca, reducir la volatilidad del Fondo de Riesgo, incrementar el menú de garantías a ofrecer a las PyMEs, establecer incentivos adicionales para otorgar garantías a largo plazo (vinculadas a créditos de inversión), y lograr una mayor penetración en el mercado bancario y de capitales.

Se espera de las SGRs una utilización más eficiente de sus recursos, en pos de promover que el sistema alcance a un número mayor de PyMEs, distribuidas a lo largo y a lo ancho de todo el territorio nacional.

El incremento de las exigencias para lograr la desgravación impositiva debería (casi por si sólo) permitir la expansión y profundización del sistema.

Uno de los principales puntos a destacar de la nueva normativa, tiene que ver con el apalancamiento. Dado que el actual marco normativo promueve un nivel multiplicador más elevado (más garantías con el mismo fondo de riesgo), las SGRs deberán asumir un mayor riesgo para lograr los niveles que la normativa establece.

No obstante, el Estado Nacional a través del FOGAPYME está acompañando dicha iniciativa, dado que decide compartir el riesgo de las garantías vinculadas a proyectos de inversión que las SGRs generen.

Concretamente, el reafianzamiento de las carteras de largo plazo de las SGRs a través de FOGAPYME se traduce en una herramienta estratégica para consolidar el sistema de garantías: no solo porque incentiva su direccionamiento hacia los proyectos de inversión de las PyMEs, sino también porque permite "liberar el multiplicador" de las SGRs, permitiendo que continúen destinando su Fondo de Riesgo a otorgar nuevas garantías, alcanzando así un mayor efecto expansivo sobre la economía real. 


\subsubsection{El proceso de otorgamiento de avales}

Para acceder a los avales de una SGR, la PyME debe realizar los siguientes pasos:

1) Definir su necesidad de financiamiento y el tipo de garantía apropiada.

2) De acuerdo con sus características y a la operación elegida, se presenta la documentación pertinente para:

a) Demostrar su carácter de pequeña o mediana empresa.

b) Solicitar su incorporación como socio partícipe.

c) Realizar su análisis de riesgo integral y calificación crediticia. Para ello, deberá tener normalizada su situación impositiva y previsional.

3) La S.G.R. acepta a la PyME como socio partícipe, define una calificación crediticia y una/s línea/s de garantías. Se solicitan las contragarantías apropiadas para avalar el certificado de garantía definido.

4) Junto con el socio partícipe, se analizan las mejores opciones de financiamiento dentro de la cartera de productos y líneas de crédito que la SGR posee convenidas con Bancos y otros monetizadores.

5) La PyME presenta las contragarantías solicitadas como aval del certificado.

6) Se emite el certificado de garantía en las condiciones pactadas y se presenta ante el monetizador elegido (entidad bancaria, mercado de capitales, empresas proveedoras, etc.) para el desembolso del crédito.

Respecto del paso 5, se destaca que en la mayoría de los casos esta presente el requerimiento de tener que aportar garantías reales (inmuebles) por parte de las PyMEs o de sus socios para poder acceder a una garantía de SGR y este requerimiento termina siendo uno de los principales obstáculos o trabas que se le presenta a las PyMEs al momento de solicitar una garantía.

\subsubsection{Beneficios de contar con el aval de una SGR}

La SGR ofrece a las PyMEs, la posibilidad, a través del otorgamiento de garantías, de acceder a alternativas de financiación en el mercado, con los siguientes beneficios:

1) Acceso a financiamiento de mediano y largo plazo.

2) Reducción de costo de acceso a crédito.

3) Mejora de capacidad negociadora de cara al sistema financiero.

4) Asistencia técnica par la elaboración de proyectos complejos.

Las SGR deben buscar flexibilidad y alternativas convenientes para sus socios, al tiempo que deben resguardar la salud de su fondo de riesgo. De esta manera y a diferencia de las tradicionales garantías con las que se maneja el sistema financiero, las SGR poseen ciertas ventajas diferenciales para sus socios. 
En lo que respecta al otorgamiento de avales para líneas de corto plazo, las que generalmente financian el capital de trabajo de la empresa, suele estar enfocado principalmente en el flujo de fondos proyectado y es frecuente como contragarantía los avales personales de los accionistas.

En cuanto a las líneas de mediano y largo plazo, garantías para acceder a créditos de compra de bienes de capital o financiación de proyectos de inversión, se suma al flujo de fondos y los avales personales, alguna contragarantía real.

Las contragarantías solicitadas y los aforos tomados de las mismas, suelen variar mucho de una SGR a otra, a este respecto Juan Jorquera (Gerente Financiero y de Mercado de Capitales de Garantizar SGR) dice que Garantizar generalmente constituye como contragarantía real el bien que se está adquiriendo o la planta donde se va a desarrollar el proyecto de inversión.

También destaca que Garantizar otorga garantías para financiar hasta el $80 \%$ del bien a adquirir cuando el mercado en general no supera el $60 \%$. Asimismo y en lo que hace a las hipotecas, el aforo con el que opera la sociedad es del $20 \%$ cuando el mercado en general llega al 100\%. Es decir que el mercado busca una relación de "dos a uno" mientras que Garantizar opera con el "uno veinte a uno".

Por último, resalta que Garantizar acepta bienes como contragarantía destinados a la producción, como por ejemplo la prenda sobre un bien específico o la planta industrial, mientras que el mercado financiero muchas veces exige contragarantías con mejor valor de realización de mercado.

\subsubsection{Garantías Formalizadas}

El sistema financiero en su conjunto ha mantenido una baja proporción de oferta crediticia dirigida a las PyMEs, liderando con comodidad el segmento de la banca pública y la cooperativa. Fue allí donde se afianzó la labor de las sociedades de garantías recíprocas, en particular liderando la oferta a mediano y largo plazo, pero donde la atención al capital de trabajo también fue una excelente oportunidad de penetración, como se evidencia en el crecimiento de los Cheques de Pago Diferido Avalados.

Cuadro 27

Montos Avalados por las SGR Avales por instrumento $2008-2009$, en millones de pesos.

\begin{tabular}{|l|c|c|c|c|}
\cline { 2 - 5 } \multicolumn{1}{c|}{} & \multicolumn{2}{c|}{ Total Mercado 2008 } & \multicolumn{2}{c|}{ Total Mercado 2009 } \\
\hline Línea & Monto & $\%$ & Monto & \% \\
\hline Entidades Financieras & 361 & $29 \%$ & 410 & $29 \%$ \\
\hline Fideicomisos Financieros & 304 & $24 \%$ & 160 & $12 \%$ \\
\hline Cheques de Pago Diferido & 593 & $47 \%$ & 820 & $59 \%$ \\
\hline Total & $\mathbf{1 . 2 5 8}$ & $\mathbf{1 0 0 \%}$ & $\mathbf{1 . 3 9 0}$ & $\mathbf{1 0 0 \%}$ \\
\hline
\end{tabular}

Fuente: Garantizar SGR. 
Gráfico 18

Cheques de Pago Diferido Garantizados por el Mercado de las SGR

Año 2009.

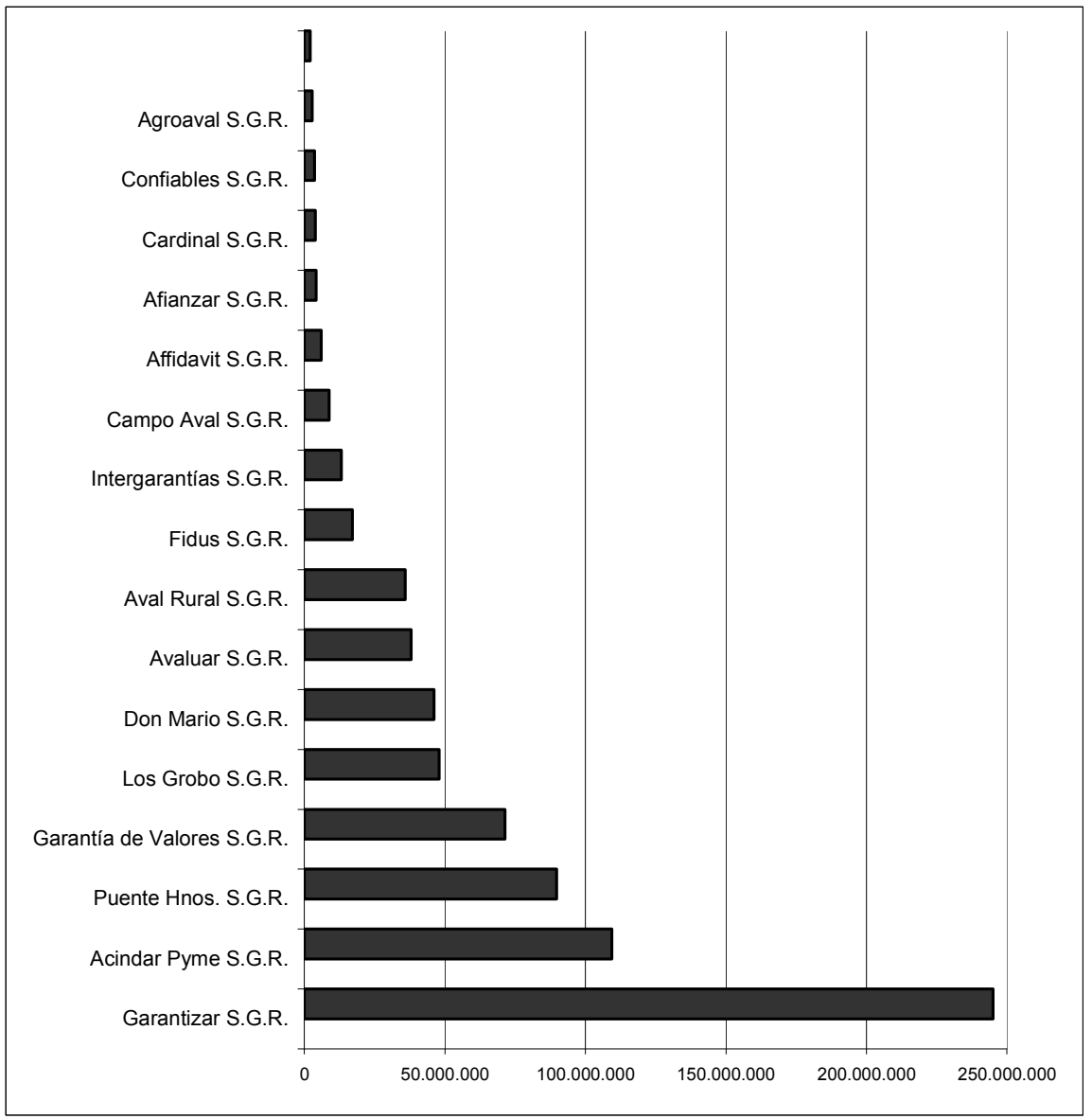

Fuente: Garantizar SGR. 


\section{Conclusiones}

A los efectos de detallar las conclusiones generadas fruto del trabajo de investigación, se procederá a dar respuesta a los objetivos planteados en el apartado 2, para luego continuar con un resumen de los hallazgos más importantes y su evaluación.

\section{Causas de las limitaciones en el acceso al financiamiento de las PyMEs.}

El desarrollo pleno de las fuentes y canales de financiamiento requeridos para la expansión de las empresas productoras de bienes y servicios requiere estabilidad institucional, monetaria y de las finanzas públicas. Si bien siempre será posible cierto desarrollo de instrumentos, vehículos, mercados e instituciones financieras en ausencia de tales condiciones, el mismo estará siempre limitado por la inestabilidad y la incertidumbre, y sujeto a su destrucción en medio de situaciones de crisis.

La Argentina presenta un escenario de inestabilidad política, económica y financiera recurrente, donde las PyMEs ven amenazada su continuidad y desarrollo permanentemente, obligándolas a reformular sus estrategias competitivas periódicamente, para lograr su supervivencia.

En lo que respecta a las barreras para el acceso al crédito y a la financiación por parte de las empresas, es particularmente grave, la carencia o escasez de financiamiento a largo plazo, ya que constituye una condición necesaria para la concreción de inversiones en escala significativa.

En este contexto, las causas de las limitaciones en el acceso al financiamiento de las PyME surgen de una situación compleja, con responsabilidades compartidas de los distintos actores intervinientes, a saber: el Estado, las instituciones financieras y las propias PyME.

- El Estado, no ha logrado mantener una estabilidad en las políticas macroeconómicas y financieras, no ha brindado un marco regulatorio e impositivo adecuado, ni la seguridad jurídica necesaria para que los agentes económicos puedan decidir con reglas de juego claras y permanentes. Específicamente, en lo que refiere a los mercados financieros, su función radica en regular la actividad y solucionar las fallas del mercado, su ausencia ha dado origen a muchos de los problemas planteados.

Es obvio que el gap de oferta y demanda de financiamiento para las PyME obedece en buena medida a la normativa crediticia vigente que no incentiva el acercamiento de los bancos a las PyME. En realidad se mantiene el espíritu de las normas crediticias del BCRA de los años noventa, con un manifiesto sesgo pro-corporación, toda vez que obligaban a los bancos a hacer mayores previsiones por los préstamos dados a las PyMEs, a partir de considerarlas como más riesgosas.

Se hace necesario actualizar la aplicación de la legislación de manera que otorgue un mayor incentivo a los bancos para atender a las PyMEs.

- Las instituciones financieras: en lo que respecta a los bancos, el sistema bancario padece descalces varios (altísima proporción de depósitos a la vista en sus pasivos, fuerte acumulación dentro de sus activos de créditos contra el sector público con vencimiento a largo plazo y mecanismos de retribución desligados de las tasas que se pagan por los depósitos), falta de rentabilidad y capitalización inadecuada, todo lo cual le impide desempeñar en forma satisfactoria su rol normal de transformador de riesgos (de plazos y de monedas). 
A los aspectos mencionados, se les debe sumar la actitud de los bancos, que concentran su financiación en empresas de mayor tamaño y a corto plazo.

Por su lado, el mercado de capitales no ha sabido atraer a las PyMEs, falta de comunicación, adecuación de instrumentos y volumen de inversores, son algunas de las cuestiones que no ha podido resolver.

- Las PyMEs, por su lado, ponen en evidencia la informalidad de sus operaciones y la falta de profesionalización en la gestión, cada vez que no pueden cumplir con los requisitos solicitados por las entidades financieras. Su incapacidad para armar un plan de negocios consistente, la baja confiabilidad de los balances contables, los problemas para la generación de información y la falta de garantías, son claros impedimentos para acceder al financiamiento.

Los bancos y el mercado de capitales muchas veces excluyen a las PyMEs por su imposibilidad de evaluarlas de forma razonable respecto de su voluntad y capacidad de pago. Esto lleva a pensar que el problema no es solamente la alta cantidad de requisitos que pueda requerir la entidad financiera, sino que también hay un serio problema de generación de información por parte de las PyMEs, lo que pone de manifiesto la falta de profesionalismo en su gestión.

\section{Efectos de la información asimétrica en el financiamiento de las empresas.}

En el apartado 5.2. se desarrollan en detalle los efectos que genera la información asimétrica de los distintos mercados financieros, a modo de conclusión se resumen las principales consecuencias que las asimetrías informativas generan en el financiamiento de las empresas, a saber:

- Racionamiento del crédito: la información asimétrica supone una ruptura en el mecanismo de los precios como criterio de asignación de recursos. El precio (interés) del préstamo, deja de ser el criterio de asignación, debiendo el oferente de fondos utilizar otro criterio a los efectos de tomar tal decisión.

El racionamiento del crédito se presenta como la actitud lógica de los oferentes de fondos ante el imperfecto conocimiento de las características de los demandantes y del nivel de riesgo de sus proyectos, ya se trate de supuestos de selección adversa o de riesgo moral.

- Exigencias de mayores garantías: en un mercado caracterizado por los problemas de las asimetrías informativas, cualquier elemento que contribuya a limar esas imperfecciones será bienvenido. En este marco, las garantías subsidiarias pueden cumplir una doble función, por un lado, constituyen un medio del que disponen los prestamistas para reducir el riesgo de selección adversa y por el otro, los tomadores de fondos dispuestos a otorgar garantías subsidiarias al prestamista, dan una señal que los distingue del resto de los agentes del mercado, haciendo ver su capacidad para cumplir los acuerdos contractuales, incluso ante la situación de fracaso del proyecto previsto.

De esta forma, la utilización de garantías subsidiarias como respaldo para la obtención de un crédito, ayuda a superar los problemas ocasionados por la información asimétrica y evita el racionamiento del crédito antes mencionado.

- Tendencia a la financiación interna: los desequilibrios que se producen en el reparto de la información plantean una nueva perspectiva de las relaciones existentes entre la 
estructura financiera de las empresas y las decisiones sobre el empleo de fondos que dichas empresas adoptan.

La consideración de fricciones informativas en el mercado supone un quiebre en la hipótesis de ilimitación de los mercados de capitales, así como la de libre acceso de la empresa a cualquiera de las modalidades de financiación.

La teoría de las preferencias financieras (Myers, 1984), establece un orden de prioridades consistente en recurrir inicialmente a la autofinanciación, para emplear posteriormente la deuda y finalmente, los fondos propios procedentes de nuevas emisiones.

Se llega así a una explicación, en términos informativos, que coincide con la teoría del pecking order, donde la preferencia de las empresas por las distintas clases de recursos financieros, colocan en el primer lugar a la generación interna de fondos, seguida de la emisión de deuda y finalmente, la ampliación de capital. Esta clasificación, en la medida en que hace depender las oportunidades de la empresa de su capacidad de generación de recursos, da origen a una serie de restricciones financieras que condicionan su inversión, generando una vinculación entre la estructura financiera de la empresa y su estructura de inversiones.

La economía de la información va perfilando una nueva visión de la estructura de capital, en la que la utilización de deuda deja de obedecer exclusivamente a un intercambio óptimo entre las ventajas fiscales de la misma y los costos de quiebra a los que puede dar origen, para incluir consideraciones relativas al riesgo correspondiente a la deuda, los incentivos al esfuerzo que proporcionan y la información que transmite.

\section{Aspectos y características particulares de los mercados financieros en Argentina.}

En el Sistema Financiero Argentino se destacan las siguientes características:

- Las fuentes de financiamiento proceden principalmente del sistema bancario, y es limitado el desarrollo del mercado de capitales.

El sistema bancario es la principal fuente de financiamiento para las PyMEs, sin embargo, la participación en el total de préstamos de los destinados a PyMEs se mantienen en niveles muy bajos.

La baja profundidad crediticia no se explica exclusivamente por la escasez de ahorro intermediado bajo la forma de depósitos bancarios sino también por la estructura de activos a los cuales se aplica la capacidad prestable del sistema bancario. A septiembre de 2009 , del total de recursos (pasivo más patrimonio neto) del sistema bancario, sólo el $35,8 \%$ se canaliza a crédito privado.

Sin duda, resulta paradójico que la transformación de ahorro en crédito privado, la principal función social que justifica la existencia de los bancos, absorbe apenas la tercera parte de los recursos intermediados.

Si además se tiene en consideración que la mitad del crédito privado están dirigidos a financiar el consumo y del resto, solo el 25\% está destinado a PyMEs (definidas como aquellas empresas con una deuda total por debajo de 5 millones de pesos), se llegaría a la conclusión de que los préstamos a PyMEs representan poco más del $4 \%$ del total de activos del sistema bancario. 
Por otro lado, hasta la crisis de 2001 prácticamente no había productos para financiar empresas PyMEs fuera del circuito bancario, pero con la crisis de 2001 y la apropiación de los depósitos algo en la relación banco-empresa se rompió y se abrió una puerta para que el mercado de capitales se convierta en una alternativa válida para financiar a las PyMEs.

Un aspecto a destacar, es que no parece haber un gran interés genuino y real por parte de las PyMEs debido a la falta de cultura financiera del empresario PyME argentino que no identifica al mercado de capitales como una alternativa de financiamiento accesible. También el empresario PyME debe entender que el mercado de valores no reemplaza a la acción de los bancos sino que actúa como fuente complementaria de financiamiento.

- El crédito al sector privado tiende a concentrarse en las empresas de mayor tamaño y en operaciones de corto plazo.

Según datos del BCRA, las PyMEs con crédito en el sistema bancario formal (definidas como aquellas empresas con una deuda total por debajo de 5 millones de pesos) representan el $99 \%$ del total de empresas deudoras y su deuda con el sistema llegaría al $25 \%$ del total de crédito comercial. Estas cifras revelan una importante, aunque esperable, concentración del crédito en los deudores más grandes.

Por otro lado, a julio de 2010, los acuerdos en cuenta y el descuento de documentos representaban el $78 \%$ del total de los préstamos a empresas del sistema bancario, lo que demuestra la elevada concentración en operaciones de muy corto plazo.

- Hay un relativo bajo nivel general de bancarización, consecuencia de que están excluidos de ella importantes sectores de la actividad económica.

En Argentina solo el 6,9\% de las empresas manifiestan hacer uso del crédito bancario, estos valores son muy bajos incluso respecto de economías con una profundidad financiera mucho mayor, como Chile y España, donde la proporción ronda el $30 \%$ y $32 \%$ respectivamente. Se encuentra un panorama similar cuando se analizan las inversiones financiadas con crédito, en el cual se ubica Argentina con 5,4\%, y a modo de comparativa se puede mencionar España con $21,9 \%$, Brasil con $33,6 \%$ y Chile con $36,1 \%$.

- Al existir una selección negativa respecto de los demandantes de crédito que presentan un mayor riesgo relativo, los márgenes de intermediación son elevados, y exceden notablemente a los que rigen en los sistemas financieros más desarrollados.

- Los mecanismos regulatorios presentan deficiencias, no tanto por la ausencia de normas sino por la insuficiencia de los mecanismos de supervisión, lo cual se refleja en deficiencias en el control de riesgos, en el grado de adecuación de los capitales a los niveles de riesgo e insuficiencias de las prácticas de provisionamiento por parte de los bancos.

\section{Causales de éxito o fracaso de los instrumentos financieros utilizados por las PyMEs en el mercado argentino}

- Instrumentos financieros del Sistema Bancario: como se menciona anteriormente, el sistema bancario es la principal fuente de financiamiento de las PyMEs, hoy en día, de acuerdo con la actividad y sector en el que actúan, están trabajando con leasing, cartas de crédito, prefinanciación de importaciones y exportaciones, acuerdos en cuenta, 
descuento de documentos y préstamos financieros a sola firma. Los plazos en su mayoría son menores a un año, hay poca financiación de mediano y largo plazo para las PyMEs, solamente hay en algunos bancos algunas líneas de hasta 36 meses para compra de bienes de capital, algunas líneas de Leasing en plazos similares y el Banco Ciudad tiene una línea hipotecaria para compra de inmuebles a 10 años, pero solo esos son los plazos más largos.

En la estrategia comercial bancaria, hoy la PyME ocupa un papel secundario, los bancos están orientados a clientes individuos, promocionando tarjetas de crédito con beneficios y descuentos en todos lados.

Por otro lado, el tema de las garantías aparece generalmente adherido a las dificultades que deben enfrentar las PyMEs para el acceso al crédito, en especial el financiamiento bancario de largo plazo.

La necesidad de dotar de mayor seguridad al proceso de otorgamiento de préstamos, intensificará la actividad de las entidades de garantía recíproca. El sistema de garantía debe integrarse en el sistema financiero, buscando la seguridad, calidad y permanencia.

Con los cambios incorporados en el marco normativo de las SGR se espera, entre otros, incrementar el menú de garantías a ofrecer a las PyMEs, estableciendo incentivos adicionales para otorgar garantías a largo plazo (vinculadas a créditos de inversión), y lograr una mayor penetración en el mercado bancario y de capitales.

Uno de los principales puntos a destacar de la nueva normativa, tiene que ver con el apalancamiento. Dado que el actual marco normativo promueve un nivel multiplicador más elevado (más garantías con el mismo fondo de riesgo), las SGRs deberán asumir un mayor riesgo para lograr los niveles que la normativa establece.

- Descuento de Cheques de Pago Diferido en la Bolsa de Comercio de Buenos Aires: esta operatoria viene creciendo significativamente en los últimos años, tiene la particularidad de permitir a las PyMEs acceder a tasas similares a las obtenidas por grandes empresas por contar con el aval de una SGR, al tiempo que es un instrumento muy atractivo para los inversores por tener un nivel de riesgo muy reducido.

En septiembre de 2010 se negociaron 4.371 cheques de pago diferido (casi un $42 \%$ más que septiembre de 2009) alcanzando un monto, en ambas modalidades (avalados y patrocinados), de $\$ 112$ millones (un 31\% más que el mismo mes del año anterior).

Las sociedades de garantía recíproca, tienen concentrados en este instrumentos el $60 \%$ del total de avales emitidos, convirtiéndolo en el principal instrumento a través del cual las SGR participan en el financiamiento de corto plazo de las PyMEs, las operaciones de mas largo plazo las canalizan con las entidades bancarias, ya que el mercado de capitales en estos momentos presenta muy pocas posibilidades para financiarse a mediano y largo plazo.

- Fideicomisos Financieros: las condiciones de emisión de los fideicomisos financieros para pymes (tasas y plazos) los convierten en una alternativa de inversión muy atractiva para adquirir y mantener hasta su vencimiento, pero no puede asegurarse la existencia de un mercado secundario para estos instrumentos, ni su liquidez en un mercado secundario, si existiere.

Es importante destacar que en el último tiempo disminuyó mucho su uso debido a las 
últimas reformas que hizo el Estado en materia del impuesto a las ganancias que ahora deben pagar los certificados de participación de los fideicomisos financieros con oferta pública. Lo que motivó que muchas empresas que operaban con el fideicomiso se vuelquen hacia otra modalidad de financiación.

Los fideicomisos financieros colectivos, están originados exclusivamente en el sector agropecuario y cuentan con el aval de las SGR, por su lado los fideicomisos financieros individuales son comerciales o de consumo casi en su totalidad, siendo prácticamente nula la presencia de fideicomisos de la construcción, servicios e industria, lo que demuestra la incapacidad de estos sectores para la utilización de este instrumento.

- Obligaciones Negociables PyME: las pequeñas y medianas empresas pueden emitir estos valores bajo un régimen simplificado de oferta pública y cotización. En lo que respecta a la calificación de riesgo, en un principio, la calificación fue de carácter obligatorio para los valores negociables representativos de deuda, como las obligaciones negociables. Esta exigencia fue modificada en el año 2000 por el decreto 749/00, que introdujo el carácter optativo según expresa el artículo 2. Ante esta situación, se pueden plantear tres posibilidades de emisión, a saber:

a) La PyME puede emitir la ON y contratar el servicio de una calificadora de riesgo para que emita su calificación respecto de la emisión, de esta manera se mejora, amplía y valida la información que se brinda a los potenciales inversores. En esta alternativa se debe verificar si el monto de la emisión, justifica el costo adicional que representa la calificación. Por tratarse de una ON PyME lo normal es que el monto de la emisión no permita distribuir el costo de la calificación, lo que genera una costo en términos de tasa que impide su aplicación.

b) La PyME puede emitir la ON optando por no realizar una calificación de riesgo (tal como le permite el decreto 749/00), trasladando la responsabilidad del análisis de riesgo al potencial inversor, lo que genera una situación de iliquidez al valor, que le quita las posibilidades de una adecuada inserción en el mercado.

c) La PyME puede emitir la ON con el aval de una SGR, de manera tal de brindar una cobertura adicional al inversor potencial que le reduce significativamente su riesgo. Ante esta posibilidad, surgen dos inconvenientes:

- Conseguir el aval de la SGR, que se encuentran concentradas en el descuento de cheques de pago diferido y fideicomisos financieros (que no suelen superar el año de plazo). Habrá que ver si la actualización de la reglamentación de las SGR, recientemente incorporada, potencia este tipo de instrumentos como se previó en su desarrollo.

- La actual falta de inversores a mediano y largo plazo en el mercado de capital argentino. Para cuya solución se requiere, un cambio en la actitud del Estado, a favor de satisfacer la necesidad de alcanzar una estabilidad institucional, monetaria y de las finanzas públicas, que acompañado de un adecuado marco regulatorio y seguridad jurídica, establecerán las condiciones para el ingreso de inversiones de mediano y largo plazo.

- Emisión de Acciones PyME: este instrumento se encuentra fuertemente limitado por la actual falta de inversores de mediano y largo plazo en el mercado de capitales argentino.

- Instrumentos financieros del Capital Riesgo: la cantidad de inversores y fondos de capital 
riesgo en el mercado argentino son reducidos y las posibilidades de obtener su financiación más aún. La mayoría de los fondos buscan apoyar financieramente proyectos más bien consolidados con posibilidad de una rápida expansión (generalmente vía exportación).

Para las empresas que puedan acceder a estos instrumentos, los beneficios son muy grandes, pero la realidad es que esta operatoria esta focalizada en un número extremadamente chico dentro del universo de PyMEs con necesidades de financiamiento.

\section{Alternativas de financiamiento para las PyMEs argentinas, en cada etapa de su desarrollo.}

Las empresas jóvenes, debido a las restricciones de financiamiento que encuentran, habrán de recurrir en sus primeras fases a los mercados privados de capital (financiación ángel, fondos aportados por el principal accionista y financiación capital-riesgo).

Para acceder a los fondos de capital riesgo, la PyME además de contar con un proyecto innovador, con grandes ventajas competitivas, que permita una rápida expansión del negocio y que estén orientados generalmente a la exportación; deberán demostrar capacidad para llevarlo a cabo, lo que requiere un management consolidado.

No son muchas las empresas que pueden satisfacer estos requisitos, pero para las que pueden acceder a estos instrumentos, los beneficios son muy grandes. Es importante destacar, que el crecimiento sostenible desde el punto de vista del financiamiento esta dado por la tasa de crecimiento del capital propio.

Los fondos de capital riesgo se asimila a capital propio para las entidades financieras y por lo tanto acrecienta las posibilidades de acceso al mercado de deuda. Por otra parte, para los aportantes de fondos, este instrumento significa rendimientos más elevados. De este modo se eficientiza el canal ahorro - inversión reduciéndose el efecto negativo de las deseconomías de escala en operaciones financieras para las PyME.

Una mejora en la dotación de capital propio en las PyME es imprescindible para la introducción de innovaciones. A su vez, el proceso de globalización, exige a las PyME hacer frente a crecientes necesidades de inversión en gastos de investigación y desarrollo, lanzando nuevos productos y/o procesos y desarrollando sus recursos humanos. Todo esto justifica ampliamente las necesidades de instrumentos especialmente diseñados para las PyME que incrementen su acceso y disponibilidad de capital propio.

En la financiación ajena, el crédito que proporcionan los proveedores juega un papel muy importante en las PyMes más jóvenes, dado por la imposibilidad de acceder a otras fuentes de financiamiento externa. El crédito de proveedores suele ser más caro, por lo que a medida que las empresas van evolucionando en los estadíos del ciclo de vida, deberían recurrir cada vez menos a esta fuente de financiación.

La relación con las entidades bancarias, debe planearse desde el inicio de la operatoria de la PyME, independientemente de su necesidad o posibilidad de acceso a este financiamiento. Las asimetrías informativas existentes en el mercado, encuentran incentivos para el mantenimiento continuado de relaciones con el mismo banco. La razón se fundamenta en las dificultades de las PyME para transmitir al mercado y a los intermediarios sus verdaderas características, motivo por el cual, las buenas empresas preferirán el mantenimiento a largo plazo de relaciones con el mismo banco. La estabilidad en las relaciones banco-empresa, 
contribuirá a obtener luego condiciones más ventajosas.

En la elección de la entidad bancaria, si se observa el comportamiento al interior del sistema bancario en lo que respecta a los créditos a las PyME, se destaca el desempeño de la banca cooperativa, la banca pública nacional y la banca privada nacional. Los bancos públicos provinciales y la banca extranjera no han evidenciado comportamiento muy favorable hacia este tipo de financiamientos.

En la selección de alternativas de financiamiento bancario para la adquisición de bienes de capital, las PyMEs deberían intensificar el uso de las líneas de leasing (disponibles en muchos bancos a plazos de hasta 36 meses), ya que además de las ventajas impositivas conocidas, por sus condiciones contractuales, resultan de más fácil acceso que otras líneas de financiamiento para el mismo plazo. De este modo no se recargaría el flujo de fondos de corto plazo con compromisos relacionados a las inversiones necesarias para su crecimiento y desarrollo.

Resulta importante destacar, que para poder supera con éxito cada una de las etapas del ciclo de vida, dinamizando el proceso de innovación e incrementando los niveles de competitividad; la empresa deberá ir incorporando conocimiento especializado en la gestión empresarial.

Consistente con el objeto de este trabajo, se hacen fundamentalmente necesarios los conocimientos relacionados con el campo de la administración financiera, donde una gestión profesional basada en la aplicación de conocimiento formal, se distingue notoriamente de otra, que por ejemplo se instrumente tomando en cuenta apreciaciones subjetivas y motivaciones propias de los responsables, es decir, basadas en un nivel de conocimiento más débil.

El profesionalismo en la gestión financiera, permitirá, entre otros, mantener a la PyME informada respecto de líneas de financiamiento promocionales con condiciones ventajosas, como las líneas de tasas subsidiada por la SEPYME, que no suelen permanecer disponibles por mucho tiempo y para su obtención es necesario cumplimentar una serie de requisitos informacionales que las PyME deberían manejar con agilidad.

A los efectos de evolucionar en los estadíos del ciclo de vida financiero, en necesario que las PyMEs tomen conciencia de la importancia de su ingreso al mercado de capitales, a los efectos de acceder a nuevas fuentes de financiamiento, reduciendo costos y disminuyendo riesgos.

En el proceso de inserción al mercado de capitales, las Sociedades de Garantía Recíproca juegan un rol facilitador muy importante. Las PyMEs puede acudir a una SGR, a fin de que garantice sus obligaciones, con el objeto de darle mayor certeza de cumplimiento y que como consecuencia del menor riesgo percibido por parte del inversor (o acreedor), se facilite su acceso y se obtenga una tasa de interés mas baja.

El descuento de cheques de pago diferidos avalados por una SGR se presenta como la mejor opción para que las PyMEs se inserten en el mercado de capitales, su operación simplificada y los beneficios de tasas que obtendrán, justificarán el tiempo destinado a los procesos de obtención de los avales y motivarán a continuar en esta línea.

Las PyMes no deben considerar a la operatoria de descuento de cheques de pago diferido en la bolsa como un fin en si mismo (como pareciera al observar la evidencia empírica), sino un medio para el acceso posterior a otros instrumentos del mercado de capitales, como 
podrían ser los fideicomisos financieros o las obligaciones negociables.

A medida que la empresa comienza a operar con la operatoria de cheques, y al conocer los requisitos de las SGR para el otorgamiento de garantías, podría comenzar a gestionar a avales para opciones de financiamiento de mediando y largo plazo (para el sistema bancario o de capitales). La emisión de Fideicomisos Financieros avalados y Obligaciones Negociables garantizadas por las SGR, son buenos instrumentos para continuar el proceso evolutivo del ciclo financiero, siendo de suma importancia la selección del momento oportuno para dicha emisión, dadas las características particulares de este mercado.

Por último, independientemente de las posibilidades concretas que brinde el actual mercado de capitales, es importante que las PyMEs en las últimas etapas de su evolución, tengan conocimiento de los requisitos para acceder a la cotización de acciones, con el objeto de que se introduzcan en las gestiones internas de las empresas, las exigencias informacionales de este instrumento, de manera tal que permitan aprovechar la oportunidad de una emisión cuando las condiciones lo permitan.

Conforme la empresa va ganando en edad, tamaño y transparencia informativa, se le va abriendo el abanico de fuentes de financiación a las que puede acceder. Además de lograr reducir los costos de financiamiento y controlar los costos de agencia haciendo uso de los contratos financieros adecuados, una política de financiamiento a largo plazo puede también buscar reducir por diferentes medios los riesgos operativos y financieros de la empresa.

Las gestiones donde priman los criterios racionales, el conocimiento formal, reflejado en modelos y herramientas, elección de alternativas, asignación de recursos, definición de objetivos y elaboración de información referida a planes de negocios y reportes para terceros; constituye una base fundamental para alcanzar los resultados pretendidos.

Para finalizar se desea mencionar los principales hallazgos encontrados en la opinión de los expertos:

- Como es sabido, el entorno en el que actúan las empresas condiciona su comportamiento y sus posibilidades de crecimiento y desarrollo. A excepción de las Oportunidades de Negocios, la Apertura del Mercado y el Contexto Económico que han sido considerados adecuados por la mayoría de las opiniones, el resto de las condiciones del entorno puestas en consideración (seguridad jurídica, infraestructura, programas gubernamentales, políticas públicas, regímenes impositivos y laborales, apoyo financiero, contexto político - institucional, mercado laboral, nivel de educación y formación, normas sociales y culturales e investigación científica y tecnológica) son inadecuados para la opinión de los expertos, lo que evidencia una situación opuesta a la requerida para un desarrollo sustentable del sector PyME.

- En lo que respecta a los obstáculos para un desarrollo sustentable del sector PyME, el apoyo financiero lidera el ranking de opiniones junto con los regímenes impositivos y laborales, lo que expone las importantes limitaciones que tienen las PyMEs para obtener fondos de canales institucionales, limitando su crecimiento a la reinversión de utilidades y a la propia capacidad financiera del empresario.

- Cuando se consultó respecto de los principales factores facilitadores de la creación de empresas y el mejoramiento de la competitividad de las PyMEs en Argentina, los 
aspectos más reiteradamente mencionados fueron los relacionados con las cuestiones de mercado, a saber: el contexto económico y las oportunidades de negocios.

En tercer lugar, está el nivel de educación y formación de los habitantes, un factor clave para el desarrollo de los países, incluyendo en este concepto la educación en escuelas, como así también la formación empresarial, científica y tecnológica de la sociedad. A este respecto, la investigación científica y tecnológica fue mencionada en quinto lugar en orden de mérito, confirmando la opinión de los entrevistados en esta línea de pensamiento.

El apoyo financiero fue mencionado en cuarto lugar en orden de importancia, dejándolo como un aspecto necesario pero no suficiente para el desarrollo sustentable del sector.

- Las principales recomendaciones de los expertos, en un contexto con expectativas de crecimiento de los agentes económicos, un adecuado nivel de oportunidades de negocios y cierta estabilidad en las variables macroeconómicas para los próximos años, están vinculados a mejorar el apoyo financiero y la seguridad jurídica. El apoyo financiero incentivaría al aprovechamiento de las oportunidades de negocios y permitiría el desarrollo de nuevas ventajas competitivas o usufructuar las actualmente relevantes. El fortalecimiento de la seguridad jurídica promovería mejores condiciones para la realización de inversiones y el ingreso de capitales externos, permitiría la planificación a mediano y largo plazo, el desarrollo de proyectos con períodos más largos de recupero de la inversión y reduciría el nivel de riesgo sistémico de la economía.

La necesidad de lograr instituciones fuertes y reglamentaciones claras también fue evidente al quedar entre el cuarto y el sexto lugar en orden de prioridad los regímenes impositivos y laborales, los programas gubernamentales, el contexto político institucional y las políticas públicas. 


\section{Recomendaciones}

Como finalización del trabajo de tesis se expondrán a continuación las recomendaciones para proyectos futuros o estudios de investigación, en lo que refiere a las políticas de asistencia financiera a PyMEs y su inserción en el mercado crediticio.

\section{1) Creación de un Ente de Calificación PyME}

Se propone la implementación de una Calificación de Riesgo para las PyMEs. A pesar de no exigirse a las PyMEs calificación de riesgo alguna, un Ente de Calificación PyME asumiría la responsabilidad de asignar una calificación que acredite su elegibilidad basándose en una metodología de calificación propia, pero en línea con las vigentes a nivel internacional.

La capacidad de cumplir los compromisos es de crucial importancia, y es a este respecto precisamente que la Calificación aludida agregaría valor al activo financiero posibilitando una disminución del descuento por riesgo aplicable al flujo de ingresos prometido por la inversión en el mismo.

La magnitud de la financiación requerida impide la justificación de un costo que, como ocurre con el de las Calificadoras aludidas, es un prerrequisito para acceder a mercados mas institucionalizados, donde el desconocimiento directo y la despersonalización exige especiales condiciones de tipificación y calificación para reconocer el "Investment Grade".

Se está en presencia pues de condiciones que operan como barreras prácticamente insuperables para las pequeñas y medianas organizaciones empresarias actuantes en el ámbito local.

Para que esta Calificación no genere erogaciones que concurrirían para determinar la inviabilidad de la iniciativa, los costos del referido Ente de Calificación PyME podrían estar a cargo de las entidades con interés legítimo en el éxito de la iniciativa y/o instituciones que evitarían, incurrir ellas mismas en erogaciones mayores para satisfacer igual necesidad. Por ejemplo, podrían tratarse de la Bolsa de Comercio de Buenos Aires, Entidades Bancarias; Consejos Profesionales, Cámaras Empresariales, Universidades y los Gobiernos de las distintas jurisdicciones (Nacional, Provinciales y Municipales).

El Consejo del Ente de Calificación PyME, cuerpo colegiado que constituiría la máxima autoridad, designaría a un Gerente o Director Ejecutivo con las formalidades y capacidades requeridas, las atribuciones necesarias y los medios indispensables para poder elaborar una propuesta de calificación sólidamente fundada en metodología y procedimientos incuestionables, cuyo perfeccionamiento requeriría la aprobación del Consejo.

La necesidad de dotar de mayor seguridad al sistema bancario, irá generando con el tiempo la necesidad de difundir y ampliar el uso de las Sociedades Calificadoras de Riesgo. En tal sentido, emerge como necesario el análisis de medidas conducentes a una mayor generalización de la acción de las empresas calificadoras de riesgo, las cuales tendrán un papel de creciente relevancia al momento de otorgar calificaciones de riesgo a las operaciones de financiamiento que otorguen los bancos.

Es fácilmente imaginable el beneficio que derivaría de esta instancia independiente de evaluación, eficiente por proveer sencillez y transparencia además de una muy importante distribución de los costos implicados entre diversas entidades, una evidente contribución al mejoramiento de la competitividad que tanto se ambiciona y necesita. 


\section{2) Actualización de la Ley de Entidades Financieras}

Se hace necesario actualizar la aplicación de la legislación de manera que otorgue un mayor incentivo a los bancos para atender a las PyME. En el mundo la experiencia indica la necesidad de especialización de la actividad financiera, por ejemplo en atender empresas pequeñas.

La diferencia evidente entre oferta y demanda de financiamiento para las PyME obedece en buena medida a la normativa crediticia vigente que no incentiva el acercamiento de los bancos a las PyME. En realidad se mantiene el espíritu de las normas crediticias del BCRA de los años noventa, con un manifiesto sesgo pro-corporación, toda vez que obligaban a los bancos a hacer mayores previsiones por los préstamos dados a las PyME, a partir de considerarlas como más riesgosas.

\section{3) Promoción y Desarrollo del Mercado de Capitales}

El Estado debe fomentar el desarrollo del Mercado de Capitales, estableciendo un marco regulatorio adecuado, brindando seguridad jurídica a los agentes económicos y aportando un contexto macroeconómico y político estable, también debería fomentar acciones o mecanismos de promoción para acercar a inversores y empresas.

El primer gran aspecto a destacar en las economías subdesarrolladas, es la existencia de mercados financieros subdesarrollados, dado que existe una correlación directa entre el grado de desarrollo económico y el desarrollo de los sistemas financieros.

Entre los factores salientes de los mercados financieros en economías subdesarrolladas, se puede mencionar:

- Mayor preferencia relativa de inversiones a corto plazo frente a inversiones de largo plazo (preferencia de liquidez). Limitada posibilidad de obtener ofertas de ahorros invertibles a mediano y largo plazo.

- Tendencia mayor al autofinanciamiento. Crecimiento de la empresa limitado a la capacidad de generación interna de fondos o por la dimensión del capital propio del empresario.

- $\quad$ Mayor importancia relativa de los mercados no organizados.

- Inversores institucionales con escasa importancia relativa en los mercados de capitales.

- Ineficientes sistemas de información (sobre rendimientos pasados, presentes y potenciales de los instrumentos financieros), que agrega mayor incertidumbre al inversor.

- $\quad$ Menor variedad de instrumentos e instituciones financieras especializadas.

- Incertidumbre en la determinación de costos efectivos en moneda local (riesgo inflacionario).

- Mayor rigidez que afecta el precio y la movilidad de los factores productivos (mano de obra, recursos naturales y capital) y las condiciones de entrada y salida de los mercados. 
Es factible mencionar algunos efectos de estos factores sobre la administración financiera de las organizaciones:

- Las decisiones, empleo de criterios y métodos de evaluación se enmarcan en un contexto de fuerte racionamiento de fondos.

- Discontinuidad de las fuentes de financiamiento.

- Imposibilidad de mantener estructuras de capital por largos períodos.

- $\quad$ No aplicación del costo medio de capital, como sí del costo marginal.

- Imposibilidad de determinar objetivamente el valor de la empresa para sus accionistas y el costo del capital propio (que de dicho valor se infiere), ya sea porque la empresa no cotiza en mercados bursátiles o porque el precio de mercado no es un parámetro adecuado (por las características propias del mercado: tamaño, información, porcentaje del paquete accionario que cotiza, participación de inversiones institucionales).

- En muchos casos, las decisiones de inversión y financiamiento deben considerarse en forma conjunta (enfoque residual), dada la existencia de financiamiento "atado" a usos de fondos o tasas subsidiadas.

- La inflación y el riesgo inflacionario, que dificultan la estimación de tasas nominales y reales de interés, modifica las preferencias de fuentes de financiamiento y las decisiones de mezcla de activos monetarios y no monetarios.

Las pequeñas empresas no se encuentran en igualdad de condiciones a las grandes en la búsqueda de financiación, viendo limitado su acceso a la propia capacidad de generación y retención de utilidades, debido a que en su mayoría son empresas familiares en las que el patrimonio de los accionistas ya está (en gran parte) comprometido en la empresa.

Por ello, es necesario potenciar fórmulas financieras que permitan el acceso a nuevas fuentes de financiamiento, como ser:

- La financiación mediante capital riesgo, para lo cual, la alternativa de salida del inversor de capital riesgo que mejor podría facilitar la realización del incremento de valor que la empresa hubiese conseguido desarrollar, está relacionada con la posibilidad de la oferta pública de acciones.

- El acceso a avales a partir de las sociedades de garantía recíproca, que mejorarían las condiciones del financiamiento para las PyME.

- La generalización del uso de las calificadoras de riesgo, para dotar de mayor seguridad al sistema financiero.

- El desarrollo de instrumentos financieros adecuados a las necesidades y características particulares del sector PyME.

\section{4) Programas de Asistencia a PyMEs}

El Estado debe promover la creación de empresas, brindando información sobre los sectores con potencial, apoyando financieramente los nuevos emprendimientos, estableciendo políticas y programas tendientes a fortalecerlas y asistirlas técnicamente, y promoviendo las 
actividades de cooperación entre empresas y entre éstas y las universidades y centros científicos y tecnológicos, a los efectos de lograr su consolidación.

En lo que respecta a la asistencia financiera, debería ser destinada principalmente a aquellas PyMEs que, teniendo capacidad y voluntad de pago, no pueden ser atendidas por una entidad financiera privada, ya sea, por ejemplo, por falta de garantías o por haber iniciado sus actividades recientemente.

Por último, es necesario que a los programas implementados se los complemente con una adecuada campaña de comunicación, ya que normalmente las PyMEs del interior no se encuentran igualmente informadas respecto de los programas gubernamentales vigentes, que las radicadas en los grandes centros urbanos. 


\section{Bibliografía}

- ACOSTA BALLESTEROS, J. y otros. "Información Asimétrica en los Mercados Bursátiles: una guía breve de la literatura". Investigaciones Europeas de Dirección y Economía de la Empresa, Vol. 6, № 3, 2000.

- AKERLOF, G. A. "The Markets for Lemons: Qualitative Uncertaintyand the Markets Mechanism”. Quarterly Journal of Economics, 84, 1970.

- ALONSO Aldo H. y LEGATO, Ana M. "Racionalidad y Modelos Financieros. Demanda de educación formal según etapas del ciclo y otros aspectos". Revista ECOS, UNLP, 2 do. Ciclo: Año 5, Vol. 1, № 9. 2009.

- ALONSO, Aldo H.; LAURIA, Daniel A. y LEGATO, Ana M. "Financiamiento: Estructuras óptimas y evidencia empírica” Encuentro Internacional de Finanzas, Chile 2001.

- ALONSO, Aldo H. "Globalización y competitividad vs. Asimetría informativa y deficiencias de intermediación”. SADAF 1996.

- ALONSO, Aldo H. "Innovaciones financieras en el ámbito regional. Justificación y Alternativas". SADAF 1995.

- ALONSO MORALES ACOSTA. "Asimetría Informativa".

- ARANDA Ferrán, MARTINEZ Ramón y CORONA Juan Francisco. "El Segundo Mercado: una fuente de financiación para la pyme”. Ediciones Gestión 2000 S.A. 1989.

- AZOFRA PALENZUELA, Valentín y LÓPEZ ITURRIAGA, Félix J. "La Asimetría Informativa en los Mercados Financieros: ¿El hallazgo de un nexo de unión?".

- AZOFRA, V. "El papel del sistema crediticio en la financiación de la empresa española". Publicación de la Universidad de Burgos, 1994.

- BAGEHOT, W. "The Only Game in Town”. Financial Analysts Journal, 27, 1971.

- BANK Magazine. Debate "Mercado Local: ¿Tiene futuro?” participantes Adelmo Gabbi (Bolsa), Luis Ribaya (MAE), Eduardo Hecker (CNV) y Luis Ossola (Rofex). Abril 2009.

- BANK Magazine. “AFJP: Duro golpe para el mercado”. Diciembre 2008.

- BARREDA, Martín E. Tesis de Magíster en Administración: "Fuentes de Financiamiento para PyME. Posibilidad de apertura al mercado de capitales".

- BAXTER, N. D. "Leverage, risk of ruin and the cost of capital". Journal of Finance, 1997.

- BEGOÑA HERRERO PIQUERAS, María. Tesis Doctoral: "Actividad bursátil y proceso de formación de precios ante la llegada de información programada y periódica: el anuncio de beneficios". Revista Española de Financiación y Contabilidad, Vol. XXXVII, N 138 , 2008.

- BEBCZUK, Ricardo N. "Información Asimétrica en Mercados Financieros" Cambridge University Press, 2000.

- BERGER, A. N. y UDELL, G. F. "The econimics of small business finance: the roles of private equity and debt markets in the financial growth cycle" Journal of Banking \& Finance, 22, 1998.

- BERGER, A. N. y UDELL, G. F. "Collateral, loan quality, and bank risk". Journal of Monetary Economic. Vol. 25, No 1. 1990.

- Bolsa de Comercio de Buenos Aires. “¿Por qué cotizar en Bolsa?”. 
- Bolsa de Comercio de La Plata. "Reglamento de Cotización de Obligaciones Negociables por parte de Pequeñas y Medianas Empresas" 1994.

- BREALEY, Richard A.; MYERS, Stewart C. y MARCUS, Alan J. "Principios de Dirección Financiera". Mc Graw Hill, 1999.

- BULLARD GONZALES, Alfredo. "La Asimetría de Información en la contratación a propósito del Dolo Omisivo". Lima. Palestra Editores, 2000.

- CARDONE, Clara y CASASOlA, María José. "La Estructura de Capital de la PYME Española: según la teoría del orden de preferencias" 2004.

- CASADO, José y MARTINEZ, Luis J. “Conocer los Fondos de Inversión”. Ediciones Gestión 2000 S.A. 1992.

- CAZORLA PAPIS, Leonardo y CANO GUILLÉN, Carlos Jesús. "El Capital Riesgo como Instrumento de Apoyo a la PYME”. Universidad de Almería 2000.

- CEPAL. "Financiamiento para Pequeñas y Medianas Empresas (pyme). El caso de Alemania. Enseñanzas para Argentina" Serie estudios y perspectivas, 2005.

- CEPAL. "Access to credit in Argentina". Serie financiamiento del desarrollo, 2007.

- CIAMPI, Eduardo B. "El desequilibrio financiero o estado de cesación de pagos de la empresa". Osmar D. Buyatti, 2009.

- COCCARO, Martín. "Cómo pasar el examen ante los inversores de riesgo". El Cronista PYME, 2 de noviembre de 2006.

- COLOMBO, Liliana. Trabajo Final de Maestría: "Financiamiento Mediante Capital de Riesgo como Factor Impulsor de la Competitividad de las Pequeñas y Medianas Empresas". UNICEN.

- COPELAND, T. E. y GALAI, D. "Information Effects on the Bid-Ask Spread”. The Journal of Finance, 38, 1983.

- DARROUGH, M. N. y STOUGHTON, N. M. "Moral hazard and adverse selection: the question of financial structure". Journal of Finance. Vol 4, № 2.

- Denver Business Journal. "FICO scores can help you win that small-business loan". 4 de marzo de 2005.

- EASTERBROOK, Frank H. y FISCHEL, Daniel R. "The Economic Structure of Corporate Law. Cambridge - London, 1991.

- FIEL, “Las Pequeñas y Medianas Empresas en la Argentina”. Año 1996.

- FINNERTY, John D. "Financiamiento de Proyectos. Técnicas modernas de ingeniería económica". Prentice Hall Hispanoamericana SA, 1998.

- Garantizar. "Mercado de Capitales: La Bolsa de las Pymes” Noticias / 45, 2010.

- Garantizar. "Ampliar el Crédito”. Noticias / 31, 2006.

- GONZALEZ, Víctor M. "Estructura de Vencimiento de la Deuda y Riesgo de Crédito en las Empresas Españolas". Universia Business Review, 2009.

- GUTIERREZ, José Eduardo. "Financiamiento y Acceso al Crédito". Foro Boliviano de Competitividad, Cochabamba 2005.

- GREENWALD, B. C. y STIGLITZ, J. E. "Asymmetric information and the new theory of the firm: financial constraints and risk behavior". American Economic Review, Vol. 80, No 2. 1990. 
- Harvard Business Review "Iniciativa Emprendedora” Ediciones Deusto S.A. 1999.

- HAUSER, H. E. "SMEs in Gerrmany". Facts and Figures. 2000.

- leralpyme. "Desarrollo de Proyectos con Capital Riesgo". Año 2, Edición N 7, 2008.

- Instituto Argentino de Mercado de Capitales. "Mercado de Capitales". IAMC, 2010.

- JAFFEE, D. y RUSSELL, T. "Imperfect information, uncertainty, and credit rationing" Quarterly Journal of Economics, Vol. 90, N 4. 1976.

- LAGOS, Martín. "Fuentes e Instrumentos de Financiamiento de las Empresas en la Argentina”. Asociación Empresaria Argentina, 2004.

- LEACH, Chris J. y MELICHER, Ronald W. "Entrepreneurial Finance" Editorial Thomson. USA 2003

- LEIVA BONILLA, Juan Carlos. "PYMES. Ciclo de Vida y Etapas de su Desarrollo". TEC Empresarial, Vol. 1, Edición 1, 2006.

- $\quad$ LELAND, H. E. y PYLE, D. H. "Informational asymmetries, financial structure and financial intermediation". Journal of Finance, Vol. 32, N² 2. 1977.

- LUCAS, D. J. y MAC DONALD, R. L. "Bank financing and investment decisions with asymmetric information about loan quality" RAND Journal of Economic, Vol. 23, $\mathrm{N}^{0} 1$, 1992.

- MARTíN UGEDO, Juan Francisco, MARTINEZ SOLANO, Pedro y YAGÜE GUIRAO, José. Línea de Investigación "Asimetría Informativa y Decisiones Financieras".

- MILLER, M. H. "Debt and taxes". Journal of Finance, 32, 1977.

- MODIGLIANI, F. y MILLER M. H. "The cost of capital, corporation finance, and the theory of investment”. American Economic Review, 48, 1958.

- MODIGLIANI, F. y MILLER M. H. "Corporate income taxes and the cost of capital: a correction". American Economic Review, 53, 1963.

- MYERS, S. C. "The capital structure puzzle". Journal of Finance, Vol. 39, № 3, 1984.

- NORTH, Douglass C. "Institutions, Institutional Change and Economic Performance". Political Economy of Institutions and Decisions, Cambridge University Press.

- PELLÓN, José Martí. "La Financiación de Pymes mediante Capital Riesgo". IMPIVA 1994.

- PERRONE, Andrea. "Información en el Mercado de Valores y Tutela del Inversor". Italia, Polit. Crim. № 7, 2009.

- POMBO GONZALEZ, Pablo. Tesis Doctoral: "Aportes conceptuales y características para una clasificación internacional de los sistemas/esquemas de garantía”. ETEA, 2006.

- Publicación de las Naciones Unidas. "Dirección y Administración de Empresas Industriales en los Países Insuficientemente Desarrollados". Departamento de Asuntos Económicos y Sociales. Nueva York, 1958.

- ROSS, S. A. "The determination of financial structure: the incentive-signalling approach". Bell Journal of Economics Vol. 8, № 1, 1977.

- RUDA, W. "Financing of small an médium-sized Enterprises in Germany" 9na. Reunión Anual de la Red PyMEs Mercosur. Universidad Nacional de General Sarmiento. 2004.

- RUDA, W. "Financing of small an médium-sized Enterprises in Germany. An approach towards the improvement of equity capitalisation" Business development in theory and 
practice. International Scientific Conference - Faculty of Economics, University of West Bohemia Cheb. Czech Republic. 1997.

- SABAL, J. "Financiamiento a Largo Plazo", 2003.

- SÁNCHEZ VIDAL, Javier y MARTÍN UGEDO, Juan Francisco. "Edad y Tamaño Empresarial y Ciclo de Vida Financiero", 2008.

- SAPAG CHAIN, Nassir. "Criterios de Evaluación de Proyectos”. Mc Graw Hill, 1997.

- SCHVARTZ, Fernando M. "Mercado de Capitales. Transparencia y mejores prácticas. El gobierno de las empresas cotizadas". Osmar D. Buyatti, 2008.

- SHARPE, S. A. "Asymmetric information, bank lending, and implicit contracts: A stylized model of customer relationships". Journal of Finance, Vol. 45, N 4, 1990.

- STOLL, H. "Inferring the Components of the Bid-Ask Spread: theory and empirical tests". The Journal of Finance, 44, 1989.

- VANDELL, K. D. "Imperfect information, uncertainty, and credit rationing: comment and extension”. Quarterly Journal of Economics, Vol. 99, № 4, 1984.

- WETTE, H. C. "Collateral in credit rationing in markets with imperfect information: note". American Economic Review. Vol. 73, N³, 1983.

- VERCHIK, Ana. “Mercado de Capitales”. Ediciones Macchi, 1997.

- VILLARO, Daniela. "Llegar a la Bolsa”. El Cronista PYME, 17 de junio de 2004.

- WARNER, J. B. "Bankruptey costs: Some evidence”. Journal of Finance, 32, 1977.

- WESTON, J. Fred y BRIGHAM, Eugene F. "Fundamentos de Administración Financiera". Décima edición, Mc Graw Hill, 1995.

- WOSSIDLO, P. R. "Finanzierung” in Pfohl H. Ch. Ed. Berlín, 1990. 


\section{Anexo I: Ciclo de vida financiero según Berger y Udell (1998)}
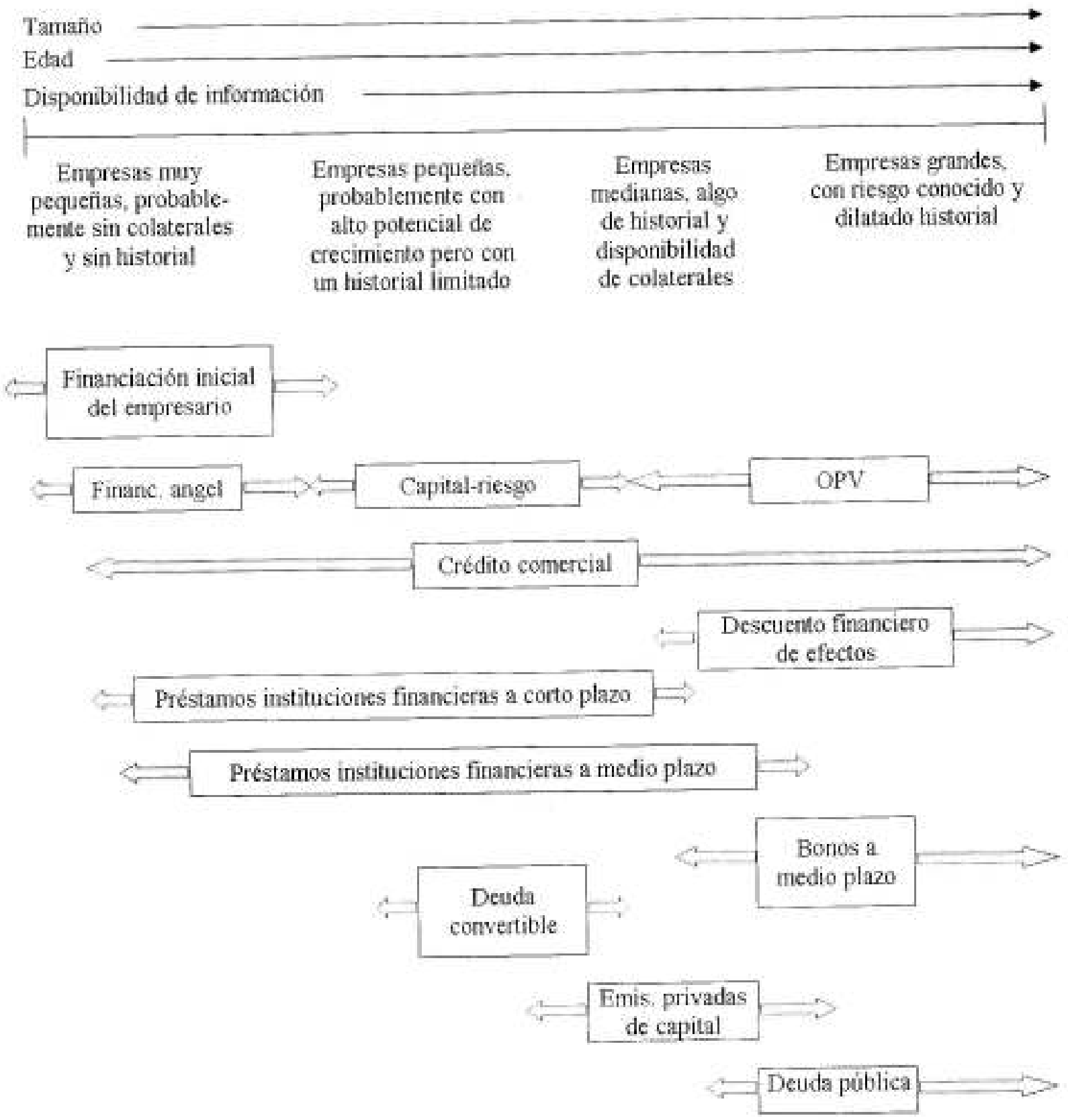